Cochrane Database of Systematic Reviews

\title{
Physical activity interventions for people with congenital heart disease (Review)
}

Williams CA, Wadey C, Pieles G, Stuart G, Taylor RS, Long L

Williams CA, Wadey C, Pieles G, Stuart G, Taylor RS, Long L.

Physical activity interventions for people with congenital heart disease.

Cochrane Database of Systematic Reviews 2020, Issue 10. Art. No.: CD013400.

DOI: 10.1002/14651858.CD013400.pub2.

www.cochranelibrary.com 
TABLE OF CONTENTS

HEADER 1

ABSTRACT

PLAIN LANGUAGE SUMMARY

SUMMARY OF FINDINGS

BACKGROUND

OBJECTIVES

METHODS

Figure 1.

RESULTS

Figure 2.

Figure 3.

Figure 4.

Figure 5.

Figure 6.

Figure 7.

Figure 8.

DISCUSSION

AUTHORS' CONCLUSIONS

ACKNOWLEDGEMENTS

REFERENCES

CHARACTERISTICS OF STUDIES

RISK OF BIAS

DATA AND ANALYSES

Analysis 1.1. Comparison 1: Physical activity promotion, exercise training and inspiratory muscle training interventions versus no activity (usual care) in people with congenital heart disease, Outcome 1: Maximal cardiorespiratory fitness

Analysis 1.2. Comparison 1: Physical activity promotion, exercise training and inspiratory muscle training interventions versus no activity (usual care) in people with congenital heart disease, Outcome 2: Health-related quality of life

Analysis 1.3. Comparison 1: Physical activity promotion, exercise training and inspiratory muscle training interventions versus no activity (usual care) in people with congenital heart disease, Outcome 3: Physical activity (device-worn)

Analysis 1.4. Comparison 1: Physical activity promotion, exercise training and inspiratory muscle training interventions versus no activity (usual care) in people with congenital heart disease, Outcome 4: Submaximal cardiorespiratory fitness (gas exchange threshold)

Analysis 1.5. Comparison 1: Physical activity promotion, exercise training and inspiratory muscle training interventions versus no activity (usual care) in people with congenital heart disease, Outcome 5: Muscular strength

Analysis 1.6. Comparison 1: Physical activity promotion, exercise training and inspiratory muscle training interventions versus no activity (usual care) in people with congenital heart disease, Outcome 6: Maximal cardiorespiratory fitness (type of ConHD subgroup analysis)

ADDITIONAL TABLES

APPENDICES

WHAT'S NEW

HISTORY

CONTRIBUTIONS OF AUTHORS

DECLARATIONS OF INTEREST

SOURCES OF SUPPORT

DIFFERENCES BETWEEN PROTOCOL AND REVIEW

NOTES

INDEX TERMS 
[Intervention Review]

\section{Physical activity interventions for people with congenital heart disease}

Craig A Williams ${ }^{1}$, Curtis Wadey ${ }^{1}$, Guido Pieles 2 , Graham Stuart², Rod S Taylor ${ }^{3}$, Linda Long 4

${ }^{1}$ Children's Health and Exercise Research Centre, University of Exeter, Exeter, UK. ${ }^{2}$ National Institute for Health Research (NIHR) Cardiovascular Biomedical Research Centre, Bristol Heart Institute, Bristol, UK. ${ }^{3 M R C / C S O}$ Social and Public Health Sciences Unit \& Robertson Centre for Biostatistics, Institute of Health and Well Being, University of Glasgow, Glasgow, UK. ${ }^{4}$ Institute of Health Research, University of Exeter Medical School, Exeter, UK

Contact address: Craig A Williams, c.a.williams@exeter.ac.uk.

Editorial group: Cochrane Heart Group.

Publication status and date: Edited (no change to conclusions), published in Issue 5, 2021.

Citation: Williams CA, Wadey C, Pieles G, Stuart G, Taylor RS, Long L. Physical activity interventions for people with congenital heart disease. Cochrane Database of Systematic Reviews 2020, Issue 10. Art. No.: CD013400. DOI: 10.1002/14651858.CD013400.pub2.

Copyright @ 2020 The Cochrane Collaboration. Published by John Wiley \& Sons, Ltd.

\section{A B S T R A C T}

\section{Background}

Congenital heart disease (ConHD) affects approximately $1 \%$ of all live births. People with ConHD are living longer due to improved medical intervention and are at risk of developing non-communicable diseases. Cardiorespiratory fitness (CRF) is reduced in people with ConHD, who deteriorate faster compared to healthy people. CRF is known to be prognostic of future mortality and morbidity: it is therefore important to assess the evidence base on physical activity interventions in this population to inform decision making.

\section{Objectives}

To assess the effectiveness and safety of all types of physical activity interventions versus standard care in individuals with congenital heart disease.

\section{Search methods}

We undertook a systematic search on 23 September 2019 of the following databases: CENTRAL, MEDLINE, Embase, CINAHL, AMED, BIOSIS Citation Index, Web of Science Core Collection, LILACS and DARE. We also searched ClinicalTrials.gov and we reviewed the reference lists of relevant systematic reviews.

\section{Selection criteria}

We included randomised controlled trials (RCT) that compared any type of physical activity intervention against a 'no physical activity' (usual care) control. We included all individuals with a diagnosis of congenital heart disease, regardless of age or previous medical interventions.

\section{Data collection and analysis}

Two review authors (CAW and CW) independently screened all the identified references for inclusion. We retrieved and read all full papers; and we contacted study authors if we needed any further information. The same two independent reviewers who extracted the data then processed the included papers, assessed their risk of bias using RoB 2 and assessed the certainty of the evidence using the GRADE approach. The primary outcomes were: maximal cardiorespiratory fitness (CRF) assessed by peak oxygen consumption; health-related quality of life (HRQoL) determined by a validated questionnaire; and device-worn 'objective' measures of physical activity.

\section{Main results}

We included 15 RCTs with 924 participants in the review. The median intervention length/follow-up length was 12 weeks (12 to 26 interquartile range $(I Q R))$. There were five RCTs of children and adolescents $(n=500)$ and 10 adult RCTs $(n=424)$. We identified three types of intervention: physical activity promotion; exercise training; and inspiratory muscle training. We assessed the risk of bias of results for 
CRF as either being of some concern $(n=12)$ or at a high risk of bias $(n=2)$, due to a failure to blind intervention staff. One study did not report this outcome. Using the GRADE method, we assessed the certainty of evidence as moderate to very low across measured outcomes.

When we pooled all types of interventions (physical activity promotion, exercise training and inspiratory muscle training), compared to a 'no exercise' control CRF may slightly increase, with a mean difference (MD) of $1.89 \mathrm{~mL} . \mathrm{kg}^{-1}$. $\mathrm{min}^{-1}(95 \% \mathrm{Cl}-0.22$ to $3.99 ; \mathrm{n}=732$; moderatecertainty evidence). The evidence is very uncertain about the effect of physical activity and exercise interventions on HRQoL. There was a standardised mean difference (SMD) of $0.76(95 \% \mathrm{Cl}-0.13$ to $1.65 ; n=163$; very low certainty evidence) in HRQoL. However, we could pool only three studies in a meta-analysis, due to different ways of reporting. Only one study out of eight showed a positive effect on HRQoL. There may be a small improvement in mean daily physical activity (PA) (SMD 0.38, $95 \% \mathrm{Cl}-0.15$ to $0.92 ; n=328$; low-certainty evidence), which equates to approximately an additional 10 minutes of physical activity daily $(95 \% \mathrm{Cl}-2.50$ to 22.20$)$.

Physical activity and exercise interventions likely result in an increase in submaximal cardiorespiratory fitness (assessed with $\mathrm{VO}_{2} \mathrm{~mL} \cdot \mathrm{kg}^{-1} \cdot \mathrm{min}^{-1}$ at the gas exchange threshold; $\mathrm{MD} 2.05,95 \% \mathrm{Cl} 0.05$ to $4.05 ; \mathrm{n}=179$; moderate-certainty evidence). Physical activity and exercise interventions likely increase muscular strength (measured by maximal voluntary contraction of knee extensions; MD 17.13, 95\% $\mathrm{Cl} 3.45$ to $30.81 ; n=18$; moderate-certainty evidence). Eleven studies ( $n=501)$ reported on the outcome of adverse events ( $73 \%$ of total studies). Of the 11 studies, six studies reported zero adverse events. Five studies reported a total of 11 adverse events; $36 \%$ of adverse events were cardiac related $(n=4)$; there were, however, no serious adverse events related to the interventions or reported fatalities (moderatecertainty evidence). No studies reported hospital admissions.

\section{Authors' conclusions}

This review summarises the latest evidence on CRF, HRQoL and PA. Although there were only small improvements in CRF and PA, and small to no improvements in $\mathrm{HRQ}$ oL, there were no reported serious adverse events related to the interventions. Although these data are promising, there is currently insufficient evidence to definitively determine the impact of physical activity interventions in ConHD. Further high-quality randomised controlled trials are therefore needed, utilising a longer duration of follow-up.

\section{PLAIN LANGUAGE SUMMARY}

\section{Physical activity interventions for people with congenital heart disease}

Review question

This review aimed to gather evidence for the use of any physical activity intervention for people with congenital heart disease. We aimed to compare interventions including exercise training, physical activity promotion or lung training with no intervention (usual care).

\section{Background}

Congenital heart disease is the term used for a range of birth defects that affect how the heart works. People with congenital heart disease have reduced life expectancy, physical fitness and quality of life. However, due to better prenatal diagnoses, surgical procedures (often performed in the early years of life) and earlier interventions, the survival rate for those born with this disease has improved dramatically, such that most people will now live into adulthood. Exercise training and physical activity interventions are known to improve fitness, physical activity, survival and quality of life in healthy people, but it is not clear how effective these programmes are for people with longterm medical conditions.

\section{Study characteristics}

We searched for studies in September 2019 and identified 15 studies involving 924 participants. The studies used three main types of interventions, including programmes designed to increase physical activity, aerobic fitness and health-related quality of life and compared physical activity intervention and control interventions in people with congenital heart disease.

\section{Key results}

We included 15 trials with 924 participants. Half of the participants were female. Of the 15 trials, 5 used a total of 500 young people (less than 18 years of age) and 10 trials used a total of 424 adult participants. We found that physical fitness and physical activity may slightly increase but we are very uncertain about quality of life. There is currently no data to say if this small increase in fitness will result in fewer visits to the hospital. But there were no recorded deaths or serious events that were related to participation in physical activity.

\section{Quality of evidence}

Using a validated scientific approach (GRADE), the certainty in the evidence base was moderate for fitness, low for physical activity and very low for quality of life. Most outcomes were limited due to small study participant numbers and poor reporting of study details. 


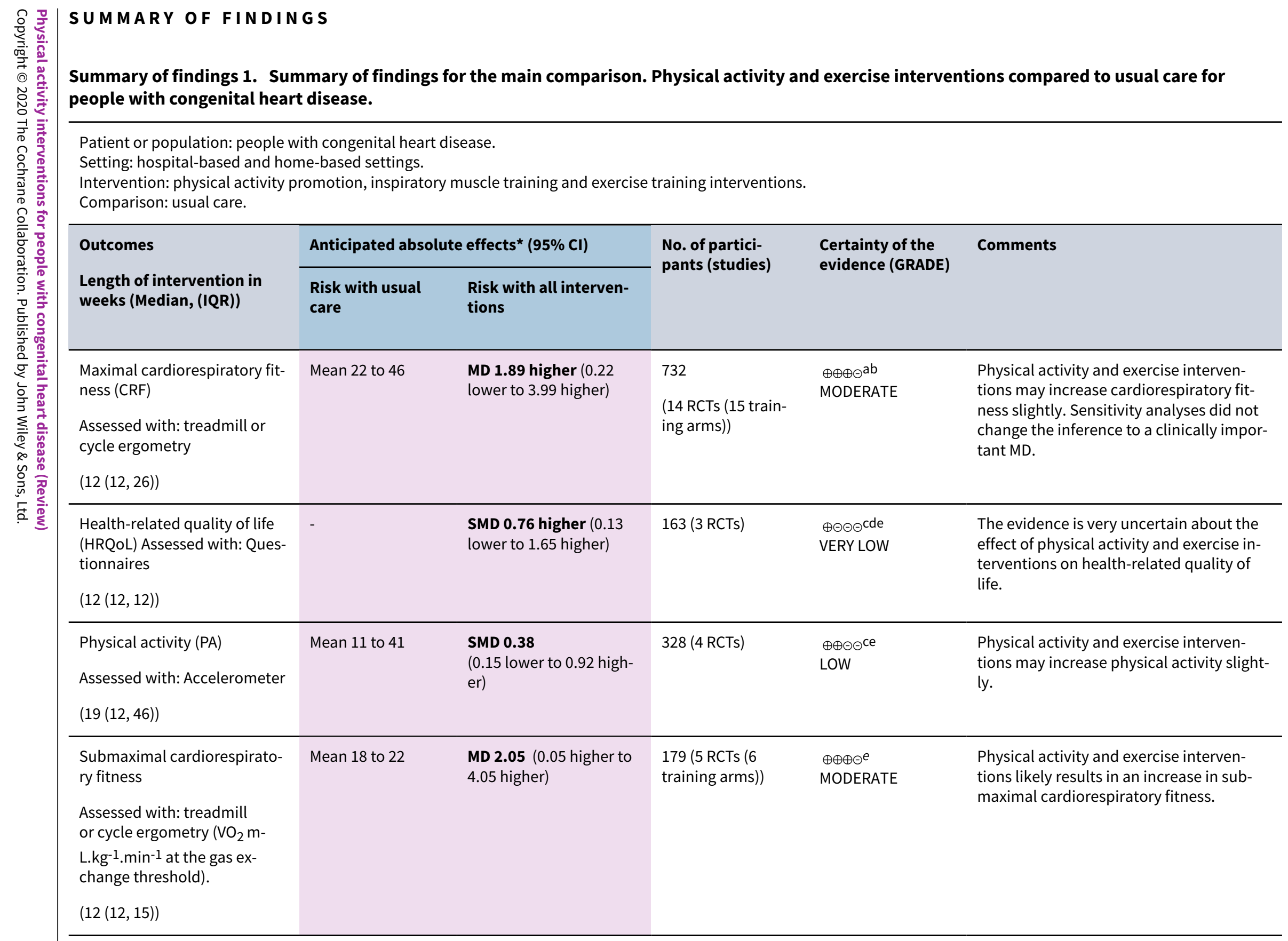

Setting: hospital-based and home-based settings.

Intervention: physical activity promotion, inspiratory muscle training and exercise training interventions.

Length of intervention in

Maximal cardiorespiratory fitness (CRF)

Assessed with: treadmill or

tionnaires

Physical activity (PA)

Assessed with: Acceleromete

Submaximal cardiorespirato-
MD 1.89 higher $(0.22$

(14 RCTs (15 train-

$9 \oplus)^{\mathrm{ab}}$

MODERATE ness slightly. Sensitivity analyses did not

change the inference to a clinically impor-

tant MD.

terventions on health-related quality of

hysical activity and exercise interven tions may increase physical activity slight- 


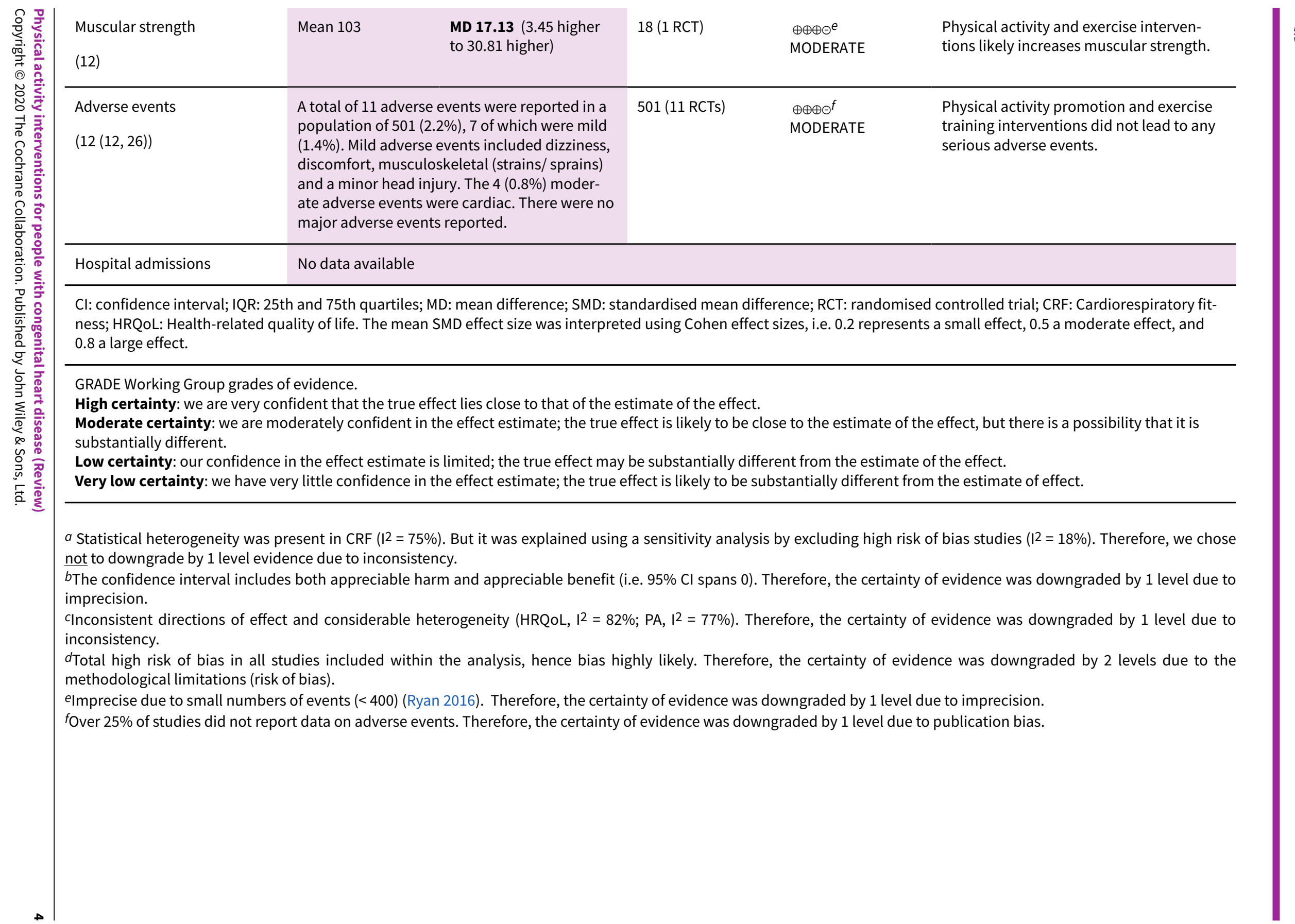




\section{B A C K G R O U N D}

\section{Description of the condition}

Congenital heart disease (ConHD) is a term for a range of developmental abnormalities of the heart or intrathoracic vessels, or both (Mitchell 1971). There are over 18 distinct types of ConHD, ranging in complexity (Rhodes 2008; Sommer 2008a; Sommer $2008 \mathrm{~b})$, that can be broadly classified as mild, moderate or severe (Hoffman 2002). During the period 2010 to 2017 the birth prevalence of ConHD is approximately $1 \%$ of all live births (9.41 per 1000 births; $95 \%$ confidence interval $(\mathrm{Cl}) 8.60$ to 10.25$)$, with the mild conditions representing $65 \%(95 \% \mathrm{Cl} 58.7 \%$ to $71.7 \%)$ of the total ConHD births (Liu 2019).

Long-term survival is reduced in ConHD, but due to improved medical care this has improved dramatically over previous decades. The most recent meta-analysis reported that survival up to the age of 10 years was $81.4 \%(95 \% \mathrm{Cl} 73.80$ to 87.90); however, $87.0 \%$ of the between-article variance can be accounted for by the year of the study (Best 2016). Consequently, survival up to the age of 10 years of age has increased from $75 \%$ to $90 \%$ over the past two decades due to improvements in surgical correction, prenatal diagnosis and earlier interventions (Best 2016). ConHD is therefore a changing chronic medical condition with the highest proportion of deaths now occurring in geriatrics (Khairy 2010).

In both healthy and clinical (coronary heart disease) populations, impaired physical activity (PA) and cardiorespiratory fitness (CRF) are associated with the development of noncommunicable disease, morbidity and mortality (Franklin 2013; Lee 2012; Letnes 2019). People with ConHD have reduced levels of fitness (Amedro 2017); reduced health-related quality of life (HRQoL) (Amedro 2015); and are less physically active (Brudy 2020; Dua 2007; McCrindle 2007; Sandberg 2016). Fitness has also been heavily associated with future health outcomes in this population (Dimopoulos 2006; Giardini 2009; Müller 2015; Udholm 2018). It is crucial, therefore, that people with ConHD lead an active lifestyle, but there is currently no consensus on how best to improve $\mathrm{PA}, \mathrm{CRF}$ and $\mathrm{HRQ}$ L in people with ConHD.

\section{Description of the intervention}

Physical activity consists of any bodily movement involving skeletal muscles that results in increased energy expenditure, whereas exercise training is a planned and structured period of PA with the intention of maintaining or improving physical fitness components (Caspersen 1985). The current guidelines for PA are an average of 60 minutes of moderate to vigorous physical activity (MVPA) a day for young people $(<18$ years old) and 150 minutes of MVPA a week in adults (Department of Health 2011). Currently within specialist paediatric cardiac clinics physical activity recommendations are not adequately discussed due to a lack of training, time and knowledge of the current exercise recommendations for people with ConHD (Williams 2017).

Interventions that aim to improve CRF, PA and HRQoL typically consist of a PA promotion (goal setting, motivational interviews etc.), or exercise training (aerobic/resistance training, sports participation etc.), or a combination of both. PA promotion interventions aim to increase habitual PA behaviours by using psychological conceptual frameworks in order to promote self-efficacy, goal-setting and intrinsic motivation. Exercise training interventions, on the other hand, usually prescribe a set 'dose' of exercise either within a hospital, centre or at home. Inspiratory muscle training (IMT) is a new method of intervention, recently gaining popularity in people with chronic cardiorespiratory conditions and aiming to improve ventilatory power and efficiency. IMT is distinctly different from PA promotion and exercise training as it involves training the inspiratory chest muscles against a breathing resistance by using a handheld device.

\section{How the intervention might work}

The 'gold standard' measure of cardiorespiratory fitness is maximal oxygen consumption, which is explained by the Fick equation where oxygen uptake is the product of the cardiac output and the arteriovenous oxygen difference ( $\dot{\mathrm{V}}_{2}=\mathrm{Q}{ }^{*} \mathrm{a}-\dot{\mathrm{V}}_{2}$ diff). Improving cardiorespiratory fitness must target improving oxygen delivery (Q) and/or oxygen extraction at the peripheral sites (a- $\mathrm{V}_{2}$ diff) of the body, namely the muscles. PA and exercise training are known to improve both cardiac output and oxygen extraction through complex molecular interactions improving myocardial contractility, mitochondrial activity, stem cell proliferation, nitric oxide bioavailability and muscle fibre adaptations (Adams 2017; Gielen 2010). There is evidence that supports inspiratory muscle training to improve ventilatory efficiency and fitness in people with chronic cardiorespiratory pathologies and in healthy people, but the adaptation mechanisms are not well understood (Shei 2018; Wong 2011). It is proposed that the increase in ventilatory efficiency is due to a combination of factors, inclusive of, but not limited to, changing motor recruitment 'diaphragm sparing' and the release of inflammatory cytokines (Shei 2018).

\section{Why it is important to do this review}

Cardiorespiratory fitness is lower in people with ConHD and deteriorates faster compared to healthy people (Amedro 2017). This has significant implications as CRF has been associated with future mortality and morbidity in several ConHD conditions (Dimopoulos 2006; Giardini 2009; Müller 2015; Udholm 2018). Currently, there is a dearth of evidence to adequately inform the effectiveness of interventions to improve CRF and consequently long-term outcomes.

Recent reviews have included both non-randomised and randomised controlled trials (RCTs), focused on specific types of interventions (e.g. home-based) or have restricted to particular age groups (Gomes-Neto 2016; Li 2019; Meyer 2020). Therefore, we present the first Cochrane Review to assess the effectiveness of all types of physical activity interventions and inclusive of all age groups, using only RCT data in people with ConHD. We hope by conducting this review that we can provide clarity on the effectiveness of physical activity interventions, highlight future avenues for research and inform future healthcare policy.

\section{O B JECTIVES}

To assess the effectiveness and safety of all types of physical activity interventions versus standard care in individuals with congenital heart disease. 


\section{METHODS}

\section{Criteria for considering studies for this review}

\section{Types of studies}

We planned to include all types of randomised controlled trial (RCT), inclusive of but not limited to parallel, cross-over and cluster designs. We included only parallel and randomised cross-over designs: these trials compared all types of physical activity interventions to a 'no physical activity/no exercise' comparator. We included trials irrespective of their duration of follow-up.

\section{Types of participants}

We included all individuals with a diagnosis of ConHD, who were deemed suitable for participation in a physical activity or exercise training intervention. We included all types of congenital heart disease, regardless of previous medical care and categorised them as mild, moderate or severe (Hoffman 2002). We also included paediatric ( 5 to 18 years old) and adult populations ( $>18$ years old).

\section{Types of interventions}

We identified and included three types of intervention: physical activity (PA) promotion; exercise training; and inspiratory muscle training (IMT). PA promotion studies incorporated psychological components to promote and educate participants on the benefits of exercise, whereas exercise training studies 'prescribed' exercise at a set dose either in a hospital or in a homebased setting. IMT was not an anticipated intervention type at the protocol phase; we included it due to its increasing use in clinical care (Pufulete 2019). Furthermore, we included interventions whether they were structured versus unstructured, supervised versus unsupervised, home versus hospital and single versus multicomponent. All interventions were compared to 'no physical activity/physical activity as usual' control; and both the intervention and control group received usual medical care.

\section{Types of outcome measures}

Studies should have intended to assess any of the outcomes in both the intervention and the control groups. At the protocol phase we intended to extract outcomes at two time points: at the end of intervention and at long-term follow-up ( $>12$ months). Due to the lack of long-term follow-up data, we only extracted the data at the end of the intervention. We sought to report the following primary and secondary outcomes, but they did not form the basis of our inclusion/exclusion criteria.

\section{Primary outcomes}

- Maximal cardiorespiratory fitness (CRF)

- Health-related quality of life determined by a validated questionnaire

- Device-worn 'objective' measures of physical activity

\section{Secondary outcomes}

- Submaximal CRF

- Validated questionnaire-based 'subjective' measures of physical activity

- Return to work or full-time education

- Hospital admissions
- Muscular strength determined by:

* grip strength

* isokinetic testing

* muscular endurance capacity

- Adverse events

We anticipated there would be substantial variability in the reported outcome measures and we approached the primary outcomes as follows.

\section{Cardiorespiratory fitness (CRF)}

We pooled peak oxygen consumption (peak $\mathrm{V}_{2}$ ) measured in millilitres per kilogram per minute $\left(\mathrm{mL}^{\mathrm{k}} \mathrm{kg}^{-1} \cdot \mathrm{min}^{-1}\right)$ as our measure of maximal CRF. Peak $\dot{\mathrm{O}}_{2}$ was assessed by validated cardiopulmonary exercise test protocols, measuring oxygen consumption directly or indirectly (by estimated oxygen consumption), using either a treadmill or cycle ergometer. The submaximal CRF outcome was oxygen consumption per kilogram of body mass $\left(\dot{\mathrm{V}}_{2} \mathrm{~mL} \cdot \mathrm{kg}^{-1} \cdot \mathrm{min}^{-1}\right)$ at the gas exchange threshold (GET).

\section{Health-related quality of life (HRQOL)}

As anticipated there was large variability in the HRQoL scales used; we pooled HRQoL data in a meta-analysis where appropriate and reported all HRQoL in Table 1 and summarised in text.

\section{Device-worn measures of physical activity}

Physical activity was measured by accelerometry only. We pooled data regardless of device (Actigraph GT3X, Actigraph GT1M), device settings (epoch ranged 5 to 60 seconds) and activity parameter measured (time spent in MVPA per day as a percentage $(n=1)$ and minutes spent in MVPA per day) as per the protocol. There were no heart rate data to analyse. and activity parameter measured (time spent in MVPA per day as a percentage $(n=1)$ and minutes spent in MVPA per day) as per the protocol. There were no heart rate data to analyse.

\section{Search methods for identification of studies}

\section{Electronic searches}

We undertook a systematic search of the following databases on 23 September 2019.

- CENTRAL in the Cochrane Library (Issue 9 of 12, 2019)

- Epub Ahead of Print, In-Process \& Other Non-Indexed Citations, MEDLINE Daily and MEDLINE (Ovid, 1946 to 19 September 2019)

- Embase (Ovid, 1980 to 2019 week 38)

- Cumulative Index to Nursing and Allied Health Literature (CINAHL) (EBSCOHost, 1937 to 23 September 2019)

- Allied and Complementary Medicine Database (AMED) (Ovid, 1985 to September 2019)

- BIOSIS Citation Index (Clarivate Analytics, 1926 to 23 September 2019)

- Web of Science Core Collection (Clarivate Analytics, 1900 to 23 September 2019)

- Latin American and Caribbean Health Sciences Literature (LILACS) (Bireme, 1982 to 23 September 2019) 
- DARE (NIHR Centre for Reviews and Dissemination www.crd.york.ac.uk, from inception to 31 March 2015 (when this database stopped adding records)).

We applied the Cochrane sensitivity-maximising RCT filter for MEDLINE and for Embase terms as recommended in the Cochrane Handbook for Systematic Reviews of Interventions (Lefebvre 2011; Higgins 2011). For CINAHL, we used the Cochrane CINAHL RCT filter (Glanville 2019). For all other databases, except CENTRAL, LILACS and DARE, we applied an adaptation of the Cochrane RCT filter. See Appendix 1 for the search strategies.

\section{Searching other resources}

We searched ClinicalTrials.gov on 11 September 2020 for ongoing or unpublished trials.

We also searched by hand the reference list of relevant reviews, randomised and non-randomised studies, and editorials for additional studies. We contacted authors of studies and experts in the field to ask for any missed, unreported or ongoing trials. We also searched for any retraction statements and errata for included studies.

\section{Data collection and analysis}

\section{Selection of studies}

Two review authors (CAW and CW) independently screened titles and abstracts for inclusion from all the potential trials we identified from the searches. We then sourced full texts and both review authors (CAW and CW) independently read them to confirm eligibility; in the event of exclusion, we documented the reasons. This was facilitated by Covidence systematic review software. Two authors (LL and RST) arbitrated if any disagreements arose that could not be rectified through discussion,. We have recorded the selection process with a PRISMA flow diagram (Figure 1) and Characteristics of excluded studies (Liberati 2009). 
Figure 1. Study flow diagram

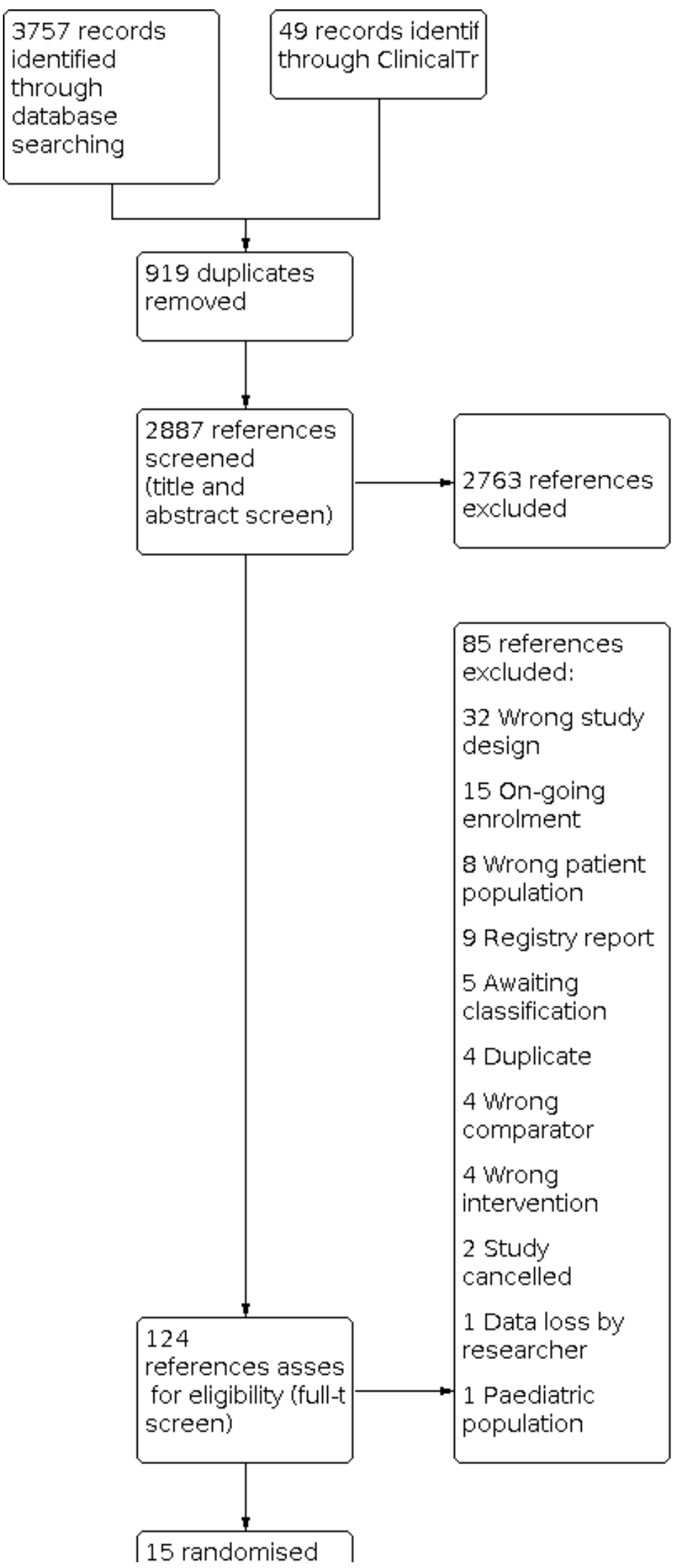


Figure 1. (Continued)

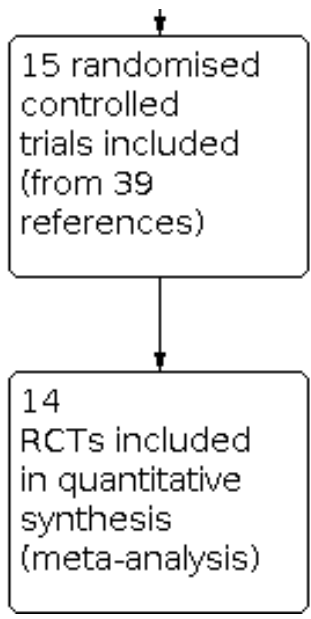

\section{Data extraction and management}

Two authors (CAW and CW) independently piloted a data collection form and independently extracted outcome data from included studies. One review author (CW) transferred data into RevMan Web 2019; and CAW checked that the data was entered correctly.

We extracted the following study characteristics.

- Participants: $\mathrm{N}$ randomised, $\mathrm{N}$ lost to follow-up, $\mathrm{N}$ analysed, mean age ( \pm standard deviation), gender, severity of condition*, inclusion criteria, and exclusion criteria.

- Methods: study design, total duration of study, study setting, date of study, withdrawals, number of study centres and location.

- Interventions: intervention description (including the frequency, intensity, duration and modality of the intervention), comparison, and co-interventions.

- Outcomes: primary and secondary outcomes specified and collected, and time points reported.

- Notes: funding for trial, and notable conflicts of interest of trial authors.

${ }^{*}$ As ConHD is an incredibly varied and complex disease we have classified the severity of the condition using the Hoffman 2002 criteria as 'mild', 'moderate' or 'severe' (see Appendix 2 for further information). We have chosen the Hoffman classification as it is very inclusive and does not bias against individual intra-diagnosis differences; it has since been adopted in the most recent guidelines from the US Task Force for adult congenital heart disease (Warnes 2008). We have used these criteria to describe the study data (to aid the reader); we have not used it for subgroup analyses.

\section{Assessment of risk of bias in included studies}

Two review authors (CAW and CW) independently assessed risk of bias for each study using the recently revised 'Risk of bias in randomised trials (RoB 2)' tool (accessed: 28 January 2020) (Higgins 2019).

We assessed risk of bias for each study outcome using the following Cochrane RoB 2 criteria (Higgins 2019).

- Bias arising from the randomisation process
- Bias due to deviations from intended interventions

- Bias due to missing outcome data

- Bias in measurement of the outcome

- Bias in selection of the reported result

For each domain a series of signalling questions with the answers (yes, probably yes, no information, probably no, no) determine the risk of bias (low risk, some concerns and high risk). We included text alongside the judgements to provide supporting information for our decisions (see Risk of bias in included studies). We decided the risk of bias for an outcome (e.g. health-related quality of life (HRQoL)) by its performance in each domain: if we judged one domain 'some concerns' or 'high risk' this judgement was taken for the whole outcome. We assessed the risk of bias of maximal and submaximal cardiorespiratory fitness (CRF), HRQoL, physical activity (PA) and muscular strength at follow-up. The effect of assignment or 'intention to treat' was our effect of interest and we have summarised the risk of bias in traffic lights on the forest plots, in Table 1 for HRQoL and in text.

\section{Measures of treatment effect}

We analysed continuous data as mean difference with 95\% confidence intervals (Cls). Where an outcome was measured and reported in more than one way, we report a standardised mean difference (SMD) with 95\% Cls. We interpreted the SMD using the two approaches recommended in the Handbook (Schünemann 2017). First, we interpreted the mean SMD effect size using the following rule of thumb based on Cohen effect sizes (i.e. 0.2 represents a small effect, 0.5 a moderate effect, and 0.8 a large effect) (Faraone 2008). In addition, for physical activity data we have converted the SMD back to the original scale units (minutes of moderate to vigorous activity) by multiplying the pooled mean SMD by an among-person standard deviation for a particular trial (Opotowsky 2018). We have corrected for any differences in the direction of the scales for HRQoL (i.e. when some scales have a lower score for a better QoL, a reduction in score would indicate an improvement, whereas a scale that awards higher scores for better QoL would see an increase in score indicating a positive outcome). We included $\mathrm{HRQ}$ oL data in the meta-analysis only if it was the overall or total HRQoL score. For the outcome 'adverse events' where there was a dichotomous variable (event or no event), we analysed this using count data and summarised in text. Where 
data were skewed and reported as medians and interquartile ranges, we converted them to means and standard deviations using validated equations (Wan 2014).

\section{Unit of analysis issues}

We only identified studies with individual randomisation. Only one study presented long-term follow-up data (Winter 2012); in this instance we extracted data at the end of the intervention to keep consistency with all the other trials. One trial contained three arm: continuous exercise training; interval exercise training; and a control group (Novakovic 2018). In this case we divided the number randomised to the control group in half to obtain the denominator for data analysis; the means and standard deviation for the control group remained unchanged for both comparisons. One study had a randomised cross-over design, but only contributed data prior to the cross-over (Fritz 2020); it was therefore not necessary to consider a washout period.

\section{Dealing with missing data}

We contacted multiple authors to verify key study characteristics (such as randomisation), clarify data queries and obtain missing numerical outcome data. Where data were presented graphically and we were unable to obtain numerical data from the authors, we used WebPlotDigitizer to extract this information.

\section{Assessment of heterogeneity}

We explored heterogeneity amongst included studies qualitatively (through visual inspection of forest plots and by comparing the characteristics of included studies), and quantitatively (using the $\mathrm{Chi}^{2}$ test of heterogeneity and the $\mathrm{I}^{2}$ statistic). We used a threshold of $\mathrm{I}^{2}$ greater than $50 \%$ to represent substantial heterogeneity for continuous outcomes (Deeks 2017).

\section{Assessment of reporting biases}

We were able to pool more than 10 studies in our primary outcome 'maximal cardiorespiratory fitness'. We subsequently created and examined a funnel plot and used the Egger test to explore possible small-study biases for this primary outcome (Egger 1997).

\section{Data synthesis}

We performed meta-analyses with $95 \% \mathrm{Cls}$ including all available studies where appropriate (i.e. when treatments, participants, and the underlying clinical question were similar enough for pooling to be appropriate). We used random-effects meta-analyses for all analyses due to the qualitative (types of interventions and severities of ConHD) and quantitative (statistical) heterogeneity present. Evidence of substantial heterogeneity was confirmed using the $1^{2}$ statistic of more than $50 \%$, giving further justification for a random-effects analysis. Random effects provides a more conservative statistical approach, as the confidence interval around a random-effects estimate is wider than a confidence interval around a fixed-effect estimate (Heran 2008a; Heran 2008b). Where an outcome was measured and reported in more than one way, we report a standardised mean difference (SMD) with $95 \% \mathrm{Cl}$.

We processed data in accordance with guidance in the Handbook (Higgins 2011). We completed data synthesis and analyses using RevMan Web software (RevMan Web 2019); and we conducted meta-regression analysis using the "metareg" command in Stata version 14.2 (Stata 2015 [Computer program]). We created additional figures using GraphPad (GraphPad Prism).

We could not pool some HRQoL. In this instance we adopted a modified version of a vote counting table, allowing us to summarise descriptive data, risk of bias and the direction of effect. Whilst this synthesis without meta-analysis (SWiM) method has significant limitations, we believe it to be the only SWiM method that allows us to communicate the results in a transparent and concise format (Campbell 2020).

\section{Subgroup analysis and investigation of heterogeneity}

We split the outcome 'maximal cardiorespiratory fitness' into two subgroup analyses: Analysis 1.1 reports the effect of the type of physical activity intervention (i.e. PA promotion, exercise training and inspiratory muscle training (IMT); and Analysis 1.6 reports the effect of the intervention in each group of ConHD (i.e. single ventricle, tetralogy of Fallot and other/mixed ConHD).

We used meta-regression to assess the potential treatment effect modifiers from all interventions (PA promotion, exercise training and IMT) on maximal cardiorespiratory fitness. Due to the limited number of studies to co-variate ratio we limited the metaregression to univariate analysis only (Higgins 2011). The metaregression included the following co-variates.

- Type of intervention (PA promotion or exercise training or IMT (categorical variable)).

- 'Dose' of exercise intervention (dose $=$ number of weeks of exercise training $\times$ average number of sessions/week $\times$ average duration of session in minutes) (continuous variable).

- Length of intervention/follow-up period (continuous variable).

- Sample size (continuous variable).

- Setting (home- or centre-based) (categorical variable).

- Study location (North America or Europe or Asia) (categorical variable).

- Age of participants (paediatrics or adults) (categorical variable).

- Percentage of male participants (continuous variable).

- Baseline cardiorespiratory fitness (continuous variable).

- Risk of bias (categorical variable).

Due to the lack of data, we pooled all individual ConHD lesions (Table 2). This has limitations due to the within-condition and between-condition heterogeneity in clinical status (Amedro 2017; Kempny 2012). We therefore used pre-intervention (baseline) cardiorespiratory fitness as a meta-regression covariate to account for the heterogeneity.

\section{Sensitivity analysis}

We performed the following sensitivity analyses for the outcome of maximal cardiorespiratory fitness: removal of high risk of bias studies; direct versus indirect methods of measuring/estimating peak $\mathrm{VO}_{2}$; the use of a fixed-effect model; insertion of all available change scores; and the removal of computed outcome scores (converting medians and interquartile ranges to means \pm standard deviations). We did not perform sensitivity analyses for the other outcomes within the review, due to the lack of studies included in the respective outcomes and the similarity of the studies pooled. 


\section{Summary of findings and assessment of the certainty of the evidence}

We created the 'Summary of findings 1' using RevMan Web 2019 and reported the following outcomes: maximal cardiorespiratory fitness (CRF), health-related quality of life (HRQoL), device-worn 'objective' measures of physical activity (PA), submaximal CRF, muscular strength, and adverse events.

Two reviewers (CAW \& CW) independently conducted GRADE analysis using GRADEpro GDT. Where disagreements arose, we asked co-authors (LL \& RST) to arbitrate. We used GRADE to assess the certainty of the available evidence, helping to inform decisions based on this evidence (Schünemann 2017). We used the five GRADE considerations (study limitations, consistency of effect, imprecision, indirectness, and publication bias) to assess the quality of the body of evidence, as it relates to the studies that contribute data to the meta-analyses for the prespecified outcomes. We justified all decisions to downgrade the quality of studies using footnotes.

We used methods and recommendations described in Section 8.5 and Chapter 12 of the Cochrane Handbook for Systematic Reviews of Interventions using GRADEpro software (Higgins 2011). Long-term follow-up (> 12 months) post intervention was our follow-up period of most interest. However, as only one study reported long-term follow-up, we only report short-term follow-up (immediately post intervention) in the 'Summary of findings' table.

\section{RE S U L T S}

\section{Description of studies}

See: Characteristics of included studies; Characteristics of excluded studies; Characteristics of ongoing studies; Characteristics of studies awaiting classification.

\section{Results of the search}

We identified 3806 references through our electronic and manual searches. After de-duplication and title and abstract screening, we retrieved 124 references. After screening the full text, we identified 15 RCTs from 39 references (see Figure 1 ). Searching of the reference lists of eligible publications did not reveal additional publications for inclusion.

We contacted 18 corresponding authors for further information regarding study inclusion. When we could not reach the authors, we included these studies $(n=5)$ in the Studies awaiting classification table.

\section{Included studies}

\section{Population}

We included 15 RCTs with 924 participants ( $50 \% \pm 12 \%$ male) in the review. There were five paediatric RCTs and 10 adult RCTs with 500 participants and 424 participants respectively. All paediatric RCTs were based in Europe, whereas adult trials were based in Europe $(n=6)$, North America $(n=3)$ and Asia $(n=1)$. There were 11 RCTs that included severe classification participants $(n=559)$; three RCTs that pooled mild, moderate and severe classifications $(n=254)$; and one RCT that included mild classification participants only $(n=$ 111). Table 2 reports the individual ConHD lesions that we pooled into the meta-analyses.

\section{Intervention}

We identified three distinct types of interventions: exercise training ( $\mathrm{n}=11$ ); physical activity promotion $(\mathrm{n}=3$ ); and inspiratory muscle training (IMT) $(n=1)$. See Table 3 for the characteristics of exercise training trials. Physical activity promotion aims were varied: Morrison 2013 and Klausen 2016 used motivational techniques (interviewing and goal setting vs. text 'e-based' encouragement) to improve physical activity and fitness in children and adolescents; whereas another intervention used a familybased psychological intervention with a subcomponent of physical activity promotion with the aim of improving HRQoL, time/ behaviour in school and sports enjoyment in young children (van der Mheen 2019). The only IMT study included within the review aimed to assess the efficacy of IMT in adults with severe ConHD (Fontan circulations). The intervention was a randomised crossover design using a commercially available inspiratory muscle trainer. The participants completing three sets of 10 to 30 repetitions every day for six months, the intensity could be adjusted from $10 \mathrm{~cm} \mathrm{H}_{2} \mathrm{O}$ to $90 \mathrm{~cm} \mathrm{H}_{2} \mathrm{O}$ and was individualised for every training session to maintain an optimal training effect (Fritz 2020).

\section{Comparison}

All studies compared to usual care for their region. Only one study had three arms: two intervention arms (interval and continuous training) and a control arm (Novakovic 2018).

\section{Primary Outcomes}

Maximal cardiorespiratory fitness (CRF) was measured in 14 out of $15(93.3 \%)$ studies. Health-related quality of life (HRQoL) was reported in 8 out of $15(53.3 \%)$ studies, using a variety of validated questionnaires summarised in Table 1 . Device-worn measures of physical activity was reported by four (26.6\%) studies, using a range of accelerometers, cut points and parameters such as time spent as a percentage in moderate to very vigorous activity, average minutes of moderate to vigorous activity (MVPA) and total minutes per day spent in MVPA assessed using accelerometer cut-points greater than 2000 counts (Duppen 2015; Klausen 2016; Morrison 2013; Opotowsky 2018). No study used disease-specific cut points.

\section{Secondary Outcomes}

Only one study numerically reported questionnaire-based physical activity (Duppen 2015). Klausen 2016 used questionnaires in combination with device-worn measures but did not report the questionnaire data as it reported similar results. No study measured return to work or full-time education. One study reported episodes off school for one or more days, however (van der Mheen 2019). No study reported on hospital admissions. Submaximal CRF was reported in a variety of ways: the most commonly reported was the oxygen consumption at the gas exchange threshold (GET) scaled to body mass (mL.kg-1. $\mathrm{min}^{-1}$ ) ( $\mathrm{n}=5$ studies) and the ventilatory equivalents ( $\dot{\mathrm{V}} \mathrm{E})$ over volume of carbon dioxide production ( $\dot{\mathrm{V}} / \mathrm{V} / \mathrm{CO}_{2}$ slope) ( $\mathrm{n}=4$ studies) (Avila 2016; Duppen 2015; Fritz 2020; Moalla 2006; Novakovic 2018; Opotowsky 2018; van Dissel 2019; Westhoff-Bleck 2013). Absolute oxygen consumption at the GET ( $\mathrm{mL} \cdot \mathrm{min}^{-1}$ ), power output in watts at the GET, VE at the GET, heart rate at the GET and the oxygen uptake efficiency slope were all reported once. Muscular strength was only reported by one study using isokinetic testing (Moalla 2006); and adverse events were reported by 11 studies, independent of whether an adverse event actually took place (Avila 2016; Duppen 2015; Fritz 
2020; Klausen 2016; Novakovic 2018; Opotowsky 2018; Sandberg 2018; Therrien 2003; van Dissel 2019; Westhoff-Bleck 2013; Winter 2012).

\section{Excluded studies}

We excluded 85 references during the full-text review, amongst which were 32 due to wrong study design, 15 because they are ongoing trials and 8 because they included the wrong patient population. For more regarding exclusions see Figure 1 and Characteristics of excluded studies.

\section{Risk of bias in included studies}

Risk of bias assessments for each outcome, including all domain judgements and support for judgement, is located in the Risk of bias section (located after the Characteristics of included studies), at the side of all forest plots and in Table 1 for HRQoL. To access further detailed risk of bias assessment data, please use the following link (doi.org/10.24378/exe.2363).
Risk of bias of outcomes across all studies was similar and predominately of 'some concerns'. Study authors reported poorly

the details of blinding outcome assessors (patient-facing members of staff conducting the outcome assessments, i.e. the person conducting the exercise test or questionnaire) and preagreed statistical analysis plans with sufficient detail.

Across most outcomes risk of bias was similar: we judged it as 'some concerns'. The only exception was HRQoL which we judged to be at high risk of bias due to the nature of self-reported questionnaires, the lack of blinding of the participants and other outcome assessors.

\section{Effects of interventions}

See: Summary of findings 1 Summary of findings for the main comparison. Physical activity and exercise interventions compared to usual care for people with congenital heart disease.

See Summary of findings 1 and forest plots (Figure 2, Figure 3, Figure 4, Figure 5, Figure 6).

Figure 2. Physical activity promotion, exercise training and inspiratory muscle training interventions versus no activity (usual care) in people with congenital heart disease. Outcome: Maximal cardiorespiratory fitness $\left(\mathrm{V}_{2}\right.$ $\mathrm{mL} \cdot \mathrm{kg}^{-1} \cdot \mathrm{min}^{-1}$ at maximal exercise).

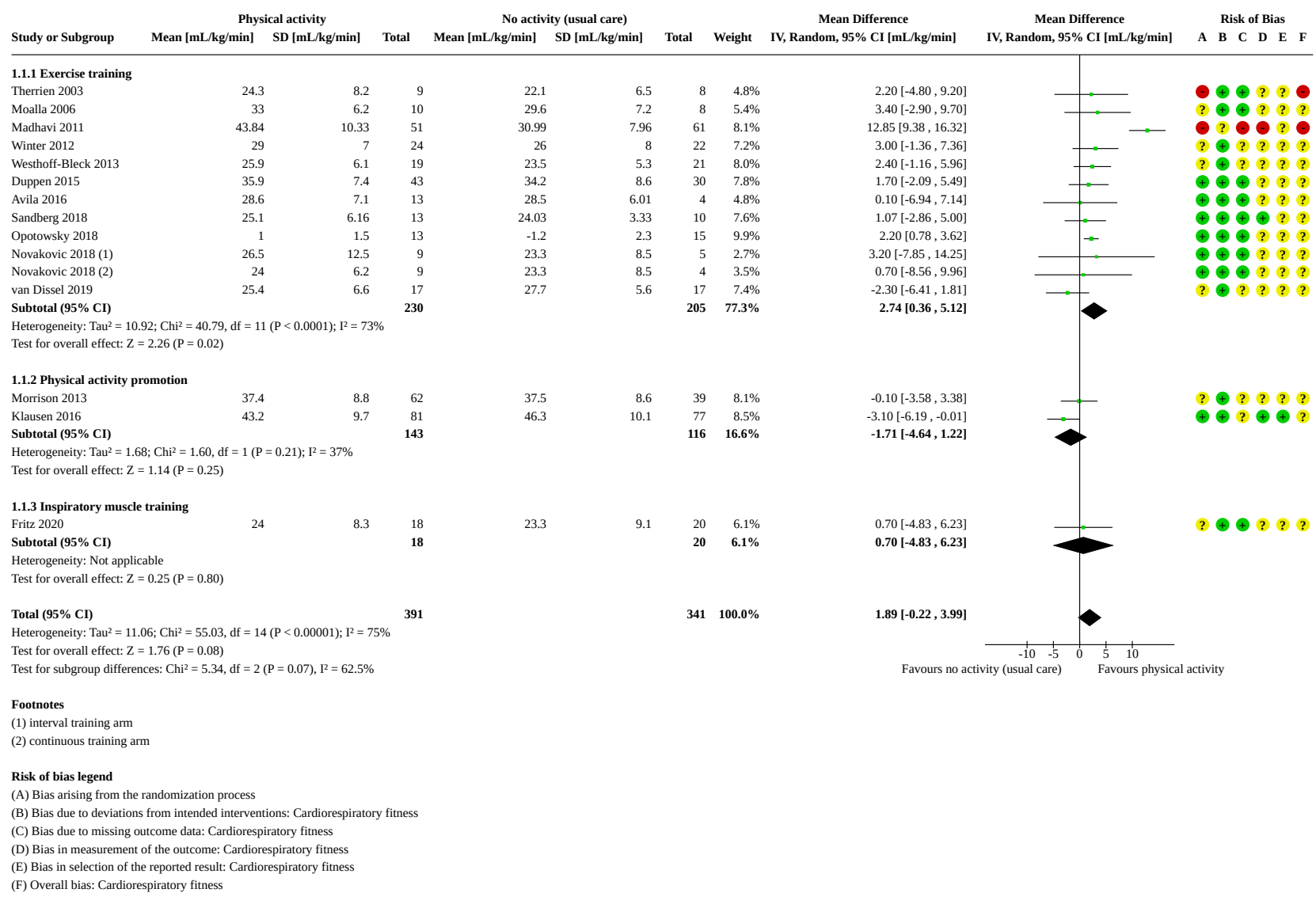


Figure 3. Exercise training versus no activity (usual care) in people with congenital heart disease. Outcome: Health related quality of life.

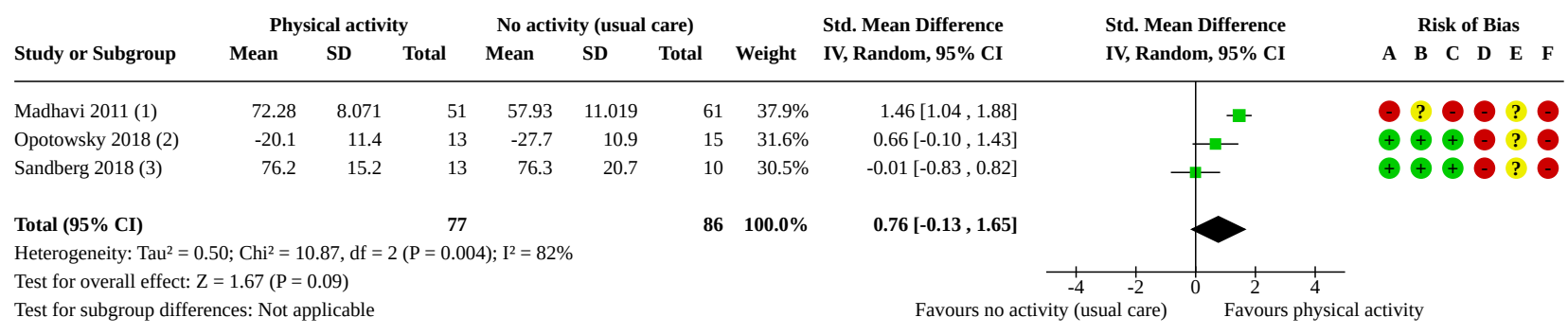

Footnotes

(1) SF-36 (total score)

(2) MLHFQ

(3) EQ5D VAS

Risk of bias legend

(A) Bias arising from the randomization process

(B) Bias due to deviations from intended interventions: Health-related quality of life

(C) Bias due to missing outcome data: Health-related quality of life

(D) Bias in measurement of the outcome: Health-related quality of life

(E) Bias in selection of the reported result: Health-related quality of life

(F) Overall bias: Health-related quality of life

Figure 4. Physical activity promotion and exercise training interventions versus no activity (usual care) in people with congenital heart disease. Outcome: Physical activity (device-worn).

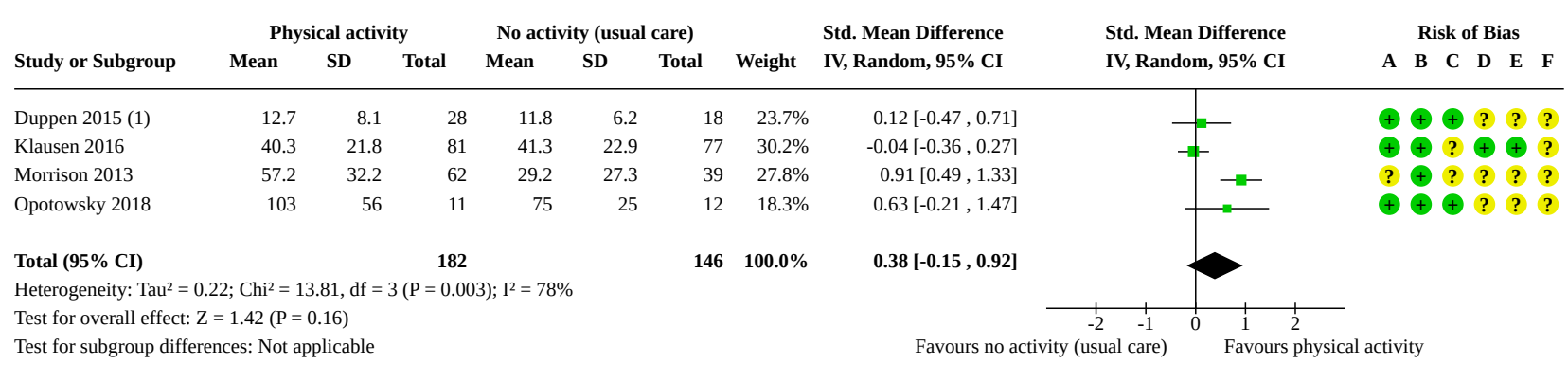

Footnotes

(1) Measure of activity: time spent in moderate-to-very-vigorous activity as a percentage. All other studies report minutes of MVPA per day.

Risk of bias legend

(A) Bias arising from the randomization process

(B) Bias due to deviations from intended interventions: Physical activity (device-worn)

(C) Bias due to missing outcome data: Physical activity (device-worn)

(D) Bias in measurement of the outcome: Physical activity (device-worn)

(E) Bias in selection of the reported result: Physical activity (device-worn)

(F) Overall bias: Physical activity (device-worn) 
Figure 5. Exercise training interventions versus no activity (usual care) in people with congenital heart disease. . Outcome: Sub-maximal cardiorespiratory fitness $\left(\mathrm{V}_{2} \mathrm{~mL} \mathrm{~kg}^{-1} \cdot \mathrm{min}^{-1}\right.$ at the gas exchange threshold).

\begin{tabular}{|c|c|c|c|c|c|c|c|c|c|c|c|c|}
\hline \multirow[b]{2}{*}{ Study or Subgroup } & \multicolumn{3}{|c|}{ Physical activity } & \multicolumn{3}{|c|}{ No activity (usual care) } & \multirow[b]{2}{*}{ Weight } & Mean Difference & \multirow{2}{*}{\multicolumn{2}{|c|}{$\begin{array}{c}\text { Mean Difference } \\
\text { IV, Random, } 95 \% \mathrm{CI}[\mathrm{mL} / \mathrm{kg} / \mathrm{min}]\end{array}$}} & \multicolumn{2}{|c|}{ Risk of Bias } \\
\hline & Mean $[\mathrm{mL} / \mathrm{kg} / \min ]$ & $\mathrm{SD}[\mathrm{mL} / \mathrm{kg} / \mathrm{min}]$ & Total & Mean [mL/kg/min] & $\mathrm{SD}[\mathrm{mL} / \mathrm{kg} / \mathrm{min}]$ & Total & & IV, Random, $95 \%$ CI [mL $/ \mathrm{kg} / \mathrm{min}]$ & & & A B C D & \\
\hline Moalla 2006 & 23.6 & 3.3 & 10 & 18.1 & 4.1 & 8 & $20.0 \%$ & $5.50[2.00,9.00]$ & & $\ldots$ & $? \oplus \odot ?$ & ? \\
\hline Westhoff-Bleck 2013 & 16.2 & 5.3 & 19 & 15.5 & 3.7 & 21 & $25.1 \%$ & $0.70[-2.16,3.56]$ & & $=-$ & ? $\odot ? ?$ & ? \\
\hline Duppen 2015 & 20.9 & 5.9 & 46 & 20.6 & 6.2 & 31 & $26.0 \%$ & $0.30[-2.47,3.07]$ & - & - & 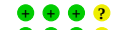 & \\
\hline Avila 2016 & 21 & 6.7 & 13 & 21.8 & 6.7 & 4 & $6.2 \%$ & $-0.80[-8.31,6.71]$ & & & $\stackrel{+}{\oplus} \oplus$ ? & \\
\hline Novakovic 2018 (1) & 20.1 & 5.4 & 9 & 18.1 & 4.2 & 4 & $10.8 \%$ & $2.00[-3.42,7.42]$ & - & & $\oplus \oplus \odot ?$ & \\
\hline Novakovic 2018 (2) & 22.6 & 5.4 & 9 & 18.1 & 4.2 & 5 & $11.9 \%$ & $4.50[-0.60,9.60]$ & & & $\hookrightarrow \odot \odot ?$ & ? \\
\hline $\begin{array}{l}\text { Total } \mathbf{9 5 \%} \text { CI) } \\
\text { Heterogeneity: Tau }{ }^{2}=2\end{array}$ & $1 ; \mathrm{Chi}^{2}=7.52, \mathrm{df}=5(\mathrm{P}$ & $=0.18) ; \mathrm{I}^{2}=33 \%$ & 106 & & & 73 & $100.0 \%$ & $2.05[0.05,4.05]$ & & & & \\
\hline Test for overall effect: $Z$ & $=2.01(P=0.04)$ & & & & & & & & -10 & $\frac{1}{5}$ & & \\
\hline
\end{tabular}

Footnotes

(1) continuous training arn

(2) interval

Risk of bias legend

(A) Blas arising from the randomization proces

Submaximal cardiorespiratory fitness (gas exchange threshold)

(C) Bias due to missing outcome data: Submaximal cardiorespiratory fitness (gas exchange threshold)

(D) Bias in measurement of the outcome: Submaximal cardiorespiratory fitness (gas exchange threshold)

(F) Overall bia: Submaritas

Figure 6. Exercise training interventions versus no activity (usual care) in people with congenital heart disease. Outcome: Muscular strength.

\begin{tabular}{|c|c|c|c|c|c|c|c|c|c|c|}
\hline \multirow[b]{2}{*}{ Study or Subgroup } & \multicolumn{3}{|c|}{ Physical activity } & \multicolumn{3}{|c|}{ No activity (usual care) } & \multirow{2}{*}{$\begin{array}{c}\text { Mean Difference } \\
\text { IV, Random, } 95 \% \text { CI [MVC (N.m)] }\end{array}$} & \multirow{2}{*}{\multicolumn{2}{|c|}{$\begin{array}{c}\text { Mean Difference } \\
\text { IV, Random, 95\% CI [MVC (N.m)] }\end{array}$}} & Risk of Bias \\
\hline & Mean [MVC $(\mathrm{N} \cdot \mathrm{m})]$ & SD [MVC (N·m)] & Total & Mean [MVC (N.m)] & SD [MVC (N·m)] & Total & & & & $\begin{array}{llllll}\text { A } & \text { B } & \text { C } & \text { D } & \text { E } & \text { F }\end{array}$ \\
\hline Moalla 2006 & 120.2 & 19.4 & 1 & 103.07 & 9.4 & & $17.13[3.45,30.81]$ & & 1 & $?+\odot \oplus ?$ ? \\
\hline isk of bias legend & & & & & & & Favours no ac & $\begin{array}{rr}-20 & -10 \\
\text { tivity (usual care) }\end{array}$ & $\begin{array}{l}10 \quad 20 \\
\text { Favours physica }\end{array}$ & activity \\
\hline
\end{tabular}

(A) Bias arising from the randomization process

Favours no activity (usual care) $\quad$ Favours physical activity

(B) Bias due to Tevions

(C) Bias due to missing outcome data: Muscular strength

(D) Bias due to missing outcome data: Muscular strength

(D) Bias in measurement of the outcome: Muscular strength

(F) Overall bias: Muscular strength

\section{Maximal cardiorespiratory fitness}

A total of 14 studies (15 training arms, 732 participants) reported maximal CRF using peak oxygen consumption (peak $\dot{\mathrm{V}}_{2}$ ) scaled to body mass ( $\left.\mathrm{mL} \cdot \mathrm{kg}^{-1} \cdot \mathrm{min}^{-1}\right)$. One study had a long-term followup at 36 months post intervention (Winter 2012); all other studies' follow-up was at the cessation of the intervention (median 12, IQR 12 to 26 weeks). Most studies reported the post-score mean and standard deviation. However, van Dissel 2019 reported both a post score and a change score from baseline and Opotowsky 2018 only reported change score from baseline. To ensure consistency, change scores were included only when no post score was reported.

We pooled all available studies into a random-effects metaanalysis, with a subgroup analysis comparing the different types of intervention; we did not consider the result of the subgroup analysis to be significant $\left(\mathrm{Chi}^{2}=5.34, \mathrm{df}=2, \mathrm{P}=0.07, \mathrm{I}^{2}=62.5 \%\right)$. In the pooled analysis there was a mean difference (MD) of 1.89 mL.kg-1. min $^{-1}(95 \% \mathrm{Cl}-0.22$ to $3.99 ; 14$ studies (15 training arms), 732 participants; $12=75 \%$ ). The subgroup exercise training consisted of 11 studies (435 participants) and there was a mean difference of $2.74 \mathrm{~mL} . \mathrm{kg}^{-1} \cdot \mathrm{min}^{-1}\left(95 \% \mathrm{Cl} 0.36\right.$ to $\left.5.12 ; \mathrm{I}^{2}=73 \%\right)$ versus a mean difference of $-1.71 \mathrm{~mL} . \mathrm{kg}^{-1} \cdot \mathrm{min}^{-1}(95 \% \mathrm{Cl}-4.64$ to $\left.1.22, \mathrm{I}^{2}=37 \%\right)$ and $0.70 \mathrm{~mL} \cdot \mathrm{kg}^{-1} \cdot \mathrm{min}^{-1}(95 \% \mathrm{Cl}-4.83$ to 6.23$)$ in physical activity promotion and inspiratory muscle training respectively (Figure 2).
We performed a further subgroup analysis for the type of congenital heart disease, which reported a pooled mean difference of $1.90 \mathrm{~mL} . \mathrm{kg}^{-1} \cdot \mathrm{min}^{-1}(95 \% \mathrm{Cl}-0.14$ to $3.95 ; 14$ studies (15 training arms), 732 participants; $12=73 \%)$. The test for subgroup differences revealed no differences between subgroups $(P=1.00)$; single ventricle (MD 2.06, $95 \% \mathrm{Cl}-0.25$ to $4.38 ; n=153$ ), tetralogy of Fallot (MD 1.97, 95\% Cl-1.11 to 5.05; $\mathrm{n}=104$ ) and other or mixed populations (MD $1.98,95 \% \mathrm{Cl}-1.67$ to $5.62 ; \mathrm{n}=474$ ) all had a similar response to a physical activity intervention (Analysis 1.6).

We performed several separate sensitivity analyses removing high risk of bias studies (MD 0.92, 95\% Cl -0.27 to $2.11 ; 12$ studies (13 training arms), 603 participants; $1^{2}=18 \%$ ) (Madhavi 2011; Therrien 2003); and studies that estimated peak $\mathrm{VO}_{2}$ using validated protocols (MD 1.07, $95 \% \mathrm{Cl}-0.14$ to $2.28 ; 12$ studies (13 training arms), 519 participants) (Madhavi 2011; Morrison 2013). We also report the use of fixed-effect meta-analyses (MD 2.00, $95 \% \mathrm{Cl} 1.09$ to $2.91 ; 14$ studies, 732 participants (15 training arms)); the insertion of all available change scores (MD 1.98, 95\% $\mathrm{Cl} 0.09$ to 3.86 ; 14 studies (15 training arms), 732 participants) (Sandberg 2018); and the removal of computed outcome scores (converting medians and interquartile ranges to means \pm standard deviations from Avila 2016, Fritz 2020, Klausen 2016, Novakovic 2018, Sandberg 2018 and Winter 2012) (MD 2.84, 95\% Cl -0.21 to 5.88 ; 8 studies, 423 participants). 
We used univariate meta-regression to assess individual predictors of peak $\dot{\mathrm{VO}}_{2}$. We regressed 10 predictors and the risk of bias and the intervention length produced significant associations (for regression coefficients and $P$ values see Table 4 and Figure 7). This indicates that the shorter the intervention and the higher the risk of bias then the greater the effect on peak $\mathrm{VO}_{2}$. There was no evidence of publication bias $(\mathrm{P}=$ 0.268) (Figure 8). Using GRADE, we assessed the evidence to be of moderate certainty because of imprecision.

Figure 7. Meta-regression analyses investigating the effect of the 'overall risk of bias' and the 'length of intervention'. Outcome: Maximal cardiorespiratory fitness (see Table 4).
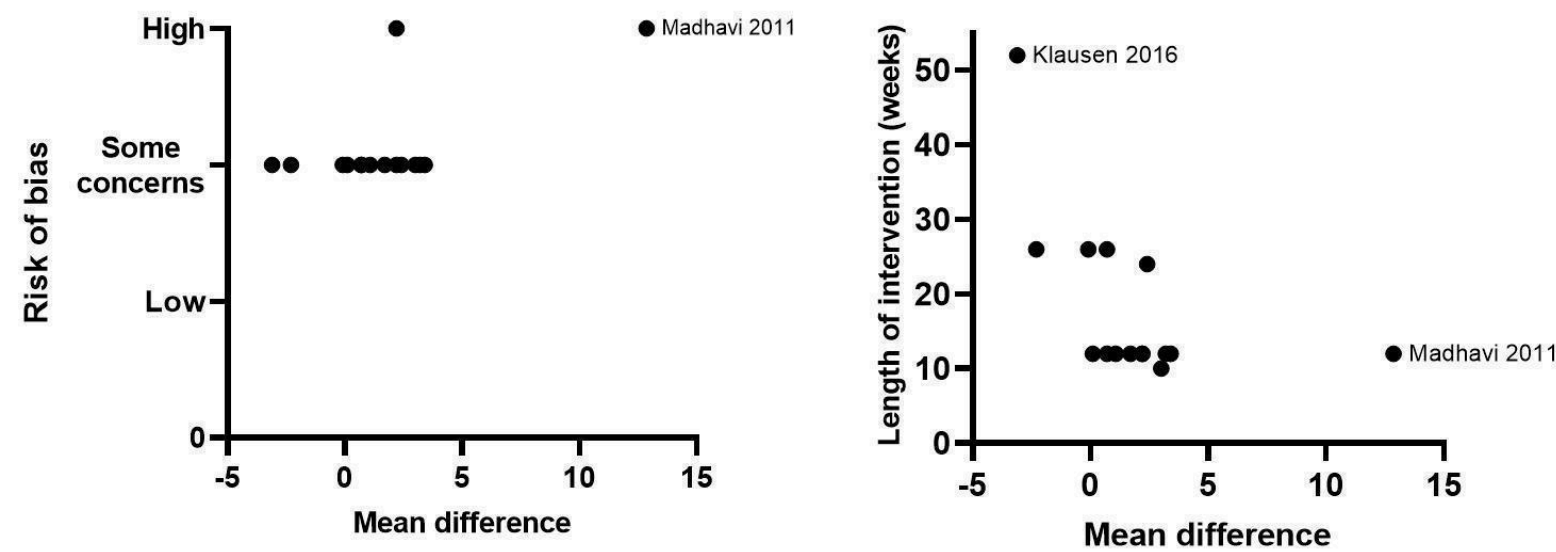
Figure 8. Funnel plot investigating publication bias. Outcome: Maximal cardiorespiratory fitness (Egger 1997 test, $P=0.268)$.

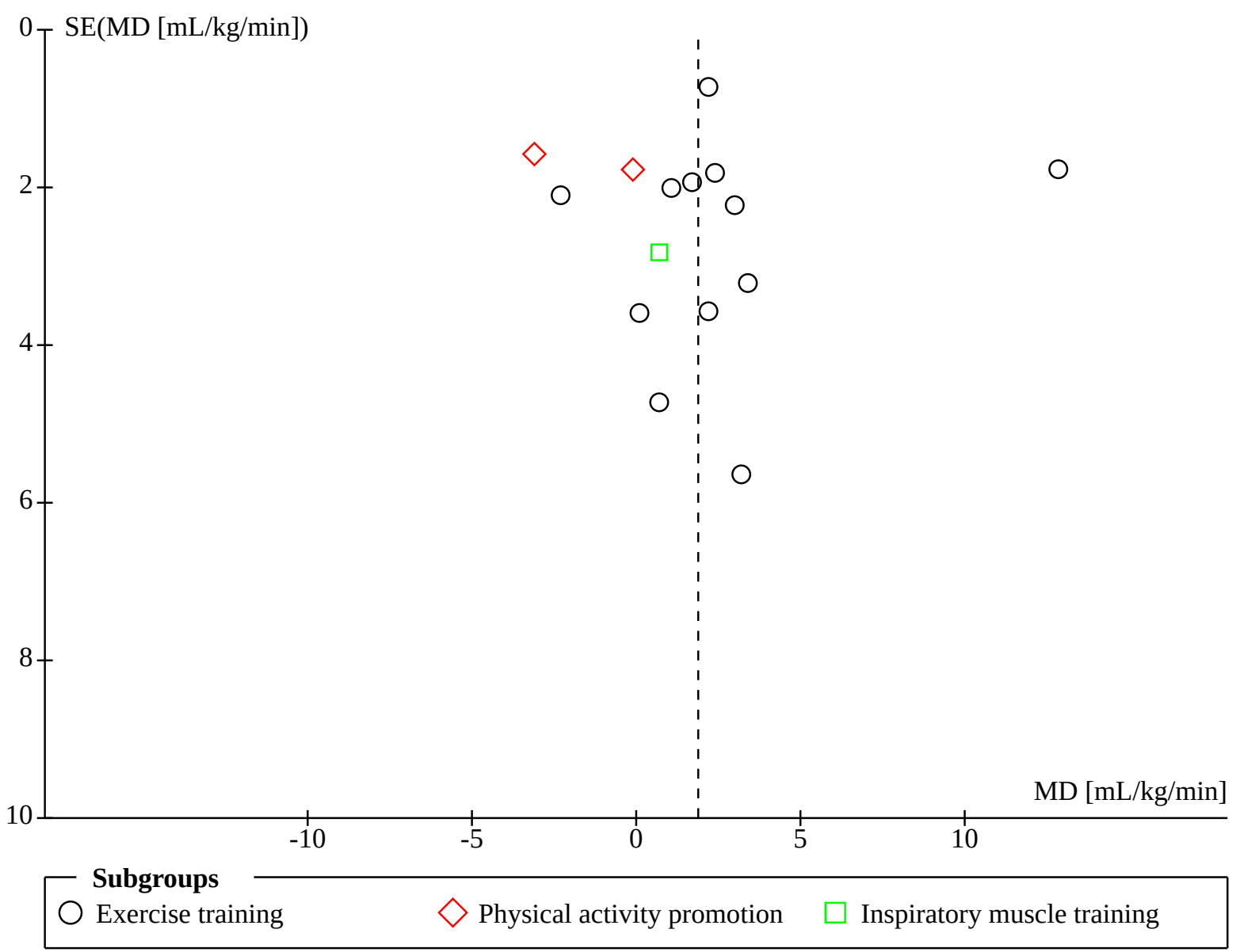

\section{Health-related quality of life (HRQOL)}

HRQoL was reported by eight studies using a variety of validated questionnaires and a median follow-up of 12 weeks (Table 1 ). The '36-item short form health survey' (SF-36) was reported most frequently $(n=5)$, followed by the 'Congenital heart disease - TNO/ AZL adult quality of life questionnaire' (ConHD TAAQoL) which was reported twice. All other questionnaires were reported once. Where possible we pooled HRQoL scores into a random-effects meta-analysis; we could enter only three studies into the analyses due to the variety of measurements reported. The result of the analysis was a standardised mean difference of $0.76(95 \% \mathrm{Cl}-0.13$ to $1.65 ; I^{2}=82 \%$ ), which suggests a moderate effect size indicating a possibly beneficial effect of interventions on HRQoL (Figure 3). When we summarised all the evidence on $\mathrm{HRQ}$ oL presented in the vote count table, however, this is not supported (Table 1 ). The vote count table aims to summarise all studies and instruments used to report HRQoL. Out of the $12 \mathrm{HRQ}$ oL questionnaires reported by the eight studies, only one questionnaire found a significant improvement in HRQoL (Madhavi 2011). Using GRADE, we judged the certainty of the evidence to be 'very low' due to serious to very serious concerns regarding risk of bias, inconsistency and imprecision.

\section{Device-worn 'objective' measures of physical activity}

Four studies (328 participants) used device-worn measures of physical activity and we entered their data into a random-effects meta-analysis (Figure 4). The median follow-up was 19 weeks (IQR 12 to 39 weeks). There is weak evidence of a small effect on physical activity levels with a standardised mean difference of $0.38\left(95 \% \mathrm{Cl}-0.15\right.$ to $\left.0.92 ; 1^{2}=78 \%\right)$. The small effect size indicates a possibly beneficial albeit small effect of moderate to vigorous physical activity levels. Re-expressing these values into the original scales we can report an approximate 10 minute increase per day in moderate to vigorous physical activity (95\% $\mathrm{Cl}-2.50$ to 22.20). Using GRADE, we downgraded the certainty of evidence by two levels to low, due to concerns over inconsistency and imprecision.

\section{Validated questionnaire-based 'subjective' measures of physical activity}

No study measured physical activity using only questionnaire measures of physical activity; two studies used them in combination with device-worn measures (Duppen 2015; Klausen 2016). Active leisure time (sports, walking and cycling) was not different after an exercise intervention; passive leisure time (television and computer) reduced significantly in both the 
intervention and control group, making its attribution to the exercise intervention challenging (Duppen 2015). Klausen 2016 did not report their questionnaire results as it did not differ from their device-worn measures.

\section{Return to work or full-time education}

van der Mheen 2019 reported days off school for children participating in a multicomponent (physical activity promotion and psychological) intervention. The intervention group had 11 episodes of one or more days off school versus 13 episodes in one month in the control group, reported by school teachers. Interestingly when this was reported by mothers there was no effect (15 vs. 15) and the direction of effect was the other direction when reported by fathers (13 vs. 11 ).

\section{Hospital admissions}

No study reported this outcome.

\section{Submaximal cardiorespiratory fitness}

A total of nine studies (10 training arms) reported a measure of submaximal CRF, with a median follow-up of 12 weeks. As previously described in the Characteristics of included studies there was a large variety of submaximal CRF parameters. Oxygen consumption scaled to body mass ( $\mathrm{mL} \cdot \mathrm{kg}^{-1} \cdot \mathrm{min}^{-1}$ ) at the gas exchange threshold (GET) was reported most often and was subsequently entered into a random-effects meta-analysis, showing a likely increase in favour of the intervention with a mean difference of $2.05(95 \% \mathrm{Cl} 0.05$ to $4.05 ; 5$ studies (6 training arms), 179 participants; $\mathrm{I}^{2}=33 \%$ ) $\mathrm{mL} \cdot \mathrm{kg}^{-1} \cdot \mathrm{min}^{-1}$ (Figure 5). All of the studies that contributed data to this meta-analysis were exercise training interventions (i.e. not PA promotion or IMT). Using GRADE, we judged the certainty of evidence as moderate-we downgraded the certainty of the evidence one level due to concerns over imprecision (<200 participants).

\section{Muscular strength}

One study (18 participants) reported muscular strength measured by maximal voluntary contraction $(\mathrm{N} \cdot \mathrm{m})$ of knee extensions in paediatrics with congenital heart disease. At the end of the exercise (cycling) intervention (12 weeks) there was a mean difference of $17.13(95 \% \mathrm{Cl} 3.45$ to 30.81$) \mathrm{N} \cdot \mathrm{m}$ in favour of exercise training (Figure 6). Using GRADE, we downgraded the certainty of evidence one level to moderate due to imprecision (only 18 participants).

\section{Adverse events (AEs)}

Eleven studies (501 participants) reported on the outcome of adverse events, over a median follow-up period of 12 weeks (IQR 12 to 26 weeks) (Avila 2016; Duppen 2015; Fritz 2020; Klausen 2016; Novakovic 2018; Opotowsky 2018; Sandberg 2018; Therrien 2003; van Dissel 2019; Westhoff-Bleck 2013; Winter 2012). Of the eleven studies, six studies reported zero adverse events and five studies reported a total of eleven adverse events. Of the 11 AEs, seven were non-cardiac (63\%), characterised by dizziness, discomfort, minor musculoskeletal and minor head injuries. The remaining four cardiac AEs were inclusive of one suspected arrhythmia, one self-limiting supraventricular arrhythmia (betablocker administered), one episode of ventricular premature complexes (managed conservatively) and one episode of nonsustained atrial tachycardia that could be related to exercise. There were no reported serious adverse events or fatality.
Eight studies (377 participants) reported no adverse myocardial changes; seven studies reported no adverse changes to cardiac biomarker B-type natriuretic peptide (NT-proBNP), with a further four studies reporting no structural or functional cardiac effects using medical imaging (cardiac magnetic resonance and echocardiography) post intervention. There were no major adverse events reported. Our judgement of the certainty of evidence using the GRADE approach was moderate due to concerns over inconsistency.

\section{DISCUSSION}

\section{Summary of main results}

We identified 15 studies (with 924 participants) that were eligible for inclusion in this review. This review shows that based on moderate to very low certainty of evidence that all types of physical activity interventions (physical activity promotion, exercise training and inspiratory muscle training) when compared to usual care may have a small effect on cardiorespiratory fitness and physical activity level but little or no effect on HRQoL. It should be noted that there was high statistical heterogeneity amongst studies assessing cardiorespiratory fitness, physical activity and HRQoL. Seventythree per cent of studies reported adverse events (six studies reported zero adverse events and five studies reported a total of eleven adverse events), of which seven of 11 events were of a noncardiac nature, and there were no reported serious adverse events or fatalities related to the physical activity interventions. We were unable to find any data related to secondary outcomes on return to work or hospital admissions. The risk of bias under the outcomes of cardiorespiratory fitness and physical activity was predominantly of 'some concerns', for the outcome of health-related quality of life it was judged to be a high risk of bias.

\section{Overall completeness and applicability of evidence}

The generalisability of previous systematic reviews was either limited to only adults ( $\mathrm{Li}$ 2019), to a specific type of intervention (Meyer 2020), or to a specific population (Scheffers 2020). This review is the first to include only randomised controlled trial data, of all age groups, types of ConHD and types of physical activity intervention. The findings of this review have potentially better external and ecological validity. Many studies have small sample sizes and all studies were published in the last 17 years. We also report 15 ongoing studies, which indicates there is continuing interest in this area. The quality of the evidence was moderate to very low for all outcomes, indicating further research is very likely to have an important impact on our confidence in the estimate of effect.

\section{Quality of the evidence}

Overall, there was a general lack of reporting details of the actual intervention. Using GRADE we assessed the quality of evidence to range from moderate to very low across all outcomes.

We downgraded the certainty of evidence for cardiorespiratory fitness to moderate using GRADE, as the confidence interval includes both appreciable harm and appreciable benefit (i.e. 95\% $\mathrm{Cl}$ spans 0 ). Therefore, we downgraded the certainty of evidence by one level due to imprecision.

We downgraded the certainty of evidence for health-related quality of life included in the meta-analysis to very low using GRADE. This 
was due to an inconsistent directions of effect (i.e. $95 \% \mathrm{Cl}$ spans 0 ), considerable heterogeneity (HRQoL, $L^{2}=82 \%$ ), a high risk of bias across all studies and impression due to the low numbers of participants $(<400)$. We therefore downgraded the certainty of evidence by three levels due to inconsistency, methodological limitations (risk of bias) and imprecision.

We downgraded the certainty of evidence for physical activity to low using GRADE. This was due to an inconsistent direction of effect and considerable heterogeneity (i.e. $95 \% \mathrm{Cl}$ spans $0 ; 1^{2}=$ $77 \%)$; there was also a low number of participants $(<400)$. We therefore downgraded the certainty of evidence by two levels due to inconsistency and imprecision.

We downgraded the certainty of evidence for submaximal cardiorespiratory fitness and muscular strength to moderate using GRADE. This was due to the small numbers of events/participants (< 400). We therefore downgraded the certainty of evidence by one level due to imprecision.

The certainty of evidence for adverse events was downgraded to moderate using GRADE. This is due to over $25 \%$ of studies not reporting data on adverse events. We therefore downgraded the certainty of evidence by one level due to publication bias.

\section{Potential biases in the review process}

We have documented and justified alterations to our methods from the published protocol in the Differences between protocol and review section (Williams 2019).

We believe this is the most comprehensive systematic review to date of RCTs in people with ConHD. However, it has some limitations as the overall risk of bias for the included studies was predominately of 'some concerns'. Specifically, blinding of outcome assessors and statistical analysis plans were poorly reported. It is impossible to blind a physical activity/exercise intervention; there were, however, very few reported attempts to blind trial staff to the allocation of participants during randomisation, assessing the outcomes and statistical analysis of the outcomes.

All included studies reported a 'no formal exercise training' intervention comparator. However, there were three active types of intervention and the amount of data is unequally distributed between these types (PA promotion $n=3$; exercise training $n=11$; and IMT $n=1$ ). This reduces the certainty of evidence in the less well represented types of interventions; they may have a significant potential for improving primary and secondary outcomes, but it could not be assessed with the limited data.

A limitation of the current data is that studies group patients using their individual ConHD lesion (diagnosis) or group multiple different types of ConHD together in a single cohort. Previous studies have reported large variations in fitness and health status between patients who have the same condition. Future studies should adopt a function-based assessments/interventions approach, which will enable scientists to observe which types of patients respond better to interventions, improving the evidence base for individualising physical activity interventions (Budts 2013; Budts 2020; Cedars 2020; Moons 2020).

\section{Agreements and disagreements with other studies or reviews}

\section{Cardiorespiratory fitness}

Both maximal and submaximal measures of CRF have been shown to be prognostic of future mortality and morbidity in congenital heart disease (Dimopoulos 2006; Giardini 2009; Müller 2015; Udholm 2018). In the current review maximal cardiorespiratory fitness increased by a mean difference of $1.89 \mathrm{~mL} \cdot \mathrm{kg}^{-1} \cdot \mathrm{min}^{-1}$ (95\% Cl -0.22 to 3.99). In a healthy population an increase of $3.5 \mathrm{~mL} . \mathrm{kg}^{-1} \cdot \mathrm{min}^{-1}$ (one MET) reduces the chance of cardiovascular diagnosis or event by approximately 15\% (Letnes 2019); and in patients with cardiovascular disease a one MET increase is associated with a $8 \%$ to $35 \%$ (median $16 \%$ ) reduction in mortality (Franklin 2013). Currently, in ConHD there is no consensus regarding what the prognostic implication is of an increase of 1.89 $\mathrm{mL} \cdot \mathrm{kg}^{-1} \cdot \mathrm{min}^{-1}$. A recent systematic review in exercise training in patients with Fontan circulations reported a similar estimate of effect to the current study of $1.73 \mathrm{~mL} \cdot \mathrm{kg}^{-1} \cdot \mathrm{min}^{-1}$ although this was not conducted using a meta-analysis (Scheffers 2020).

Our ConHD subgroup analysis reported no difference in the response to the intervention between single ventricle, tetralogy of Fallot and other/mixed ConHD populations $(P=1.0)$. All subgroups responded similarly to the intervention; this may suggest that a functional-based classification (over the traditional diagnosis/ lesion-based approach), may help to identify groups who respond better to interventions.

This was the first systematic review and meta-analysis that assessed submaximal fitness parameters. The oxygen consumption at the gas exchange threshold (GET) improved modestly (MD 2.05, $95 \% \mathrm{Cl} 0.05$ to 4.05 ); this has also been accompanied with an increase in power output (watts) at the GET (Moalla 2006; WesthoffBleck 2013). Participants therefore had a greater period of time where they could operate in a predominantly aerobic state, which is an indicator of improved fitness.

\section{Health-related quality of life}

Health-related quality of life was reported in a variety of ways making pooling difficult: we pooled only three studies and there was a standardised mean difference indicating a moderate effect size (SMD $0.76,95 \% \mathrm{Cl}-0.13$ to 1.65 ), which we judged as very low certainty of evidence. However, using a modified vote-counting table (Table 1), only one study out of eight showed a significant and positive effect on health-related quality of life (Madhavi 2011). Gratz 2009 and Amedro 2015 reported that people with ConHD had a significantly poorer health-related quality of life in the domains of physical functioning/physical well-being and general health. Gratz 2009 also stated that the ConHD population dangerously overestimate their exercise capacity and this could explain the small to no increase in HRQoL within this review.

\section{Physical activity}

Re-calculating the effect estimate into the original scales (minutes of moderate to vigorous physical activity (MVPA)), we can report an approximate 10 -minute increase per day in MVPA $(95 \% \mathrm{Cl}-2.50$ to 22.20). Whilst this is a small increase of MVPA, accumulatively over the course of a week more participants will be achieving the physical activity guidelines. To our knowledge this is the 
first review to quantitatively analyse the effects of physical activity interventions on physical activity in people with ConHD. However, were unable to perform a meta-regression on this outcome, due to the lack of studies contributing to the analyses.

This review summarises the latest evidence on CRF, HRQoL and PA. Although there were only small improvements in CRF and PA and small to no improvements in $\mathrm{HRQ}$ oL, there were no serious adverse events related to the interventions or adverse cardiac remodelling. These observations support the proposition that physical activity and exercise is safe and the benefits outweigh the potential risks (Koyak 2012). Although these data are promising, there is currently insufficient evidence to definitively determine the impact of physical activity interventions in ConHD. Therefore, further highquality randomised control trials are needed utilising a longer duration of follow-up.

\section{AUTHORS' CONCLUSIONS}

\section{Implications for practice}

Currently there are no guidelines outlined by the National Institute for Health and Care Excellence (NICE) for physical activity and exercise training in congenital heart disease. Moreover, in the UK there is no provision for cardiac rehabilitation (inclusive of physical activity interventions) for children and adolescents with congenital heart disease and clinical teams are encouraged to develop pathways to increase exercise and physical activity habits. By targeting young people it is suggested that good health and health behaviours will track into adulthood, subsequently reducing hospital admissions, reducing future morbidity and contributing to increasing survival rates.

\section{Implications for research}

This review reports small and modest improvements in maximal and submaximal cardiorespiratory fitness, but there is uncertainty in the prognostic implications of this improvement over a longterm follow-up. We require an international effort to produce a large and long-term randomised multicentre trial of physical activity and exercise interventions with long-term outcomes of mortality, morbidity, cost effectiveness, cardiorespiratory fitness and health-related quality of life. Future interventions should classify their patients (and modify the interventions) based on their functional capacity over their lesion-specific diagnosesthis should help define what types of populations respond to interventions the best (Budts 2013; Budts 2020; Cedars 2020; Moons 2020). A prognostic factors systematic review is also required to assess the current evidence of the prognostic power of cardiorespiratory fitness for patients with congenital heart disease, as it will enable physical activity and exercise interventions to be individualised and evaluated more effectively.

\section{ACK N O WLEDGEMENTS}

The background and methods section of this review is based on a standard template provided by Cochrane Heart. We would like to thank the Cochrane Heart Group and in particular Nicole Martin for their support in the drafting of this paper. We would like to acknowledge Kerry Dwan from the Cochrane Editorial and Methods Department, Andrea Takeda, Charlene Bridges and Aparna Kulkarni from Cochrane Heart and peer reviewers Professor Neil A. Smart

and $\mathrm{Dr}$ Ari Cedars M.D. Furthermore, we would also like to acknowledge the University of Exeter, Bristol Heart Institute and the University of Glasgow as host institutions. 


\section{R E F E R E N C E S}

\section{References to studies included in this review}

Avila 2016 \{published data only\}

Avila P, Marcotte F, Dore A, Mercier LA, Shohoudi A, Mongeon FP, et al. Exercise and ventricular arrhythmias in adults with tetralogy of fallot: a randomized pilot clinical trial. Heart Rhythm 2015:S395.

* Avila P, Marcotte F, Dore A, Mercier LA, Shohoudi A, Mongeon FP, et al. The impact of exercise on ventricular arrhythmias in adults with tetralogy of Fallot. International Journal of Cardiology 2016;219:218-24. [DOI: https:// dx.doi.org/10.1016/j.ijcard.2016.06.011]

Duppen 2015 \{published data only\}https://dx.doi.org/10.1016/ j.ahj.2015.06.018

Dulfer K, Duppen N, Blom NA, van Dijk AP, Helbing WA, Verhulst FC, et al. Effect of exercise training on sports enjoyment and leisure-time spending in adolescents with complex congenital heart disease: the moderating effect of health behavior and disease knowledge. Congenital Heart Disease 2014;9(5):415-23. [DOI: https://doi.org/10.1111/chd.12154]

Dulfer K, Duppen N, Blom NA, Van Domburg RT, Helbing WA, Verhulst FC, et al. Effects of exercise training on behavioral and emotional problems in adolescents with tetralogy of Fallot or a Fontan circulation: a randomized controlled trial. International Journal of Cardiology 2014;172(3):e425-47. [DOI: https://dx.doi.org/10.1016/j.ijcard.2013.12.244]

Dulfer K, Duppen N, Kuipers IM, Schokking M, van Domburg RT, Verhulst FC, et al. Aerobic exercise influences quality of life of children and youngsters with congenital heart disease: a randomized controlled trial. Journal of Adolescent Health 2014;55(1):65-72. [DOI: https://dx.doi.org/10.1016/ j.jadohealth.2013.12.010]

Dulfer K, Duppen N, Van Dijk AP, Kuipers IM, Van Domburg RT, Verhulst FC, et al. Parental mental health moderates the efficacy of exercise training on health-related quality of life in adolescents with congenital heart disease. Pediatric Cardiology 2015;36(1):33-40. [DOI: https://dx.doi.org/10.1007/ s00246-014-0961-z]

* Duppen N, Etnel JR, Spaans L, Takken T, van den BergEmons RJ, Boersma E, et al. Does exercise training improve cardiopulmonary fitness and daily physical activity in children and young adults with corrected tetralogy of Fallot or Fontan circulation? A randomized controlled trial. American Heart Journal 2015;170(3):606-14. [DOI: https://dx.doi.org/10.1016/ j.ahj.2015.06.018]

Duppen N, Etnel Jr G, Spaans L, Takken T, Van Den BergEmons, RJ, Boersma E, et al. Does exercise training improve cardio-respiratory fitness and daily physical activity in adolescents with corrected tetralogy of Fallot or Fontan circulation? A randomized controlled trial. Cardiology in the Young 2014:S39.

Duppen N, Geerdink LM, Kuipers IM, Bossers SS, Koopman LP, van Dijk AP, et al. Regional ventricular performance and exercise training in children and young adults after repair of tetralogy of Fallot: randomized controlled pilot study. Circulation: Cardiovascular Imaging 2015;8(4):e002006. [DOI: https:// dx.doi.org/10.1161/CIRCIMAGING.114.002006]

Duppen N, Kapusta L, De Rijke Y, Snoeren M, Kuipers IM, Blank AC, et al. Exercise training improves fitness without adverse cardiac remodelling in patients after repair of tetralogy of Fallot: preliminary results of the TOFFIT study. Cardiology in the Young 2013:S95.

Duppen N, Kapusta L, De Rijke Y, Snoeren M, Kuipers IM, Koopman LP, et al. The effect of exercise training on cardiac remodelling in adolescents with corrected tetralogy of Fallot and Fontan circulation: a randomized control trial. Cardiology in the Young 2014:S104-5.

Duppen N, Kapusta L, de Rijke YB, Snoeren M, Kuipers IM, Koopman LP, et al. The effect of exercise training on cardiac remodelling in children and young adults with corrected tetralogy of Fallot or Fontan circulation: a randomized controlled trial. International Journal of Cardiology 2015;179:97-104. [DOI: https://dx.doi.org/10.1016/ j.ijcard.2014.10.031]

Fritz 2020 \{published data only\}https://dx.doi.org/10.1016/ j.ijcard.2020.01.015

Fritz C, Müller J, Nagdyman N, Oberhoffer R, Ewert P, Hager A. Inspiratory muscle training improves oxygen saturation and hemoglobin levels in patients with fontan circulation - results from a randomized home-based training study. Cardiology in the Young 2019:S29.

* Fritz C, Müller J, Oberhoffer R, Ewert P, Hager A. Inspiratory muscle training did not improve exercise capacity and lung function in adult patients with Fontan circulation: a randomized controlled trial. International Journal of Cardiology 2020;305:50-5. [DOI: https://doi.org/10.1016/ j.ijcard.2020.01.015]

Fritz C, Müller J, Oberhoffer R, Ewert P, Hager A. Inspiratory muscle training did not improve physical capacity in adult patients with Fontan circulation. Cardiology in the Young 2018:S30-1.

Klausen 2016 \{published data only\}https://dx.doi.org/10.1016/ j.ijcard.2016.07.092

* Klausen SH, Andersen LL, Søndergaard L, Jakobsen JC, Zoffmann V, Dideriksen K, et al. Effects of eHealth physical activity encouragement in adolescents with complex congenital heart disease: the PReVaiL randomized clinical trial. International Journal of Cardiology 2016;221:1100-6. [DOI: https://dx.doi.org/10.1016/j.ijcard.2016.07.092]

Klausen SH, Hwiid S, Mikkelsen UR, Hirth A, Wetterslev J, Kjaergaard $\mathrm{H}$, et al. Effects on exercise capacity of eHealth encouragements in adolescents with congenital heart disease; development of a prospective and randomised complex intervention. European Journal of Cardiovascular Nursing 2012:S47-8 
Madhavi 2011 \{published data only\}

* Madhavi K, Abhachandra AG, Maiya G. Influence of graded aerobic exercise in post-surgical adult acyanotic congenital heart disease - a prospective randomized clinical trial. Indian Journal of Physiotherapy \& Occupational Therapy 2011;5(4):87-94.

\section{Moalla 2006 \{published data only\}}

* Moalla W, Maingourd Y, Gauthier R, Cahalin LP, Tabka Z Ahmaidi S. Effect of exercise training on respiratory muscle oxygenation in children with congenital heart disease. European Journal of Cardiovascular Prevention and Rehabilitation 2006;13(4):604-11.

Moalla W, Elloumi M, Chamari K, Dupont G, Maingourd Y, Tabka Z, et al. Training effects on peripheral muscle oxygenation and performance in children with congenital heart diseases. Applied Physiology, Nutrition and Metabolism 2012;37(4):621-30.

Moalla W, Gauthier R, Maingourd Y, Ahmaidi S. Six-minute walking test to assess exercise tolerance and cardiorespiratory responses during training program in children with congenital heart disease. International Journal of Sports Medicine 2005;26(9):756-62.

Morrison 2013 \{published data only\}https://dx.doi.org/10.1136/ heartjnl-2013-303849

Morrison ML, Sands AJ, McCusker CG, McKeown P, McMahon M, Gordon J, et al. Exercise training improves activity and psychosocial wellbeing in adolescents with congenital heart disease. Irish Journal of Medical Science 2011:S398-9.

* Morrison ML, Sands AJ, McCusker CG, McKeown PP, McMahon M, Gordon J, et al. Exercise training improves activity in adolescents with congenital heart disease. BMJ Heart 2013;99(15):1122-8. [DOI: http://dx.doi.org/10.1136/ heartjnl-2013-303849]

Novakovic 2018 \{published data only\}https://

dx.doi.org/10.1016/j.ijcard.2017.12.105

* Novaković M, Prokšelj K, Rajkovič U, Cuderman TV, Trontelj KJ, Fras Z, et al. Exercise training in adults with repaired tetralogy of Fallot: a randomized controlled pilot study of continuous versus interval training. International Journal of Cardiology 2018;255:37-44. [DOI: https://dx.doi.org/10.1016/ j.ijcard.2017.12.105]

Opotowsky 2018 \{published data only\}https://

dx.doi.org/10.1177/2150135117752123

* Opotowsky AR, Rhodes J, Landzberg MJ, Bhatt AB, Shafer KM, Yeh DD, et al. A randomized trial comparing cardiac rehabilitation to standard of care for adults with congenital heart disease. World Journal for Pediatric and Congenital Heart Surgery 2018;9(2):185-93. [DOI: https:// dx.doi.org/10.1177/2150135117752123]

Opotowsky AR, Rhodes J, Moko L, Bradley R, Systrom D, Waxman $A$, et al. A randomized trial of cardiac rehabilitation for adolescents and adults with congenital heart disease. Journal of the American College of Cardiology 2016;13(Suppl 1):987.
Tikkanen AU, Rhodes J, Landzberg M, Bhatt A, Systrom DM, Waxman $A$, et al. A randomized trial of cardiac rehabilitation for adolescents and adults with congenital heart disease. PM\&R 2016:S169.

Sandberg 2018 \{published data only\}https://dx.doi.org/10.1111/ chd.12562

* Sandberg C, Hedstrom M, Wadell K, Dellborg M, Ahnfelt A, Zetterstrom AK, et al. Home-based interval training increases endurance capacity in adults with complex congenital heart disease. Congenital Heart Disease 2018;13(2):245-62. [DOI: https://dx.doi.org/10.1111/chd.12562]

Sandberg C, Hedstrom M, Dellborg M, Magnusson A, Zetterstom AK, Wadell K, et al. Increased endurance capacity in adults with complex congenital heart disease after home-based interval exercise training on ergometer cycle. European Heart Journal 2015:458.

\section{Therrien 2003 \{published data only\}}

* Therrien J, Fredriksen P, Walker M, Granton J, Reid G, Webb G. A pilot study of exercise training in adult patients with repaired tetralogy of Fallot. Canadian Journal of Cardiology 2003;19(6):685-9.

van der Mheen 2019 \{published data only\}https:// dx.doi.org/10.1017/S1047951119001732

Van Der Mheen M, McCusker CG, Van Beynum IM, Dulfer K, Van Galen E, Bogers AJ, et al. CHIP-Family to improve psychosocial wellbeing of young children with congenital heart disease and their families. Cardiology in the Young 2018:S28.

* van der Mheen M, Meentken MG, van Beynum IM, Van Der Ende J, Van Galen E, Zirar A, et al. CHIP-Family intervention to improve the psychosocial well-being of young children with congenital heart disease and their families: results of a randomised controlled trial. Cardiology in the Young 2019;29(9):1172-82. [DOI: https://dx.doi.org/10.1017/ S1047951119001732]

van Dissel 2019 \{published data only\}https:// dx.doi.org/10.1016/j.ijcard.2018.12.042

Hooglugt JQ, Van Dissel AC, De Haan FH, Blok IM, Jorstad HR, Mulder BJ, et al. Efficacy and compliance of long-term, individualised exercise training in adults with congenital heart disease and heart failure symptoms: a randomized controlled trial. European Heart Journal 2018:Suppl 1:245.

* van Dissel AC, Blok IM, Hooglugt JL, de Haan FH, Jørstad HT, Mulder BJ, et al. Safety and effectiveness of home-based, self-selected exercise training in symptomatic adults with congenital heart disease: A prospective, randomised, controlled trial. International Journal of Cardiology 2019;278:59-64. [DOI: https://dx.doi.org/10.1017/S1047951119001732]

Westhoff-Bleck 2013 \{published data only\}https:// dx.doi.org/10.1016/j.ijcard.2013.10.009

* Westhoff-Bleck M, Schieffer B, Tegtbur U, Meyer GP, Hoy L, Schaefer A, et al. Aerobic training in adults after atrial switch procedure for transposition of the great arteries improves exercise capacity without impairing systemic right ventricular 
function. International Journal of Cardiology 2013;170(1):24-9. [DOI: https://dx.doi.org/10.1016/j.ijcard.2013.10.009]

Winter 2012 \{published data only\}https://dx.doi.org/10.1016/ j.ijcard.2014.10.042

Balducci A, Winter MM, Fabi M, Donti A, Prandstraller D, Formigari $\mathrm{R}$, et al. Exercise training is beneficial and safe in adult patients with a systemic right ventricle. Giornale Italiano di Cardiologia 2011:16S.

Van Der Bom T, Winter MM, De Vries LCS, Bouma BJ, Van Dijk APJ, Van Der Plas MN, et al. Exercise training improves exercise capacity in adult patients with a systemic right ventricle. European Heart Journal 2010:Suppl 1:615.

Van Der Bom T, Winter MM, Knaake JL, Cervi E, De Vries LS, Balducci A, et al. Long-term benefits of exercise training in patients with a systemic right ventricle. International Journal of Cardiology 2015;179(105):105-11. [DOI: https:// dx.doi.org/10.1016/j.ijcard.2014.10.042]

* Winter MM, van der Bom T, de Vries LC, Balducci A, Bouma BJ, Pieper PG, et al. Exercise training improves exercise capacity in adult patients with a systemic right ventricle: a randomized clinical trial. European Heart Journal 2012;33(11):1378-85. [DOI: https://dx.doi.org/10.1093/eurheartj/ehr396]

\section{References to studies excluded from this review}

\section{Ali Faisal 2016 \{published data only\}}

Ali-Faisal SF, Benz Scott L, Johnston L, Grace SL. Cardiac rehabilitation referral and enrolment across an academic health sciences centre with eReferral and peer navigation: a randomised controlled pilot trial. BMJ Open 2016;6(3):e010214. [DOI: https://dx.doi.org/10.1136/bmjopen-2015-010214]

\section{Altamirano Diaz 2017 \{published data only\}}

Altamirano-Diaz L, Rombeek M, De Jesus S, Welisch E, Prapavessis H, Dempsey AA, et al. Remote lifestyle counseling influences cardiovascular health outcomes in youth with overweight or obesity and congenital heart disease. Front 2017;5:269. [DOI: https://dx.doi.org/10.3389/fped.2017.00269]

\section{Amedro 2019 \{published data only\}}

Amedro P, Gavotto A, Legendre A, Lavastre K, Bredy C, De La Villeon $\mathrm{G}$, et al. Impact of a centre and home-based cardiac rehabilitation program on the quality of life of teenagers and young adults with congenital heart disease: the QUALI-REHAB study rationale, design and methods. International Journal of Cardiology 2019;283:112-8. [DOI: https://dx.doi.org/10.1016/ j.ijcard.2018.12.050]

\section{Babu 2013 \{published data only\}}

Babu AS, Padmakumar R, Maiya AG. A review of ongoing trials in exercise based rehabilitation for pulmonary arterial hypertension. Indian Journal of Medical Research 2013;137:900-6.

\section{Babu 2017 \{published data only\}}

Babu AS, Ramachandran P, Maiya AG. Effects of homebased exercise training in Eisenmenger's syndrome: secondary analysis from a RCT. Journal of Cardiopulmonary Rehabilitation and Prevention 2017;37(5):367-8. [DOI: http:// dx.doi.org/10.1097/HCR.0000000000000293]

Becker Gruenig 2012 \{published data only\}

Becker-Gruenig T, Ehlken N, Gorenflo M, Hager A, Halank M, $\mathrm{K}$ lose $\mathrm{H}$, et al. Efficacy of exercise training in congenital heart disease associated pulmonary hypertension. European Respiratory Journal 2012;40(56):P927.

Bhasipol 2018 \{published data only\}

Bhasipol A, Sanjaroensuttikul N, Pornsuriyasak P, Yamwong S, Tangcharoen $\mathrm{T}$. Effect of the home cardiac rehabilitation program for adult with complex congenital heart disease: the EMPOWER trial. European Heart Journal 2018;39(Suppl 1):22. [DOI: http://dx.doi.org/10.1093/eurheartj/ehy564.226]

Bhasipol 2018a \{published data only\}

Bhasipol A, Sanjaroensuttikul N, Pornsuriyasak P, Yamwong S, Tangcharoen T. Efficiency of the home cardiac rehabilitation program for adults with complex congenital heart disease. Congenital Heart Disease 2018;13(6):952-8. [DOI: http:// dx.doi.org/10.1111/chd.12659]

\section{BoaSorteSilva 2017 \{published data only\}}

Boa Sorte Silva NC, Gregory MA, Gill DP, Petrella RJ. Multiplemodality exercise and mind-motor training to improve cardiovascular health and fitness in older adults at risk for cognitive impairment: a randomized controlled trial. Archives of Gerontology and Geriatrics 2017;68:149-60. [DOI: 10.1016/ j.archger.2016.10.009]

\section{Callaghan 2018 \{published data only\}}

Callaghan S, Morrison ML, McCusker C, Mckeown P, Casey F. A structured intervention programme can improve the biophysical wellbeing in children with congenital heart disease. Ulster Medical Journal 2018;87(2):146.

\section{Camargo 2007 \{published data only\}}

Camargo DM, Campos MT, Sarmiento JM, Garzón M, Navia J, Merchán A. Hemodynamic response to training in resistance and muscular strength of upper limbs in cardiac rehabilitation [Respuesta hemodinámica con el entrenamiento en resistencia y fuerza muscular de miembros superiores en rehabilitación cardiaca]. Revista Colombiana de Cardiología 2007;14(4):198-206.

\section{Chen 2017 \{published data only\}}

Chen CW, Fanjiang YY, Chiang YT, Ho CL. Mobile health program to promote self management in youths with congenital heart disease design and development of the cool randomized controlled trial. Cardiology in the Young 2017;27(4):S89. [DOI: http://dx.doi.org/10.1017/S104795111700110X]

\section{Coats 1992 \{published data only\}}

Coats AJ, Adamopoulos S, Radaelli A, McCance A, Meyer TE, Bernardi L, et al. Controlled trial of physical training in chronic heart failure. Exercise performance, hemodynamics, ventilation, and autonomic function. Circulation 1992;85(6):2119-31. [DOI: 10.1161/01.Cir.85.6.2119] 


\section{Cordina 2013 \{published data only\}}

Cordina RL, O'Meagher S, Karmali A, Rae CL, Liess C, Kemp GJ, et al. Resistance training improves cardiac output, exercise capacity and tolerance to positive airway pressure in Fontan physiology. International Journal of Cardiology 2013;168(2):780-8. [DOI: https://doi.org/10.1016/ j.ijcard.2012.10.012]

\section{Curnier 2012 \{published data only\}}

Curnier D, Lalonde F, Mathieu ME, Fournier A, Bigras JL, Miro J, et al. Children with congenital heart disease and exercise rehabilitation. Journal of Cardiopulmonary Rehabilitation and Prevention 2012;32(4):232. [DOI: http://dx.doi.org/10.1097/ HCR.0b013e3182243798]

\section{DRKS00011363 \{published data only\}}

DRKS00011363. Breathing training in children, adolescents and young adults with Tetralogy of Fallot after total surgical repair. www.who.int/trialsearch/Trial2.aspx?TrialID=DRKS00011363 (accesed prior to 21 October 2020).

\section{Du 2015 \{published data only\}}

Du Q, Zhou X, Wang X, Chen S, Yang X, Chen N, et al. Passive movement and active exercise for very young infants with congenital heart disease: a study protocol for a randomized controlled trial. Trials 2015;16:288. [DOI: https:// dx.doi.org/10.1186/s13063-015-0816-9]

\section{Du 2017 \{published data only\}}

Du Q, Salem Y, Liu HH, Zhou X, Chen S, Chen N, et al. A homebased exercise program for children with congenital heart disease following interventional cardiac catheterization: study protocol for a randomized controlled trial. Trials 2017;18(1):38. [DOI: https://dx.doi.org/10.1186/s13063-016-1773-7]

Dua 2010 \{published data only\}

Dua JS, Cooper AR, Fox KR, Graham Stuart A. Exercise training in adults with congenital heart disease: feasibility and benefits. International Journal of Cardiology 2010;138(2):196-205. [DOI: https://dx.doi.org/10.1016/j.ijcard.2009.01.038]

\section{Fredriksen 2000 \{published data only\}}

Fredriksen PM, Walker M, Granton J, Webb G, Reid G, Therrien J. A controlled trial of exercise training in adult patients with repaired tetralogy of Fallot. Canadian Journal of Cardiology 2000;16(Suppl F):137F.

\section{Fredriksen 2000a \{published data only\}}

Fredriksen PM, Kahrs N, Blaasvaer S, Sigurdsen E, Gundersen O, Roeksund O, et al. Effect of physical training in children and adolescents with congenital heart disease. Cardiology in the Young 2000;10(2):107-14.

\section{Gierat Haponiuk 2014 \{published data only\}}

Gierat-Haponiuk K, Haponiuk I, Jaworski R, Chojnicki M, Szalewska D, Leszczynska K, et al. Physical activity in patients with grown-up congenital heart defects after comprehensive cardiac rehabilitation. Polish Journal of Thoracic and Cardiovascular Surgery 2014;11(4):452-8. [DOI: https:// dx.doi.org/10.5114/kitp.2014.47352]

\section{Goldbeck 2011 \{published data only\}}

Goldbeck L, Holling I, Schlack R, West C, Besier T. The impact of an inpatient family-oriented rehabilitation program on parent-reported psychological symptoms of chronically ill children. Klinische Pädiatrie 2011;223(2):79-84. [DOI: https:// dx.doi.org/10.1055/s-0030-1262831]

Gomes Neto 2016 \{published data only\}

Gomes-Neto M, Saquetto, MB, da Silva e Silva CM, Conceicao CS, Carvalho VO. Impact of exercise training in aerobic capacity and pulmonary function in children and adolescents after congenital heart disease surgery: a systematic review with meta-analysis. Pediatric Cardiology 2016;37(2):217-24. [DOI: https://dx.doi.org/10.1007/ s00246-015-1270-x]

\section{Gotink 2017 \{published data only\}}

Gotink RA, Younge JO, Wery MF, Utens E, Michels M, Rizopoulos D, et al. Online mindfulness as a promising method to improve exercise capacity in heart disease: 12 month follow-up of a randomized controlled trial. PloS One 2017;12(5):e0175923. [DOI: 10.1371/journal.pone.0175923]

\section{Hedlund 2018 \{published data only\}}

Hedlund ER, Lundell B, Soderstrom L, Sjoberg G. Can endurance training improve physical capacity and quality of life in young Fontan patients? Cardiology in the Young 2018;28(3):438-46. [DOI: 10.1017/s1047951117002360]

\section{Hooglugt 2018a \{published data only\}}

Hooglugt JQ, van Dissel AC, Blok IM, de Haan FH, Jorstad HT, Bouma BJ, et al. The effect of exercise training in symptomatic patients with grown-up congenital heart disease: a review. Expert Review of Cardiovascular Therapy 2018;16(6):379-86. [DOI: https://dx.doi.org/10.1080/14779072.2018.1471356]

IlarrazaLomel 2008 \{published data only\}

Ilarraza Lomelí H, Quiroga P, Rius Suárez MD. Cardiac rehabilitation in children [Rehabilitación cardíaca en población pediátrica. Más allá que ayudar a un niño a readaptar su corazón]. Archivos de Cardiología de México 2008;78(2):129-33.

IoannisLaoutaris 2015 \{published data only\}

loannis Laoutaris ID, Dritsas A, Kariofyllis P, Manginas A. Benefits of inspiratory muscle training in patients with pulmonary arterial hypertension. European Journal of Preventive Cardiology 2015;22(Suppl 1):S78. [DOI: http:// dx.doi.org/10.1177/2047487315586736]

\section{IRCT20180417039341N1 \{published data only\}}

IRCT20180417039341N1. Evaluation of self-care education on self-efficacy and quality of life in adolescents with congenital heart disease. www.who.int/trialsearch/Trial2.aspx? TrialID=IRCT20180417039341N1 (accessed prior to 21 October 2020).

\section{ISRCTN74393113 \{published data only\}}

ISRCTN74393113. Biophysical \& psychosocial wellbeing in children with congenital heart disease. www.who.int/ trialsearch/Trial2.aspx?TrialID=ISRCTN74393113 (accessed prior to 21 October 2020). 
Joshi 2019 \{published data only\}

Joshi VL, Tang LH, Zwisler AD, Taylor RS. Rehabilitation for people with cardiac conditions: an overview of systematic reviews. Physiotherapy (United Kingdom) 2019;105(Suppl 1):e11-2. [DOI: http://dx.doi.org/10.1016/j.physio.2018.11.250]

Kobashigawa 1999 \{published data only\} Kobashigawa JA, Leaf DA, Lee, N, Gleeson MP, Liu H, Hamilton MA, et al. A controlled trial of exercise rehabilitation after heart transplantation. New England Journal of Medicine 1999;340(4):272-7.

\section{Lalonde 2014 \{published data only\}}

Lalonde D, Welisch E, Altamirano-Diaz L, De Jesus S, Prapavessis $\mathrm{H}$, Rombeek $\mathrm{M}$, et al. The impact of a structured lifestyle intervention on body composition and exercise capacity in obese children with congenital heart defect (Smart Heart Trial). Journal of Physical Activity and Health 2014;11:S163-4.

\section{Lam 2014 \{published data only\}}

Lam K, Dias P, Green G, Maiorana A. Echocardiographic Findings of chronic heart failure patients following exercise training. Journal of the American Society of Echocardiography 2014;27(6):B119.

\section{Longmuir 1985 \{published data only\}}

Longmuir PE, Turner JA, Rowe RD, Olley PM. Postoperative exercise rehabilitation benefits children with congenital heart disease. Clinical and Investigative Medicine 1985;8(3):232-8.

\section{Longmuir 2013 \{published data only\}}

Longmuir PE, Tyrrell PN, Corey M, Faulkner G, Russell JL, McCrindle BW. Home-based rehabilitation enhances daily physical activity and motor skill in children who have undergone the Fontan procedure. Pediatric Cardiology 2013;34(5):1130-51. [DOI: https://dx.doi.org/10.1007/ s00246-012-0618-8]

\section{Lozada 2017 \{published data only\}}

Lozada MA, Balderas J, Bunyi MI, Suarez C. Comparison of the effectiveness of four(4) session play module versus the conventional cardiovascular rehabilitation therapy among post operative congenital heart disease pediatric patients ages 512 years old. Cardiology in the Young 2017;27(4):S144. [DOI: http:// dx.doi.org/10.1017/S104795111700110X]

\section{Marra 2015 \{published data only\}}

Marra AM, Egenlauf B, Bossone E, Eichstaedt C, Grunig E, Ehlken N. Principles of rehabilitation and reactivation: pulmonary hypertension. Respiration 2015;89(4):265-73. [DOI: 10.1159/000371855]

\section{McKillop 2018 \{published data only\}}

McKillop A, Grace SL, Ghisi GL, Allison KR, Banks L, Kovacs AH, et al. Adapted motivational interviewing to promote exercise in adolescents with congenital heart disease: a pilot trial. Pediatric Physical Therapy 2018;30(4):326-34. [DOI: https:// dx.doi.org/10.1097/PEP.0000000000000534]
NCT00930800 \{published data only\}

NCT00930800. Exercise training in children with congenital heart defect. clinicaltrials.gov/show/nct00930800 (first posted 2 July 2009).

\section{NCT01463800 \{published data only\}}

NCT01463800. Rehabilitation in patients with congenital heart disease. clinicaltrials.gov/show/nct01463800 (first posted 2 November 2011)

NCT01671566 \{published data only\}

NCT01671566. Interval training in adults with congenital heart disease a randomized trial. clinicaltrials.gov/show/nct01671566 (first posted 23 August 2012).

NCT01822769 \{published data only\} NCT01822769. Cardiopulmonary rehabilitation for adolescents and adults with congenital heart disease. clinicaltrials.gov/ show/nct01822769 (first posted 2 April 2013).

NCT02632253 \{published data only\}

NCT02632253. Effects of high-intensity interval training on exercise capacity in patients with grown-up congenital heart disease. clinicaltrials.gov/show/nct02632253 (first posted 16 December 2015).

NCT02643810 \{published data only\}

NCT02643810. Exercise training in adults with corrected Tetralogy of Fallot. clinicaltrials.gov/show/nct02643810 (first posted 31 December 2015).

NCT02980393 \{published data only\}

NCT02980393. Smart Heart Trial: structured lifestyle intervention for overweight and obese youth with operated heart defects. clinicaltrials.gov/show/nct02980393 (first posted 2 December 2016).

\section{NCT03297918 \{published data only\}}

NCT03297918. Impact of a structural phonation training on respiratory muscle function in patients with structural heart disease. clinicaltrials.gov/show/nct03297918 (first posted 29 September 2017).

Nehyba 2009 \{published data only\}

Nehyba S, Chaloupka V, Soucek R, Chaloupkova S, Vysoky R, Stetka F, et al. The programme of managed ambulatory rehabilitation for patients after heart valve defect surgery. Vnitr̆ni Lékařstvi 2009;55(12):1118-25.

\section{NTR2527 \{published data only\}}

NTR2527. High intensity interval training after cardiac resynchronization therapy. www.who.int/trialsearch/ Trial2.aspx?TrialID=NTR2527 (date of registration 25 September 2010).

\section{NTR3041 \{published data only\}}

NTR3041. Effects of high intensity interval training on cardiac function at rest and during exercise. www.who.int/trialsearch/ Trial2.aspx?TrialID=NTR3041 (date of registration 19 August 2011). 
Rhodes 2006 \{published data only\}

Rhodes J, Curran TJ, Camil L, Rabideau N, Fulton DR, Gauthier NS, et al. Sustained effects of cardiac rehabilitation in children with serious congenital heart disease. Pediatrics 2006;118(3):e586-93.

\section{Rowland 2016 \{published data only\}}

Rowland T. Cardiovascular physiology and disease in youth. Pediatric Exercise Science 2016;28(1):44-7. [DOI: 10.1123/ pes.2016-0013]

\section{Ruttenberg 1983 \{published data only\}}

Ruttenberg HD, Adams TD, Orsmond GS, Conlee RK, Fisher AG. Effects of exercise training on aerobic fitness in children after open heart surgery. Pediatric Cardiology 1983;4(1):19-24.

\section{Stefani 2014 \{published data only\}}

Stefani L, Galanti G, Innocenti G, Mercuri R, Maffulli N. Exercise training in athletes with bicuspid aortic valve does not result in increased dimensions and impaired performance of the left ventricle. Cardiology Research and Practice 2014;2014:238694. [DOI: https://dx.doi.org/10.1155/2014/238694]

\section{Sutherland 2018 \{published data only\}}

Sutherland N, Jones B, Westcamp Aguero S, Melchiori T, du Plessis K, Konstantinov IE, et al. Home- and hospitalbased exercise training programme after Fontan surgery. Cardiology in the Young 2018;28(11):1299-305. [DOI: https:// dx.doi.org/10.1017/S1047951118001166]

\section{Tan 1996 \{published data only\}}

Tan LL, Huang JF, Wang H. The effect of rehabilitation training on postoperative recovery of children with congenital heart disease. Chinese Journal of Nursing 1996;31(6):314-5.

\section{Tikkanen 2016 \{published data only\}}

Tikkanen AU, Rhodes J, Landzberg M, Bhatt A, Systrom DM, Waxman A, et al. Poster 26A: randomized trial of cardiac rehabilitation for adolescents and adults with congenital heart disease. PM\&R 2016;8(9):S169. [DOI: 10.1016/ j.pmrj.2016.07.069]

\section{Zhou 2017a \{published data only\}}

Zhou X, Duqing, Sun K. GW28-e0722 randomized controlled trial of a home-based exercise program for children with congenital heart disease following interventional cardiac catheterization: a preliminary study. Journal of the American College of Cardiology (JACC) 2017;70:C165. [DOI: 10.1016/ j.jacc.2017.07.601]

\section{Zhou 2017b \{published data only\}}

Zhou X, Duqing, Sun K. Randomized controlled trial of a homebased exercise program for children with congenital heart disease following interventional cardiac catheterization: a preliminary study. Journal of the American College of Cardiology 2017;70(16 Supplement 1):C165. [DOI: http:// dx.doi.org/10.1016/j.jacc.2017.07.601]

\section{References to studies awaiting assessment}

Ali 2018 \{published data only\}

Ali LA, Pingitore A, Piaggi P, Brucini F, Passera M, Marotta M, et al. Respiratory training late after Fontan intervention: impact on cardiorespiratory performance. Pediatric Cardiology 2018;39(4):695-704. [DOI: 10.1007/s00246-018-1808-9]

Callaghan 2017 \{published data only\}

Callaghan S, Morrison ML, McCusker C, Mckeown P, Casey F. A structured intervention programme can improve the biophysical wellbeing in children with congenital heart disease. Cardiology in the Young 2017;27(4):S228-9. [DOI: http:// dx.doi.org/10.1017/S104795111700110X]

Morrison 2015 \{published data only\}

Morrison BN, DeSouza AM, Voss C, Potts JE, Sandor GG, Harris KC. The use of individualized exercise prescription and activity trackers to promote physical activity in children with congenital heart disease. Canadian Journal of Cardiology 2015;31(10 Suppl 1):S123-4

Neidenbach 2017 \{published data only\}

Neidenbach RC, Oberhoffer R, Nagdyman N, Seitz U, Ewert $\mathrm{P}$, Kaemmerer $\mathrm{H}$, et al. Inspiratory muscle training in children after fontan operation increases oxygen saturation. Cogent Medicine 2017;4(1):18. [DOI: http:// dx.doi.org/10.1080/2331205X.2017.1408251]

\section{Nilsson 2019 \{published data only\}}

Nilsson H, Nylander E, Borg S, Tamas E, Hedman K. Cardiopulmonary exercise testing for evaluation of a randomized exercise training intervention following aortic valve replacement. Clinical Physiology and Functional Imaging 2019;39(1):103-10. [DOI: 10.1111/cpf.12545]

\section{References to ongoing studies}

Ganzoni 2019 \{published data only\}

Ganzoni C, Arslani K, Pfister O, Freese M, Strobel W, Muller C, et al. Regular phonation and respiratory muscle training improve respiratory muscle strength and quality of life in patients with structural heart disease-the HeartChoir randomized clinical controlled trial. Cardiovascular Medicine 2019;22:P29. [DOI: http://dx.doi.org/10.4414/cvm.2019.02052]

\section{ISRCTN74643496 \{published data only\}}

ISRCTN74643496. Improving the effectiveness of psychological interventions for depression and anxiety in the cardiac rehabilitation pathway: a single-blind randomised controlled trial. www.who.int/trialsearch/Trial2.aspx? TrialID=ISRCTN74643496 (date assigned 8 April 2015).

\section{NCT01397110 \{published data only\}}

NCT01397110. Respiratory and physical therapy in patients with associated pulmonary arterial hypertension (APAH) with congenital heart defects. clinicaltrials.gov/show/nct01397110 (first posted 19 July 2011). 


\section{NCT02240147 \{published data only\}}

NCT02240147. Start-to-Sport - home-based exercise for adolescents and adults with congenital heart disease. clinicaltrials.gov/show/nct02240147 (first posted 15 September 2014).

\section{NCT02283255 \{unpublished data only\}}

NCT02283255. Cardiovascular, pulmonary and skeletal muscle evaluation in late postoperative period of the Fontan surgery. clinicaltrials.gov/ct2/show/NCT02283255 (first posted 5 November 2014).

\section{NCT02658266 \{unpublished data only\}}

NCT02658266. Effect of resistance training in adults with complex congenital heart disease. clinicaltrials.gov/ct2/show/ NCT02658266 (first posted 18 January 2016).

\section{NCT03335475 \{published data only\}}

NCT03335475. Congenital heart disease physical activity lifestyle study. clinicaltrials.gov/show/nct03335475 (first posted 7 November 2017).

\section{NCT03435354 \{published data only\}}

NCT03435354. Enhanced physical activity support in congenital heart disease clinical care. clinicaltrials.gov/show/nct03435354 (first posted 19 February 2018).

\section{NCT03479957 \{published data only\}}

NCT03479957. Remotely monitored and coached cardiac rehabilitation northern Sweden. clinicaltrials.gov/show/ nct03479957 (first posted 27 March 2018).

\section{NCT03690518 \{published data only\}}

NCT03690518. Rehabilitation of adolescents and young adults with congenital heart diseases. clinicaltrials.gov/show/ nct03690518 (first posted 1 October 2018).

\section{NCT03999320 \{published data only\}}

NCT03999320. Sophrology and congenital heart disease. clinicaltrials.gov/show/nct03999320 (first posted 26 June 2019).

\section{NCT04135859 (YACHD-PALS) \{published data only\}}

NCT04135859. Young adult congenital heart disease physical activity lifestyle study (YACHD-PALS). clinicaltrials.gov/ct2/ show/NCT04135859 (first posted 23 October 2019).

\section{NCT04208893 \{published and unpublished data\}}

NCT04208893. Exercise training strategies for children with repaired Tetralogy of Fallot. clinicaltrials.gov/ct2/show/ NCT04208893 (first posted 23 December 2019).

NCT04264650 \{published data only\}

NCT04264650. Effectiveness of an mHealth intervention for youth with congenital heart disease. clinicaltrials.gov/ct2/show/ NCT04264650 (first posted 11 February 2020).

\section{UMIN000021661 \{published data only\}}

UMIN000021661. Evaluation test about safety and efficacy of the respiratory muscle training therapy by abdominal respiratory weight exercises in chronic cardiovascular disease patients. www.who.int/trialsearch/Trial2.aspx?TrialID=JPRNUMIN000021661 (date of disclosure 1 April 2016).

\section{Additional references}

\section{Adams 2017}

Adams V, Reich B, Uhlemann M, Niebauer J. Molecular effects of exercise training in patients with cardiovascular disease: focus on skeletal muscle, endothelium, and myocardium. American Journal of Physiology. Heart and Circulatory Physiology 2017;5(313):72-88.

\section{Amedro 2015}

Amedro P, Dorka R, Moniotte S, Guillaumont S, Fraisse A, Kreitmann B, et al. Quality of life of children with congenital heart diseases: a multicenter controlled cross-sectional study. Pediatric Cardiology 2015;36(8):1588-601.

\section{Amedro 2017}

Amedro P, Gavotto A, Guillaumont S, Bertet H, Vincenti M, De La Villeon $\mathrm{G}$, et al. Cardiopulmonary fitness in children with congenital heart diseases versus healthy children. Heart (British Cardiac Society) 2017;104(12):1026-36.

\section{Best 2016}

Best KE, Rankin J. Long-term survival of individuals born with congenital heart disease: A systematic review and meta-analysis. Journal of the American Heart Association 2016;5(6):1-16.

\section{Brudy 2020}

Brudy L, Hock J, Häcker AL, Meyer M, Oberhoffer R, Hager A, et al. Children with congenital heart disease are active but need to keep moving: a cross-sectional study using wrist-worn physical activity trackers. Journal of Pediatrics 2020;217:13-19.

\section{Budts 2013}

Budts W, Börjesson M, Chessa M, Van Buuren F, Trigo Trindade P, Corrado D, et al. Physical activity in adolescents and adults with congenital heart defects: individualized exercise prescription. European Heart Journal 2013;34(47):3669-74.

\section{Budts 2020}

Budts W, Pieles GE, Roos-Hesselink JW, Sanz de la Garza M, D’Ascenzi F, Giannakoulas G, et al. Recommendations for participation in competitive sport in adolescent and adult athletes with Congenital Heart Disease (CHD): position statement of the Sports Cardiology \& Exercise Section of the European Association of Preventive Cardiology (EAPC), the European Society of Cardiology (ESC) Working Group on Adult Congenital Heart Disease and the Sports Cardiology, Physical Activity and Prevention Working Group of the Association for European Paediatric and Congenital Cardiology (AEPC). European Heart Journal 2020 Aug 26 [E-pub ahead of print]. [DOI: 10.1093/eurheartj/ehaa501]

\section{Campbell 2020}

Campbell M, McKenzie JE, Sowden A, Katikireddi SV, Brennan SE, Ellis S, et al. Synthesis without meta-analysis (SWiM) in systematic reviews: reporting guideline. BMJ 2020;16:368. [DOI: http://dx.doi.org/10.1136/bmj.l6890] 


\section{Caspersen 1985}

Caspersen CJ, Powell KE, Christenson GM. Physical activity, exercise, and physical fitness: definitions and distinctions for health-related research. Public Health Reports (Washington, D.C. : 1974) 1985;100(2):126.

\section{Cedars 2020}

Cedars AM, Kutty S. The way forward in congenital heart disease research. JAMA Cardiology 2020;5(9):979-80. [DOI: 10.1001/ jamacardio.2020.2034]

\section{Covidence [Computer program]}

Veritas Health Innovation Covidence systematic review software. Melbourne, Australia: Veritas Health Innovation, accessed before 2 October 2020. Available at www.covidence.org.

\section{Deeks 2017}

Deeks JJ, Higgins JP, Altman DG (editors) on behalf of the Cochrane Statistical Methods Group. Chapter 9: Analysing data and undertaking metaanalyses. In: Higgins JP, Churchill $\mathrm{R}$, Chandler J, Cumpston MS (editors), Cochrane Handbook for Systematic Reviews of Interventions version 5.2.0 (updated June 2017), Cochrane, 2017. Available from www.training.cochrane.org/handbook.

\section{Department of Health 2011}

Department of Health, Physical Activity, Health Improvement and Protection. Start active, stay active: a report on physical activity from the four home countries. assets.publishing.service.gov.uk/government/uploads/ system/uploads/attachment_data/file/216370/dh_128210.pdf (accessed 13 August 2019).

\section{Dimopoulos 2006}

Dimopoulos K, Okonko DO, Diller GP, Broberg CS, Salukhe TV, Babu-Narayan SV, et al. Abnormal ventilatory response to exercise in adults with congenital heart disease relates to cyanosis and predicts survival. Circulation 2006;113(24):2796-802.

\section{Dua 2007}

Dua J, Cooper AR, Fox KR, Stuart AG. Physical activity levels in adults with congenital heart disease. European Journal of Cardiovascular Prevention and Rehabilitation 2007;14(2):287-93.

\section{Egger 1997}

Egger M, Smith GD, Schneider M, Christoph M. Bias in meta-analysis detected by a simple, graphical test. $B M J$ 1997;315(7109):629.

\section{Faraone 2008}

Faraone, S. Interpreting Estimates of Treatment Effects. Pharmacy and Therapeutics 2018;33(12):700.

\section{Franklin 2013}

Franklin BA, Lavie CJ, Squires RW, Milani RV. Exercise-based cardiac rehabilitation and improvements in cardiorespiratory fitness: implications regarding patient benefit. Mayo Clinic Proceedings 2013;88(5):431-7.

\section{Giardini 2009}

Giardini A, Hager A, Lammers AE, Derrick G, Müller J, Diller GP, et al. Ventilatory efficiency and aerobic capacity predict event-free survival in adults with atrial repair for complete transposition of the great arteries. Journal of the American College of Cardiology 2009;53(17):1548-55.

\section{Gielen 2010}

Gielen S, Schuler G, Adams V. Cardiovascular effects of exercise training molecular mechanisms. Circulation 2010;122(12):1221-38.

\section{Glanville 2019}

Glanville J, Dooley G, Wisniewski S, Foxlee R, Noel-Storr A. Development of a search filter to identify reports of controlled clinical trials within CINAHL Plus. Health Information \& Libraries Journal 2019;36(1):73-90.

\section{Gomes-Neto 2016}

Gomes-Neto M, Saquetto MB, Silva CM, Conceição CS, Carvalho VO. Impact of exercise training in aerobic capacity and pulmonary function in children and adolescents after congenital heart disease surgery: a systematic review with meta-analysis. Pediatric Cardiology 2016;37(2):217-24.

\section{GRADEpro GDT [Computer program]}

McMaster University (developed by Evidence Prime, Inc) GRADEpro GDT. Hamilton (ON): McMaster University (developed by Evidence Prime, Inc), 2015. Available at gradepro.org.

\section{GraphPad Prism [Computer program]}

GraphPad Software Inc. GraphPad Prism. Version 8.1.0. California USA: GraphPad Software Inc., 2019. Available at www.graphpad.com/scientific-software/prism. [WEBSITE: www.graphpad.com]

\section{Gratz 2009}

Gratz A, Hess J, Hager A. Self-estimated physical functioning poorly predicts actual exercise capacity in adolescents and adults with congenital heart disease. European Heart Journal 2009;30(4):497-504.

\section{Heran 2008a}

Heran BS, Wong MM, Heran IK, Wright JM. Blood pressure lowering efficacy of angiotensin converting enzyme (ACE) inhibitors for primary hypertension. Cochrane Database of Systematic Reviews 2008, Issue 4. Art. No: CD003823. [DOI: 10.1002/14651858.CD003823.pub2]

\section{Heran 2008b}

Heran BS, Wong MMY, Heran IK, Wright JM. Blood pressure lowering efficacy of angiotensin receptor blockers for primary hypertension. Cochrane Database of Systematic Reviews 2008, Issue 4. Art. No: CD003822. [DOI: 10.1002/14651858.CD003822.pub2]

\section{Higgins 2011}

Higgins JP, Green S (editors). Cochrane Handbook for Systematic Reviews of Interventions Version 5.1.0 (updated March 2011). The Cochrane Collaboration, 2011. Available from handbook.cochrane.org. 


\section{Higgins 2019}

Higgins JP, Savovic J, Page MJ, Elbers RG, Sterne JA. Chapter 8: Assessing risk of bias in a randomized trial. Draft version (29 January 2019) for inclusion in: Higgins JP, Thomas J, Chandler J, Cumpston M, Li T, Page MJ, Welch Va (editors). Cochrane Handbook for Systematic Reviews of Interventions. London: Cochrane. Available from www.training.cochrane.org/ handbook.

\section{Hoffman 2002}

Hoffman JI, Kaplan S. The incidence of congenital heart disease. Journal of the American College of Cardiology 2002;39(12):1890-900.

\section{Kempny 2012}

Kempny A, Dimopoulos K, Uebing A, Moceri P, Swan L, Gatzoulis MA, et al. Reference values for exercise limitations among adults with congenital heart disease. Relation to activities of daily life-single centre experience and review of published data. European Heart Journal 2012;33(11):1386-96.

\section{Khairy 2010}

Khairy P, Ionescu-Ittu R, Mackie AS, Abrahamowicz M, Pilote L, Marelli AJ. Changing mortality in congenital heart disease. Journal of the American College of Cardiology 2010;56(14):1149-57.

\section{Koyak 2012}

Koyak Z, Harris L, de Groot JR, Silversides CK, Oechslin EN, Bouma BJ, et al. Sudden cardiac death in adult congenital heart disease. Circulation 2012;126(16):1944-54.

\section{Lee 2012}

Lee IM, Shiroma EJ, Lobelo F, Puska P, Blair SN, Katzmarzyk PT, Lancet Physical Activity Series Working Group. Effect of physical inactivity on major non-communicable diseases worldwide: an analysis of burden of disease and life expectancy. Lancet 2012;380(9838):219-29.

\section{Lefebvre 2011}

Lefebvre C, Manheimer E, Glanville J. Chapter 6: Searching for studies. In: Higgins JPT, Green S (editors). Cochrane Handbook for Systematic Reviews of Interventions Version 5.1.0 (updated March 2011). The Cochrane Collaboration, 2011. Available from handbook.cochrane.org.

\section{Letnes 2019}

Letnes JM, Dalen H, Vesterbekkmo EK, Wisløff U, Nes BM. Peak oxygen uptake and incident coronary heart disease in a healthy population: the HUNT Fitness Study. European Heart Journal 2019;40(20):1633-9. [DOI: doi:10.1093/eurheartj/ehy708]

\section{Li 2019}

Li X, Chen N, Zhou X, Yang Y, Chen S, Song Y, et al. Exercise training in adults with congenital heart disease: a systematic review and meta-analysis. Journal of Cardiopulmonary Rehabilitation and Prevention 2019;39(5):299-307.

\section{Liberati 2009}

Liberati A, Altman DG, Tetzlaff J, Mulrow C, Gøtzsche PC, Ioannidis JP, et al. The PRISMA statement for reporting systematic reviews and meta-analyses of studies that evaluate health care interventions: explanation and elaboration. PLOS medicine 2009;6(7):e1000100. [10.1371/journal.pmed.1000100]

\section{Liu 2019}

Liu Y, Chen S, Zü L, Black GC, Choy M, Li N, Keavney BD. Global birth prevalence of congenital heart defects 1970-2017: updated systematic review and meta-analysis of 260 studies. International Journal of Epidemiology 2019;48(2):455-63. [DOI: 10.1093/ije/dyz009]

\section{McCrindle 2007}

McCrindle BW, Williams RV, Mital S, Clark BJ, Russell JL, Klein G, et al. Physical activity levels in children and adolescents are reduced after the Fontan procedure, independent of exercise capacity, and are associated with lower perceived general health. Archives of Disease in Childhood 2007;92(6):509-14.

\section{Meyer 2020}

Meyer M, Brudy L, García-Cuenllas L, Hager A, Ewert P, Oberhoffer R, et al. Current state of home-based exercise interventions in patients with congenital heart disease: $\mathrm{A}$ systematic review. Heart 2020;106(5):333-41.

\section{Mitchell 1971}

Mitchell SC, Korones SB, Berendes HW. Congenital heart disease in 56,109 births. Incidence and natural history. Circulation 1971;43(3):323-32

\section{Moons 2020}

Moons P, Luyckx K, Thomet C, Budts W, Enomoto J, Sluman MA, et al. Physical functioning, mental health, and quality of life in different congenital heart defects: comparative analysis in 3538 patients from 15 countries. Canadian Journal of Cardiology 2020 Apr 6 [Epub ahead of print]. [DOI: 10.1016/ j.cjca.2020.03.044]

\section{Müller 2015}

Müller J, Hager A, Diller GP, Derrick G, Buys R, Dubowy KO, et al. Peak oxygen uptake, ventilatory efficiency and QRSduration predict event free survival in patients late after surgical repair of tetralogy of Fallot. International Journal of Cardiology 2015;196:158-64.

\section{Pufulete 2019}

Pufulete, M. Effectiveness and cost-effectiveness of INSPIRatory musclE training (IMT) for reducing postoperative pulmonary complications (PPC): a sham-controlled randomised controlled trial (RCT) (INSPIRE). Available at europepmc.org/grantfinder/ grantdetails?query=pi\%3A $\% 22$ Pufulete $\% 2 \mathrm{BM} \% 22 \% 2 \mathrm{Bgid} \% 3 \mathrm{~A}$ $\% 2216 \% 2 \mathrm{~F} 140 \% 2 \mathrm{~F} 07 \% 22 \% 2 \mathrm{Bga} \% 3 \mathrm{~A} \% 22$ National\%2OInstitute \%20for\%20Health\%20Research\%20\%28Department\%20of $\% 20 \mathrm{Health} \% 29 \% 22$.

\section{RevMan Web 2019 [Computer program]}

The Cochrane Collaboration Review Manager Web (RevMan Web). Version 5.3. The Cochrane Collaboration, 2019. Available at: revman.cochrane.org. 


\section{Rhodes 2008}

Rhodes JF, Hijazi ZM, Sommer RJ. Pathophysiology of congenital heart disease in the adult, part II: simple obstructive lesions. Circulation 2008;117(9):1228-37.

\section{Ryan 2016}

Ryan R, Hill S. How to GRADE the quality of the evidence, version 3. Cochrane Consumers and Communication Group 2016;3:.. [http://cccrg.cochrane.org/author-resources.]

\section{Sandberg 2016}

Sandberg C, Pomeroy J, Thilén U, Gradmark A, Wadell K, Johansson $B$. Habitual physical activity in adults with congenital heart disease compared with age- and sex-matched controls. Canadian Journal of Cardiology 2016;32(4):547-53.

\section{Scheffers 2020}

Scheffers LE, Berg LE, Ismailova G, Dulfer K, Takkenberg JJ, Helbing WA. Physical exercise training in patients with a Fontan circulation: A systematic review. European Journal of Preventive Cardiology 2020 Jul 27 [E-pub ahead of print]. [DOI: $10.1177 / 2047487320942869]$

\section{Schünemann 2017}

Schünemann HJ, Oxman AD, Vist GE, Higgins JP, Deeks JJ, Glasziou P, et al, Cochrane Applicability and Recommendations Methods Group. Chapter 12: Interpreting results and drawing conclusions. In: Higgins JP, Churchill R, Chandler J, Cumpston MS (editors) Chapter 12: Interpreting results and drawing conclusions. In: Higgins JPT, Churchill R, Chandler J, Cumpston MS (editors), Cochrane Handbook for Systematic Reviews of Interventions version 5.2.0 (updated June 2017). Cochrane, 2017. Available from www.training.cochrane.org/handbook..

\section{Shei 2018}

Shei RJ. Recent advancements in our understanding of the ergogenic effect of respiratory muscle training in healthy humans: a systematic review. Journal of Strength and Conditioning Research 2018;32(9):2665.

\section{Sommer 2008a}

Sommer RJ, Hijazi ZM, Rhodes JF. Pathophysiology of congenital heart disease in the adult: part III: Complex congenital heart disease. Circulation 2008;117(10):1340-50.

\section{Sommer 2008b}

Sommer RJ, Hijazi ZM, Rhodes JF. Pathophysiology of congenital heart disease in the adult: part I: Shunt lesions. Circulation 2008;117(8):1090-9.

\section{CHARACTERISTICS OF STUDIES}

Characteristics of included studies [ordered by study ID]

\section{Stata 2015 [Computer program] [Computer program]}

Stata. StataCorp L, Version 15. College Station, TX, USA: StataCorp, 2015. Available at www.stata.com.

\section{Udholm 2018}

Udholm, S Aldweib, N Hjortdal, VE Veldtman, GR. Prognostic power of cardiopulmonary exercise testing in Fontan patients: a systematic review. Open Heart 2018;5(1):e000812.. [DOI: doi:10.1136/ openhrt-2018-000812]

\section{Wan 2014}

Wan X, Wang W, Liu J, Tong T. Estimating the sample mean and standard deviation from the sample size, median, range and/or interquartile range. BMC Medical Research Methodology 2014;14(1):135.

\section{Warnes 2008}

Warnes CA, Williams RG, Bashore TM, Child JS, Connolly HM, Dearani JA, et al. ACC/AHA 2008 guidelines for the management of adults with congenital heart disease: a report of the American College of Cardiology/American Heart Association Task Force on practice guidelines (Writing Committee to develop guidelines on the management of adults with congenital heart disease). Journal of the American College of Cardiology 2008;52(23):e143e263.

\section{WebPlotDigitizer [Computer program]}

Web Plot Digitizer. Version 4.2. San Francisco: Ankit Rohatgi, 2019. Available at automeris.io/WebPlotDigitizer.

\section{Williams 2017}

Williams CA, Gowing L, Horn R, Stuart AG. A survey of exercise advice and recommendations in United Kingdom paediatric cardiac clinics. Cardiology in the Young 2017;27(5):951-6.

\section{Wong 2011}

Wong E, Selig S, Hare DL. Respiratory muscle dysfunction and training in chronic heart failure. Heart, Lung and Circulation 2011;20(5):289-94.

\section{References to other published versions of this review \\ Williams 2019}

Williams CA, Wadey C, Pieles G, Stuart G, Taylor RS, Long L. Physical activity interventions for people with congenital heart disease (Protocol). Cochrane Database of Systematic Reviews 2019;8:1-14. [DOI: 10.1002/14651858.CD013400.]

* Indicates the major publication for the study

Avila 2016

\section{Study characteristics}


Avila 2016 (Continued)

Methods
Aim of study: to assess the impact of exercise on ventricular arrhythmias in adults with tetralogy of Fallot

Study design: parallel-group randomised controlled trial (2:1 randomisation)

No. of centres: 1 (Montreal Heart Institute Adult Congenital Centre)

Country: Canada

Participants

N randomised: 17 (exercise 13; control 4)
Diagnosis (\% of pts):

ConHD total: 17 (100\%); intervention: 13 (100\%); comparator 4 (100\%)

Severity of condition (corrected tetralogy of Fallot):

Exercise: severe $=13(100 \%)$; Control: severe $=4(100 \%)$

Age (mean \pm SD), years: total: $35 \pm 11.3$; exercise: $35 \pm 11.3$ : control: $34 \pm 14.5$ (converted from median and IQR).

Percentage male: total 65\%; exercise 69\%; control 50\%

Percentage white: not reported

Inclusion criteria: adults ( $\geq 18$ years of age) with surgically repaired tetralogy of Fallot

Exclusion criteria: non-cardiac contraindications to exercising, prior sustained ventricular arrhythmias, aborted sudden death, or New York Heart Association (NYHA) functional class III or IV symptoms. Pregnant women and patients unable to provide informed consent.

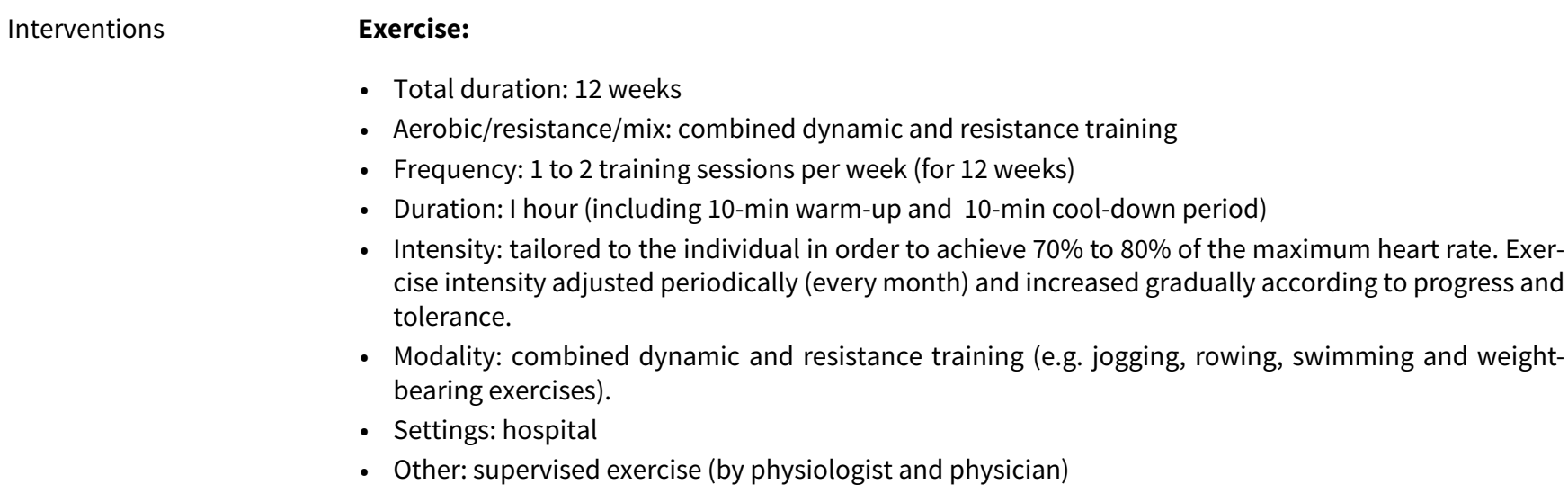

- Total duration: 12 weeks

- Aerobic/resistance/mix: combined dynamic and resistance training

- Frequency: 1 to 2 training sessions per week (for 12 weeks)

- Duration: I hour (including 10-min warm-up and 10-min cool-down period)

- Intensity: tailored to the individual in order to achieve $70 \%$ to $80 \%$ of the maximum heart rate. Exercise intensity adjusted periodically (every month) and increased gradually according to progress and tolerance.

- Modality: combined dynamic and resistance training (e.g. jogging, rowing, swimming and weightbearing exercises).

- Settings: hospital

- Other: supervised exercise (by physiologist and physician)

\section{Control group/Comparison}

Usual care (standard clinical care with encouragement to perform moderate-intensity aerobic activities for at least 30 minutes a minimum of 3 days per week, in conjunction with moderate intensity muscle-strengthening activities at least 2 days per week).

\begin{tabular}{ll}
\hline Outcomes & Maximal and submaximal CRF \\
& Adverse events \\
\hline Notes & Adults randomised in a 2:1 ratio \\
& $\begin{array}{l}\text { All patients randomised to the exercise program were required to wear a portable 2-lead Holter moni- } \\
\text { tor (Quark 12, Cosmed, Rome, Italy) during each exercise session. But compliance to target heart rate } \\
\text { not reported. }\end{array}$
\end{tabular}

Physical activity interventions for people with congenital heart disease (Review) 
Avila 2016 (Continued)

Country and settings: Canada; single centre

Follow-up: 3 months

Duppen 2015

\section{Study characteristics}

Methods

Aim of study: assess effects of an exercise training program on cardiopulmonary fitness and daily physical activity in patients with corrected tetralogy of Fallot (ToF) or Fontan circulation.

\section{Study design: RCT}

No. of centres: 5

Country: the Netherlands

\section{Participants}

N randomised total: 93; intervention: 56; comparator: 37

Diagnosis of ConHD total: 93; intervention: 56; comparator: 37

Severity of condition (corrected tetralogy of Fallot or Fontan):

- intervention: severe $=56(100 \%)$

- comparator: severe $=37(100 \%)$

Age (mean \pm SD) total $15 \pm 3$; intervention $15 \pm 3$; control $16 \pm 3$

Percentage male total: 66 (73\%); intervention 40 (76\%); control 26 (70)

$\mathbf{N}$ lost to follow-up total: intervention: 1 refused; comparator: 0

N analysed total: 90; intervention: 53; comparator: 37

Inclusion criteria: correction of ToF, using the transatrial-transpulmonary approach, had to be performed before the age of 3.5 years. The Fontan circulation had to be completed before the age of 6 years. All participants had to be able, both mentally as well as physically, to adhere to a training programme.

Exclusion criteria: excluded were patients with contraindications for exercise, mental retardation, standard contraindications for magnetic resonance imaging, or a ventricular outflow obstruction (peak Doppler gradient $>60 \mathrm{~mm} \mathrm{Hg}$ ).

Setting: hospital

Supervision: supervised

\section{Detail of exercise}

- Modality: aerobic dynamic

- Intensity: resting heart rate plus $60-70 \%$ of the heart rate reserve

- Resistance training included? No

- Dose

* 1 - Length of session: 12 weeks

* 2 - Frequency/no. of sessions a week: 2 to 3 (2.5)

* 3 - Duration of session: 60 minutes

* Dose of exercise: $1{ }^{\star} 2 * 3=1800$ 
Duppen 2015 (Continued)

$\begin{array}{ll}\text { Outcomes } & \text { Maximal and submaximal CRF } \\ & \text { - Physical activity } \\ & \text { HRQoL }\end{array}$

Notes

No. of centres: 5

Country: the Netherlands

Comparator:

Description: regular medical care

Co-interventions: none

Fritz 2020

\section{Study characteristics}

\begin{tabular}{|c|c|}
\hline \multirow[t]{4}{*}{ Methods } & $\begin{array}{l}\text { Aim of study: the aims of the current study were (1) to investigate the effect of a telephone supervised, } \\
\text { daily inspiratory muscle training for six months on exercise capacity and } 2 \text { ) on lung volumes in adult } \\
\text { patients with Fontan circulation. }\end{array}$ \\
\hline & Study design: RCT \\
\hline & No. of centres: 1 \\
\hline & Country: Germany \\
\hline \multirow[t]{8}{*}{ Participants } & $\mathbf{N}$ randomised total: 42; intervention: 20; comparator: 22 \\
\hline & Age $($ mean \pm SD) total: $28.6(24.7 ; 36.5)$; intervention $28.8(25.3 ; 38.3)$; control $27.7(23.7 ; 36.0)$ \\
\hline & Percentage male total: 21 (50\%); intervention: 11(55\%); comparator: 10(45\%) \\
\hline & Severity of condition: \\
\hline & - intervention: severe = $20(100 \%)$ \\
\hline & - comparator: severe $=22(100 \%)$ \\
\hline & Inclusion criteria: 18 years and older, Fontan physiology \\
\hline & $\begin{array}{l}\text { Exclusion criteria: patients who underwent cardiac catheter examination in the last } 6 \text { months or heart } \\
\text { surgery in the last } 12 \text { months were excluded from the study. Further exclusion criteria were a change } \\
\text { in drug administration in the last } 3 \text { months, planned intervention in the near future, neuromuscular or } \\
\text { mental disorders, moderate to severe ventricular dysfunction as well as an unstable general state of } \\
\text { health. }\end{array}$ \\
\hline \multirow[t]{6}{*}{ Interventions } & Setting: home/hospital/internet delivery or combination: home \\
\hline & Supervision: supervised/unsupervised/not reported: telephone semi-supervised \\
\hline & Detail of exercise: \\
\hline & $\begin{array}{l}\text { - } 3 \text { sets with } 10 \text { to } 30 \text { reps daily. An adjustment from } 10 \mathrm{~cm} \mathrm{H}_{2} \mathrm{O} \text { to } 90 \mathrm{~cm} \mathrm{H}_{2} \mathrm{O} \text { was possible; inspiratory } \\
\text { load was adjusted individually until maximum for every training session to maintain an optimal train- } \\
\text { ing effect. }\end{array}$ \\
\hline & - Modality: inspiratory muscle training \\
\hline & - Resistance training included? No \\
\hline
\end{tabular}


Fritz 2020 (Continued)

$\begin{array}{ll}\text { Outcomes } & \text { CRF } \\ & - \text { Adverse events } \\ & \text { Other outcomes measured: } \\ & - \text { FVC FEV1 } \\ & - \text { Oxygen saturation }\end{array}$

\section{Notes}

Klausen 2016

\section{Study characteristics}

Methods

Aim of study: to assess benefit and harms of adding an eHealth intervention to health education and individual counselling in adolescents with congenital heart disease

Study design: randomised clinical trial.

No. of centres: (nationwide?)

Country: Denmark

\section{Participants}

N randomised total: 158; intervention: 81; comparator: 77

N lost to follow-up total: 39; intervention: 23; comparator: 16

N analysed total: intervention: 81 ; comparator: 77

\section{Severity of condition:}

- intervention: severe $=81$;

- comparator: severe $=77$;

(Other reported - impossible to know so assumed severe; furthermore, included criteria state complex, albeit not referencing Hoffman 2002 criteria).

Inclusion criteria: age between 13 and 16 years, previous repair for a complex $\mathrm{CHD}$, and assignment to lifelong medical follow-up

Exclusion criteria: residual defects significant for physical activity restrictions, assessed by the participants' regular cardiologist tailored text messages to encourage physical activity. Patients recorded exercise duration and type in a mobile application that translated intensity into virtual points, a system designed to provide motivation.

Setting: home/internet delivery

Supervision: unsupervised but self-reported adherence using an app.

Detail of exercise: activity encouragement.

Modality : text/technology based PA encouragement

Intensity: text encouraged 'high intensity' but this it is probably more appropriate to state MVPA due to a loose definition of high intensity.

\section{Resistance training included? NR}


Klausen 2016 (Continued)

\section{Impossible to assess dose}

\begin{tabular}{ll}
\hline Outcomes & CRF \\
& Physical activity (accelerometer)
\end{tabular}

Notes

Adherence to the eHealth program was assessed by patient registration of physical activities via the eHealth application for at least two consecutive weeks during the trial.

Not statistically powered (needed 216 randomised)

Madhavi 2011

\section{Study characteristics}

\begin{tabular}{|c|c|}
\hline Methods & $\begin{array}{l}\text { Aim of study: to find out the influence of graded aerobic exercise on post-surgical adult acyanotic con- } \\
\text { genital heart diseases. } \\
\text { Study design: RCT } \\
\text { Country: India }\end{array}$ \\
\hline Participants & $\begin{array}{l}\text { N randomised total: } 111 \text {; intervention: } 60 \text {; comparator: } 51 \\
\text { N analysed total: NR; intervention: NR; comparator: NR } \\
\text { Severity of condition: } \\
\text { - intervention: mild = } 60 \text {; moderate }=0 \text {; severe }=0 \\
\text { - comparator: mild = 51; moderate }=0 \text {; severe }=0 \\
\text { Inclusion criteria: atrial septal defect (ASD) with pulmonary stenosis, ventricular septal defect (VSD), } \\
\text { patent ductus arteriosus (PDA), left to right shunts. } \\
\text { Exclusion criteria: cyanotic heart disease; severe pulmonary vascular disease; cardiomyopathy; sev- } \\
\text { ere atrioventricular valve regurgitation; exercise-induced ventricular arrhythmia; samples with moder- } \\
\text { ate to severe obstructive lesions }\end{array}$ \\
\hline Interventions & $\begin{array}{l}\text { Description: individualized structured exercise protocol and were modified weekly as per the individ- } \\
\text { ual tolerance } \\
\text { Setting: home/hospital/internet delivery or combination: NR assumed hospital based } \\
\text { Supervision: supervised/unsupervised/not reported - assumed supervised } \\
\text { Detail of exercise: } \\
\text { - Modality : NR } \\
\text { - Intensity: NR } \\
\text { - Resistance training included? NR } \\
\text { - } 1 \text { - Length of session: } 12 \text { weeks } \\
\text { - } 2 \text { - Frequency/no. of sessions a week: NR } \\
\text { - } 3 \text { - Duration of session: NR }\end{array}$ \\
\hline Outcomes & $\begin{array}{ll}\text { - } & \mathrm{HRQOL} \\
\text { - } & \mathrm{CRF}\end{array}$ \\
\hline
\end{tabular}

Notes 


\section{Study characteristics}

\begin{tabular}{|c|c|}
\hline Methods & $\begin{array}{l}\text { Aim of study: to assess exercise tolerance, and to investigate how the } 6^{\prime} W T \text { could be a useful test in the } \\
\text { follow-up of rehabilitation programme in children with CHD } \\
\text { Study design: RCT } \\
\text { Country: France }\end{array}$ \\
\hline Participants & $\begin{array}{l}\text { N randomised total: } 18 \text {; intervention: } 10 \text {; comparator: } 8 \\
\text { - intervention: mild }=3 \text {; severe }=7 \\
\text { - comparator: mild = } 1 \text {; severe }=7 \\
\text { Age (mean } \pm \text { SD); intervention: } 13.0 \pm 1.4 \text {; comparator: } 12.8 \pm 1.3 \\
\text { Inclusion criteria: the left ventricle ejection fraction (LVEF) of CHD group was }<40 \% \text {. All patients had } \\
\text { undergone cardiac surgery reconstruction for complex heart disease. The CHD subjects had to be stabi- } \\
\text { lized with drug treatment for at least } 3 \text { month; their medication was the same during the training pe- } \\
\text { riod. Medical therapy included diuretics, cardiotonics, antivitamins } \mathrm{K} \text {, and angiotensin-converting en- } \\
\text { zyme inhibitor. }\end{array}$ \\
\hline
\end{tabular}

Exclusion criteria: subjects with additional diagnoses of locomotor or mental disorders or other diseases that could limit muscle performance were excluded from the study. Beta-blockers, pacemaker.

\begin{tabular}{|c|c|}
\hline Interventions & $\begin{array}{l}\text { Description: cycling } 12 \text { week intervention } \\
\text { Setting: home } \\
\text { Supervision: unsupervised - pulse monitors checked weekly for compliance } \\
\text { Detail of exercise: } \\
\text { - Modality : cycling } \\
\text { - Intensity: Hr at the VT/GET } \\
\text { - Resistance training included? No } \\
\text { - } 1 \text { - Length of session: } 12 \text { weeks } \\
\text { - } 2 \text { - Frequency/no. of sessions a week: } 3 \\
\text { - 3 - Duration of session: } 60 \text { mins } \\
\text { - Dose of exercise: } 1^{\star} 2 * 3=2160\end{array}$ \\
\hline Outcomes & $\begin{array}{l}\text { - CRF maximal and submaximal } \\
\text { - Strength } \\
\text { - NIRS }\end{array}$ \\
\hline
\end{tabular}

\section{Study characteristics}

Methods $\quad \begin{aligned} & \text { Aim of study: to ascertain if motivational techniques and a structured exercise programme can in- } \\ & \text { crease activity in adolescents afflicted with congenital heart disease }\end{aligned}$

\section{Study design: RCT}


N analysed total: 101; intervention: 62; comparator: 39

Severity of condition: mild $=39$; moderate $=61$; severe $=43$

Age (mean \pm SD) intervention: 15.24; comparator: 15.89

Percentage male total: $60 \%$; intervention: $66.7 \%$; comparator: $53.5 \%$

Inclusion criteria: people with ConHD 12 to 20 years old

Exclusion criteria: patients were excluded if they had a syndromic diagnosis, major learning difficulty, or if exercise was contraindicated (i.e. severe left ventricular outflow tract obstruction, severe aortic stenosis).

6 activity interventions days. Motivational interviewing techniques promoting exercise/activity. Given bespoke training plan to implement at home.

Setting: home/hospital combination: home-based

Supervision: unsupervised - patients were contacted 1 month into 6-month intervention to check problems

Detail of exercise: programme suitable for their diagnosis no specifics reported

Not possible to calculate exercise dosage.

\begin{tabular}{ll}
\hline Outcomes & CRF \\
& $\cdot$ Physical activity
\end{tabular}

Notes

\title{
Study characteristics
}

Methods

\begin{abstract}
Aim of study: the aim of the study was to compare high-interval exercise training with moderate continuous training in terms of improving exercise capacity, vascular function, disease-specific biomarkers, cardiac autonomic function (heart rate variability (HRV)) and post-exercise heart rate recovery (HRR)) and HRQoL, in patients with repaired ToF.
\end{abstract}

Study design: RCT with 3 parallel groups

No. of centres: 1

Country: Slovenia

Participants

N randomised total; HIE intervention: 10; CIE intervention: 10; comparator: 10

N lost to follow-up total: 3; HIE intervention: 1; CIE intervention: 1; comparator: 1

N analysed total: 27; HIE intervention: 9; CIE intervention: 9; comparator: 9

Severity of condition: 
Novakovic 2018 (Continued)

- HIE intervention: severe $=10$

- CIE intervention: severe $=10$

- comparator: severe $=10$

Age (mean \pm SD) total: 38.5 (8.7); HIE intervention: 36.2 (6.8); 7 CIE intervention: 40.1 (10.4); comparator: $38.4(8.9)$

Percentage male total: 37; HIE intervention: 22; CIE intervention: 44; comparator: 44

Inclusion criteria: adults with surgically repaired ToF in childhood

Exclusion criteria: exclusion criteria included known or symptomatic atherosclerotic disease, unstable cardiovascular disease or recent ( $<3$ months prior to inclusion) cardiovascular events, acute illness or recent (<3 months prior to inclusion) non-cardiovascular diseases requiring hospitalisations, emergency or unplanned specialist management, unstable or poorly controlled dysrhythmias, permanent atrial fibrillation, pregnancy and intellectual development disorder.

Setting: h ome/hospital/Internet delivery or combination: not reported assumed hospital-based

Supervision: supervised/unsupervised/not reported: not reported assumed supervised

\section{Detail of exercise:}

- Modality : cycling or speed walking

- Intensity: 80 of HR peak (intensity increased 5\% HR peak-points at 12 th and 24 th training session)

- Resistance training included? No

- 1 - Length of session: 36 sessions (12 weeks)

- 2 - Frequency/no. of sessions a week: $2 / 3(2.5)$

- 3 - Duration of session: 42

- Dose of exercise: $1^{\star} 2 * 3=1260$

\begin{tabular}{ll}
\hline Outcomes & CRF \\
& Other: \\
& HRQoL \\
& Echocardiography \\
& Disease specific biomarkers (NT-proBNP etc.) \\
& Beart rate variability \\
& Blood pressure \\
\hline
\end{tabular}

Notes

Opotowsky 2018

\section{Study characteristics}

Methods

Aim of study: compare the effects of standard of care to SOC plus participant in a typical clinical CR program in ACHD.

\section{Study design: RCT}

No. of centres: 4 
Opotowsky 2018 (Continued)

\section{Country: USA}

Participants

N randomised total: 33; intervention: 18; comparator: 15

Diagnosis of ConHD total: 33; intervention: 18; comparator: 15

\section{Severity of condition:}

- intervention: mild $=0$; moderate to severe $=18$

- comparator: mild $=0 ;$ moderate to severe $=5$

$\mathbf{N}$ analysed total: 28; intervention: 13; comparator: 15

(5 did not receive intervention due to geographical reasons)

Age (mean \pm SD) total: 41.1 (12.1); intervention: 47.5 (9.0); comparator: 35.7 (11.9)

Percentage male total: 50; intervention: 53.9; comparator: 46.7

Inclusion criteria: age $>16$ years, ability to provide informed consent, ability and willingness to participate in a 12-week CR program and repeated cardiopulmonary exercise testing (CPET), impaired aerobic capacity defined as peak_ $\mathrm{VO}_{2}<80 \%$ predicted on baseline exercise test, baseline resting oxygen saturation $\left(\mathrm{sO}_{2} \%\right)>92 \%$, and $\mathrm{CHD}$ of at least moderate complexity.

Exclusion criteria: cardiac intervention (catheterization or surgery) within the prior 6 months or planned cardiac intervention within 12 months of enrolment, formal CR within 24 months prior to enrolment, current or recent pregnancy (delivery < 90 days prior to enrolment), pregnancy planned within 12 months, active heart failure or hospitalization or other major clinical change during the 30 days prior to enrolment, and other recent or planned events expected to substantially impact exercise capacity.

\section{Setting: hospital}

\section{Supervision: supervised}

\section{Detail of exercise}

- Modality : walking, cycling, rowing, resistance

- Intensity: HR at gas exchange threshold

- Resistance training included? Yes

- 1 - Length of session: 12 weeks

- 2 - Frequency/no. of sessions a week: 2

- 3 - Duration of session: 1 hour

- Dose of exercise: $1^{\star} 2^{\star} 3=1440$

\begin{tabular}{ll}
\hline Outcomes & CRF \\
& $\cdot$ HRQoL \\
& $\cdot$ Activity
\end{tabular}

Notes 


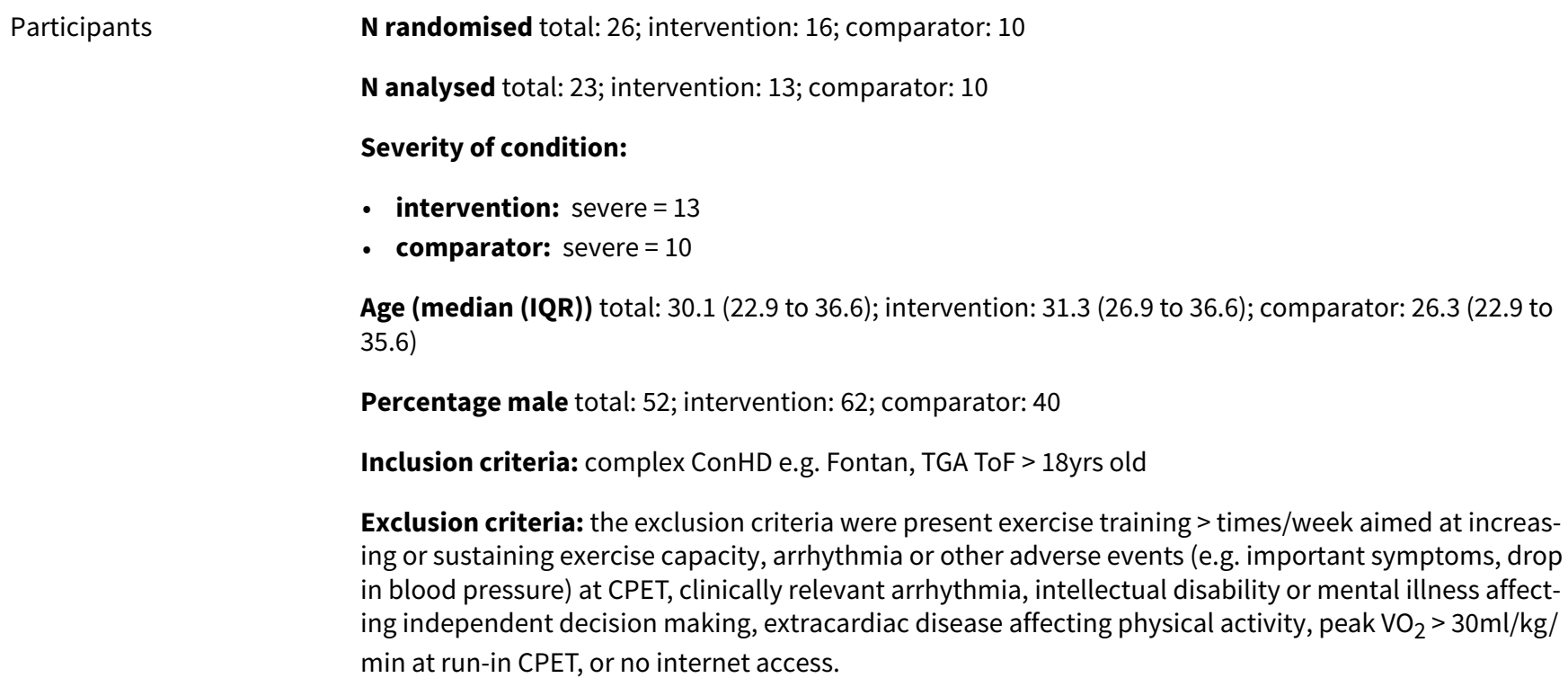

Exclusion criteria: the exclusion criteria were present exercise training > times/week aimed at increasing or sustaining exercise capacity, arrhythmia or other adverse events (e.g. important symptoms, drop in blood pressure) at CPET, clinically relevant arrhythmia, intellectual disability or mental illness affecting independent decision making, extracardiac disease affecting physical activity, peak $\mathrm{VO}_{2}>30 \mathrm{ml} / \mathrm{kg} /$ min at run-in CPET, or no internet access.

Interventions

Description: home-based cycling intervention

Setting: home

Supervision: semi-supervised

Detail of exercise:

- Modality : cycling

- Intensity: training heart rate (THR) was calculated according to the Karvonen method and to achieve BORG 15 to 16.

- Resistance training included? No

- 1 - Length of session: 12 weeks

- 2 - Frequency/no. of sessions a week: 3

- 3 - Duration of session: 31 mins (avg interval of $3.5 \mathrm{~min}$ and including work and rest unloaded intervals)

- Dose of exercise: $1^{\star} 2^{\star} 3=1116$ (individualised)

\begin{tabular}{ll}
\hline Outcomes & Cardiorespiratory fitness \\
& - Health-related quality of life
\end{tabular}

Notes

Comparator: usual care

\section{Study characteristics}

$\begin{array}{ll}\text { Methods } & \text { Aim of study: assess impact of exercise training on aerobic capacity in repaired tetralogy of Fallot (ToF) } \\ \text { patients. } & \\ \text { Study design: RCT } \\ \text { No. of centres: } 1\end{array}$




\section{Country: Canada}

Participants

Diagnosis of ConHD total: 18; intervention: 9 ; comparator: 9

Severity of condition: repaired ToF

- intervention: severe $=9$

- comparator: severe $=8$

Age (mean \pm SD) intervention: 35 (9.5); comparator: 43.3 (7.3)

Percentage male \%: total @ randomisation: 55; intervention: 55; comparator: 55

N randomised total: 18; intervention: 9; comparator: 9

$\mathbf{N}$ lost to follow-up total: 1; intervention: 0; comparator: 1

N analysed total: 17; intervention: 9; comparator: 8

Inclusion criteria: adult patients with repaired ToF

Exclusion criteria: recent surgery, syncope or malignant arrhythmia

Description: 12-week structured exercise programme, patients in the exercise group were evaluated by an exercise physiologist (MW) and given an individualized aerobic training programme. Exercise sessions were held once a week at the Toronto General Hospital Cardiac Rehabilitation Department under the direct supervision of the exercise physiologist.

Setting: combination of home ( $2^{*}$ weekly walking) and hospital based

Supervision: both supervised and unsupervised

Detail of exercise:

- Modality : cycling and walking

- Intensity: $60 \%$ to $85 \%$ of baseline peak $\mathrm{VO}_{2}$

- Resistance training included? No

- $\mathbf{1}$ - Length of session: 12 weeks

- 2 - Frequency/no. of sessions a week: 3 (1 hospital and 2 home)

- 3 - Duration of session: 50 mins

- Dose of exercise: $1^{\star} 2 * 3=1800$

Comparator:

Description: usual care; regular daily exercise

Co-interventions:

Outcomes $\quad$ CRF

\section{Adverse events} study period. Occasional premature ventricular and atrial beats were recorded in 4 patients during exercise testing (at baseline study in 2 patients and follow-up study in 2 patients). None of these episodes required any intervention or discontinuation of testing. Furthermore, no significant ST segment shift was observed in any patient during the exercise or recovery period of either the baseline or follow-up cardiopulmonary testing. Of note: patients were not on telemetry during hospital training sessions. 
van der Mheen 2019

\section{Study characteristics}

Methods Aim: does participating in the CHIP-Family intervention improve the psychosocial well-being of children with CHD and their parents, family functioning, and parents' disease-specific knowledge?

Study Design: single-blinded parallel randomised controlled trial

No. of centres: 1

Country: the Netherlands

Participants

N randomised total: 93 ; intervention: 49 ; comparator: 44

Diagnosis of ConHD: total 90; intervention: 47; comparator: 43

Severity of condition: limited to 1: atrial septal defect, patent ductus arteriosus, pulmonary valve stenosis, total anomalous pulmonary venous connection, ventricular septal defect.

Mild, moderate, severe: anomalous left coronary artery from the pulmonary artery, atrioventricular septal defect, coarctation of the aorta, complex biventricular (e.g. truncus arteriosus, aortic arch defects with ventricular septal defect), univentricular heart defects - Fontan circulation, Ebstein's anomaly (sub)valvular aortic stenosis, tetralogy of Fallot (ToF) including main aorta to pulmonary connecting artery, transposition of the great arteries

- intervention: limited to none: $14 ;$ mild to severe $=33$

- comparator: limited to none: 12 ; mild to moderate to severe $=31$

Age (mean \pm SD) intervention: $5.43 \pm 1.30$; comparator: $5.21 \pm 1.26$

Percentage male total: 50\%; intervention: 53.2\%; comparator: $46.5 \%$

$\mathbf{N}$ lost to follow-up total: parents of three children did not complete any questionnaires after randomisation.

N analysed total: 90; intervention: 45 (Baseline assessment data: $n=47$ families; Follow-up assessment data: $n=45$ families; Excluded from analyses: $n=2$ (no complete questionnaires)); comparator: 40 (Baseline assessment data: $n=40$ families; Follow-up assessment data: $n=40$ families; Excluded from analyses: $\mathrm{n}=1$ (no complete questionnaires)).

Inclusion criteria: underwent at least one invasive medical procedure for $\mathrm{CHD}$ (i.e. cardiac catheterisation or open heart surgery or both); and (2) were attending kindergarten or first or second year of primary school at the time of first assessment and were eligible for participation. Can speak Dutch.

Exclusion criteria: children with known intellectual impairment (intelligence quotient $\leq 70$ ) were excluded, as a sufficient level of intelligence was required to participate in the child intervention programme. Moreover, prematurely born children (i.e. gestational age at birth $<37$ weeks) with no CHD other than a patent ductus arteriosus were excluded, as families of prematurely born children experience different psychosocial problems

Interventions

Description: the CHIP-Family is an adaptation and extension of the CHIP-School intervention. 36 CHIPFamily consisted of a 6-hour group workshop ( 3 to 5 families per workshop) for parents and children and an individual 1-hour follow-up session per parent couple. The 1-day parent workshop consisted of problem prevention therapy, psychoeducation, general parenting skills, skills specific to parenting a child with CHD (provided by 2 senior clinical psychologists for 4 hours), and medical issues (provided by a paediatric cardiologist supported by a senior clinical psychologist for 1 hour). Approximately 4 weeks after the workshop, each parent couple received an individual follow-up session provided by a senior psychologist who was present at the parent workshop and a psychologist who was present at the child workshop. The CHIP-Family module also comprised a specific child module. The child module consisted of a workshop that was held concurrently with the parent workshop. The child workshop consisted of cognitive behavioural exercises based on the evidence-based 'Fun FRIENDS' protocol and focused on strengthening self-esteem, regulating emotions, relaxation, problem-solving skills, and positive thinking (provided by 2 junior psychologists who were supervised by 2 senior clinical psychol- 
ogists for 4 hours). The children also did sport exercises based on a standardised exercise programme specifically developed for children with CHD and their siblings (provided by a physiotherapist and assistant for 1 hour). Each child was allowed to bring a 4- to 10-year-old sibling or friend to normalise participation and to stimulate practice at home.

Setting: hospital

Supervision: supervised

Detail of exercise: as above

- Modality: range of dynamic sports exercises

- Intensity: moderate

- Resistance training included? No

- Dose: 1 day

- 1 - Length of session: 1 to 4 hours

- 2 - Frequency/no. of sessions a week: 3

- 3 - Duration of session: $1 \times 240$ mins and $2 \times 60$ mins

- Dose of session: $1^{\star} 2^{\star} 3=720$ (calculated as average 2 hours $\times 3$ sessions $\times 120 \mathrm{~min}$ )

\begin{tabular}{ll}
\hline Outcomes & HRQoL \\
& - Days off school
\end{tabular}

Notes

Due to logistical reasons in the starting phase of the project, the first 4 families who consented to participate were allocated to the CHIP-Family group without randomisation.

van Dissel 2019

\section{Study characteristics}

Methods Aim of the study: physical activity promotion and exercise training interventions for people with congenital heart disease

\section{Study design: RCT}

No. of centres: 1

Country: the Netherlands

Participants

N randomised total: 40 ; intervention: 20 ; comparator: 20

Diagnosis of ConHD total: 40; intervention: 20; comparator: 20

Severity of condition: eligible patients were adults with CHD and New York Heart Association (NYHA) class II or III symptoms: tetralogy of Fallot; transposition of the great arteries; Fontan circulation; pulmonary atresia; other

- intervention: moderate $=2 ;$ severe $=18$

- comparator: moderate $=1$; severe $=19$

Age (mean \pm SD) total; intervention: $39.9 \pm 8.6$; comparator: $40.0 \pm 15.4$

Percentage male total: 55\%; intervention: 9 (45\%); comparator: 13 (65\%)

N lost to follow-up total: 6; intervention: 3; comparator: 3

N analysed total: 34; intervention: 17; comparator: 17 
Inclusion criteria: eligible patients were adults with CHD and New York Heart Association (NYHA) class II or III symptoms, included in the CONgenital CORvitia database, the Dutch nationwide registry and DNA-bank for adults with CHD

Exclusion criteria: exclusion criteria were NYHA class I or IV, presence of exercise-induced arrhythmia, major comorbidities or limitations that could interfere with exercise training, recent ( $\leq 6$ months) major cardiovascular events or procedures, cyanosis at rest, a resting blood pressure $\mathrm{N} 200 \mathrm{~mm} \mathrm{Hg}$ or diastolic blood pressure $\mathrm{N} 110 \mathrm{~mm} \mathrm{Hg}$, pregnancy (wish) or mental or physical incapability to participate in a home-based exercise training programme.

Interventions

Description: home-based exercise training programme, with a target training regimen of minimum 3 sessions of 45 min per week for the duration of 6 consecutive months.

Setting: home

Supervision: unsupervised - compliance and adherence monitored.

Detail of exercise:

- Modality: self-selected

- Intensity: $80 \%$ max HR achieved in CPET

- Resistance training included? No

- 1 - Length of session: 26 weeks

- 2 - Frequency/no. of sessions a week: 3

- 3 - Duration of session: 45 mins

- Dose of exercise: $\mathbf{1}^{\star} \mathbf{2} \mathbf{3}=3510$

Control group/Comparator: patients randomised to the control group did not receive any formal advice on exercise training, and were neither encouraged, nor discouraged to participate in sports. All patients were asked to continue habitual daily activities, even if these included regular physical exercise.

\begin{tabular}{ll}
\hline Outcomes & Maximal and submaximal CRF \\
& $\cdot$ HRQoL
\end{tabular}

- HRQoL

Notes

Patients in the exercise training group reportedly exercised for a median of $2.5 \mathrm{~h}$ per week. 13 of the 17 patients in the exercise training group exercised at or above the target training level of $2 \frac{1}{4} \mathrm{~h}$ per week. The remaining 4 patients exercised at least $1 \mathrm{~h}$ per week. The main reason patients could not fully adhere to the training regimen was lack of time related to work or family commitments. The types of sports performed by patients in the exercise group are high-dynamic sports (76\%) and a small subset of those patients $(23 \%)$ practised sports both at the highest static and dynamic level, such as rowing, cycling and ice-skating.

\section{Study characteristics}

Methods Aim of study: investigated the effect of 6-month aerobic exercise training on cardiorespiratory and subaortic RV function in a prospective randomised trial.

\section{Study design: RCT}

No. of centres: 1

Country: Germany

Participants N randomised total: 48; intervention: 24; comparator: 24

Diagnosis of ConHD: total 48; intervention: 24; comparator: 24 
Westhoff-Bleck 2013 (Continued)

Severity of condition: adult patients with previous atrial redirection surgery for D-TGA were eligible for the study. At our institution all patients underwent the Mustard procedure.

- intervention: mild $=0$; moderate $=0$; severe $=24$

- comparator: mild $=0 ;$ moderate $=0$; severe $=24$

Age (mean \pm SD) total: $29.3 \pm 3.4$; intervention: $29.9 \pm 3.1$; comparator: $28.6 \pm 3.1$

Percentage male total: 31; intervention: 13; comparator: 18

N lost to follow-up total: 8; intervention: 5; comparator: 3

N analysed total: 40; intervention: 19; comparator: 21

Inclusion criteria: adult patients with previous atrial redirection surgery for D-TGA were eligible for the study (mustard procedure). Additional inclusion criteria were: stable heart failure according to classification of New York Heart association (NYHA) class I/II, unchanged medication angiotensin-converting enzyme inhibitors, beta-blockers) for the last 6 months, no physical training programme at inclusion, and the physical and mental ability to follow a controlled training programme.

Exclusion criteria: exclusion criteria were: clinical diagnosis of NYHA functional class III-IV, known pulmonary vascular disease, significant baffle-obstruction, recent onset or change of heart failure medication within the last 6 months, pregnancy, pacemaker or defibrillator implantation, history of ventricular arrhythmias, renal/liver insufficiency, claustrophobia, and mental retardation.

Interventions

Description: patients randomised to training participated in a structured exercise programme with a goal of improved exercise capacity over a period of 24 weeks. As home equipment, patients received a bicycle ergometer and heart rate monitors (Polar USA Inc. New York, New York). Patients in the training group were advised to document heart rate and number and duration of training units.

Setting: home

Supervision: unsupervised weekly phone calls to monitor adherence.

Detail of exercise:

- Modality : cycling

- Intensity: heart rate corresponding to $50 \%$ of peak oxygen uptake

- Resistance training included? No

- 1 - Length of session:

- 2 - Frequency/no. of sessions a week:

- 3 - Duration of session:

- Dose of exercise: $1^{\star} 2^{\star} 3=2550$ (see calculation below)

* No Weeks * Frequency per * Duration of session

* $3^{\star} 3^{\star} 10=90$

* $33^{*} 3 * 15=135$

* $3^{\star} 5^{\star} 15=225$

* $3^{\star} 5^{\star} 20=300$

* $12{ }^{\star} 5^{\star} 30=1800$

* $1800+300+225+135+90=\mathbf{2 5 5 0}$

\section{Comparator:}

Description: usual care

\section{Co-interventions:}

Outcomes

Other outcomes measured:

- MRI 
Westhoff-Bleck 2013 (Continued)

$$
\text { - Bloods }
$$

Notes

During the study, 2 patients in the training and 1 patient in the control group experienced an episode of supra-ventricular tachycardia, which was terminated by cardioversion. None of these episodes were timely related to physical training or to cardiac decompensation.

Winter 2012

\section{Study characteristics}

Methods

Aim of study: the primary aim of our study was to determine whether exercise training improves maximal exercise capacity in adult patient with a systemic RV. Additionally, we aimed to determine whether exercise training decreases serum $\mathrm{N}$-terminal pro hormone brain natriuretic peptide (NT-proBNP) levels and improves quality of life in these patients

Study design: RCT

No. of centres: 4

Country: the Netherlands (3 sites) Italy (1 site)

Diagnosis of ConHD total: 54; intervention: 28; comparator: 26

Severity of condition: adults with a systemic RV due to a congenitally or surgically corrected TGA.

- intervention: mild $=$ moderate $=$ severe $=28$

- comparator: mild $=$ moderate $=$ severe $=26$

Age (mean \pm SD) total: $32 \pm 11$; intervention: $31 \pm 10$; comparator: $34 \pm 11$

Percentage male total: 23; intervention: 9; comparator: 14

N lost to follow-up total: 8; intervention: 4; comparator: 4

$\mathbf{N}$ analysed total: 46; intervention: 24; comparator: 22

N randomised total: 54; intervention: 28; comparator: 26

N lost to follow-up total: 8; intervention: 6; comparator: 8

$\mathbf{N}$ analysed total: 40; intervention: 22; comparator: 18

Inclusion criteria: eligible participants were adults with a systemic RV due to a congenitally or surgically corrected TGA

Exclusion criteria: exclusion criteria were mental or physical incapability to participate in a homebased exercise training programme, the presence of exercise-induced arrhythmia, symptomatic myocardial ischaemia, a resting systolic blood pressure $.200 \mathrm{~mm} \mathrm{Hg}$ and/or diastolic blood pressure.110 $\mathrm{mm} \mathrm{Hg}$, New York Heart Association (NYHA) class III or IV, pregnancy during the training period, and non-cardiac co-morbidity that could affect exercise performance or that could aggravate by exercise.

Interventions

Description: the training protocol was home-based, and consisted of 3 sessions of steps aerobics per week for the duration of 10 consecutive weeks.

Setting: home

Supervision: unsupervised but compliance followed up through email and calls

\section{Detail of exercise:}


Winter 2012 (Continued)

- Modality : step aerobics

- Intensity: $75 \%$ to $90 \%$ of max heart rate (target HR increased with intervention length).

- Resistance training included? No

- $\mathbf{1}$ - Length of session: 10 weeks

- 2 - Frequency/no. of sessions a week: 3

- 3 - Duration of session: 42 mins

- Dose of exercise: $1^{\star} 2^{\star} 3=1260$

Comparator:

Description: usual care

Co-interventions: none

\begin{tabular}{ll}
\hline Outcomes & Other outcomes measured: \\
- BP & BNP \\
\hline Notes & $\begin{array}{l}\text { Exercise tests could be performed without complications in all patients. One baseline exercise test was } \\
\text { aborted due to nausea of the patient, but was repeated successfully } 6 \mathrm{~h} \text { later. As stated above, } 1 \text { pa- } \\
\text { tient developed ventricular bigeminy in the recovery phase, and was excluded from participation in the } \\
\text { study. During the training protocol, } 1 \text { patient sustained calf injury during exercise, and had to discon- } \\
\text { tinue the protocol for } 2 \text { weeks. No other complaints or complications were reported. }\end{array}$ \\
\hline
\end{tabular}

Characteristics of excluded studies [ordered by study ID]

\begin{tabular}{|c|c|}
\hline Study & Reason for exclusion \\
\hline Ali Faisal 2016 & Wrong intervention \\
\hline Altamirano Diaz 2017 & Wrong study design \\
\hline Amedro 2019 & Wrong study design \\
\hline Babu 2013 & Wrong study design \\
\hline Babu 2017 & Wrong study design \\
\hline Becker Gruenig 2012 & Wrong study design \\
\hline Bhasipol 2018 & Wrong study design \\
\hline Bhasipol 2018a & Wrong study design \\
\hline BoaSorteSilva 2017 & Wrong patient population \\
\hline Callaghan 2018 & Duplicate \\
\hline Camargo 2007 & Wrong comparator \\
\hline Chen 2017 & Wrong intervention \\
\hline Coats 1992 & Wrong patient population \\
\hline
\end{tabular}




\begin{tabular}{|c|c|}
\hline Study & Reason for exclusion \\
\hline Cordina 2013 & Wrong study design \\
\hline Curnier 2012 & Wrong study design \\
\hline DRKS00011363 & Registry Report \\
\hline Du 2015 & Wrong study design \\
\hline Du 2017 & Wrong study design \\
\hline Dua 2010 & Wrong study design \\
\hline Fredriksen 2000 & Wrong study design \\
\hline Fredriksen 2000a & Wrong study design \\
\hline Gierat Haponiuk 2014 & Wrong study design \\
\hline Goldbeck 2011 & Wrong study design \\
\hline Gomes Neto 2016 & Wrong study design \\
\hline Gotink 2017 & Wrong intervention \\
\hline Hedlund 2018 & Wrong study design \\
\hline Hooglugt 2018a & Wrong study design \\
\hline IlarrazaLomel 2008 & Wrong study design \\
\hline IoannisLaoutaris 2015 & Wrong patient population \\
\hline IRCT20180417039341N1 & Registry report \\
\hline ISRCTN74393113 & Registry report \\
\hline Joshi 2019 & Wrong study design \\
\hline Kobashigawa 1999 & Data loss by researcher \\
\hline Lalonde 2014 & Wrong study design \\
\hline Lam 2014 & Wrong patient population \\
\hline Longmuir 1985 & Wrong study design \\
\hline Longmuir 2013 & Wrong study design \\
\hline Lozada 2017 & Wrong comparator \\
\hline Marra 2015 & Wrong study design \\
\hline McKillop 2018 & Wrong comparator \\
\hline NCT00930800 & Registry report \\
\hline
\end{tabular}




\begin{tabular}{|c|c|}
\hline Study & Reason for exclusion \\
\hline NCT01463800 & Study cancelled \\
\hline NCT01671566 & Registry report \\
\hline NCT01822769 & Registry report \\
\hline NCT02632253 & Study cancelled \\
\hline NCT02643810 & Registry report \\
\hline NCT02980393 & Wrong study design \\
\hline NCT03297918 & Registry report \\
\hline Nehyba 2009 & Wrong patient population \\
\hline NTR2527 & Wrong patient population \\
\hline NTR3041 & Wrong patient population \\
\hline Rhodes 2006 & Wrong study design \\
\hline Rowland 2016 & Wrong study design \\
\hline Ruttenberg 1983 & Wrong study design \\
\hline Stefani 2014 & Wrong study design \\
\hline Sutherland 2018 & Wrong comparator \\
\hline Tan 1996 & Wrong intervention \\
\hline Tikkanen 2016 & Duplicate \\
\hline Zhou 2017a & Duplicate \\
\hline Zhou 2017b & Paediatric population \\
\hline
\end{tabular}

Characteristics of studies awaiting classification [ordered by study ID]

Ali 2018

\section{Methods}

\begin{tabular}{ll} 
Participants & Fontan patients \\
\hline Interventions & Controlled respiratory training \\
\hline Outcomes & CPET
\end{tabular}

\section{Notes}


Callaghan 2017

Methods

\begin{tabular}{ll}
\hline Participants & ConHD \\
\hline Interventions & Physical activity \\
\hline Outcomes & Potentially HRQoL \\
\hline Notes & \\
\hline
\end{tabular}

Morrison 2015

Methods

\begin{tabular}{ll}
\hline Participants & ConHD \\
\hline Interventions & PA promotion \\
\hline Outcomes & Physical activity \\
\hline Notes & \\
\hline
\end{tabular}

Neidenbach 2017

Methods

\begin{tabular}{ll}
\hline Participants & Fontan patients \\
\hline Interventions & Inspiratory muscle training \\
\hline Outcomes & Oxygen saturations \\
\hline Notes & \\
\hline
\end{tabular}

Nilsson 2019

\begin{tabular}{ll}
\hline Methods & RCT \\
\hline Participants & Patients following aortic valve replacement \\
\hline Interventions & Exercise training \\
\hline Outcomes & Cardiopulmonary exercise testing \\
\hline Notes & \\
\hline
\end{tabular}


Characteristics of ongoing studies [ordered by study ID]

Ganzoni 2019

Study name

Impact of a structural phonation training on respiratory muscle function in patients with structural heart disease - HeartChoir (Study NCT03297918)

\begin{tabular}{ll}
\hline Methods & RCT \\
\hline Participants & Inclusion criteria: \\
& - Informed consent as documented by signature (Appendix Informed Consent Form) \\
- & Age $\geq 18$ years \\
- & Known cardiomyopathy from acquired heart disease (ischemic or dilated) or patients with com- \\
& plex CHD (cyanotic congenital heart disease, Fontan palliation, subaortic right ventricle or re- \\
& paired tetralogy of Fallot)
\end{tabular}

Interventions Active comparator: intervention group - patients will be asked to participate in a structured singing and respiratory training for 12 weeks vs. no activity control.

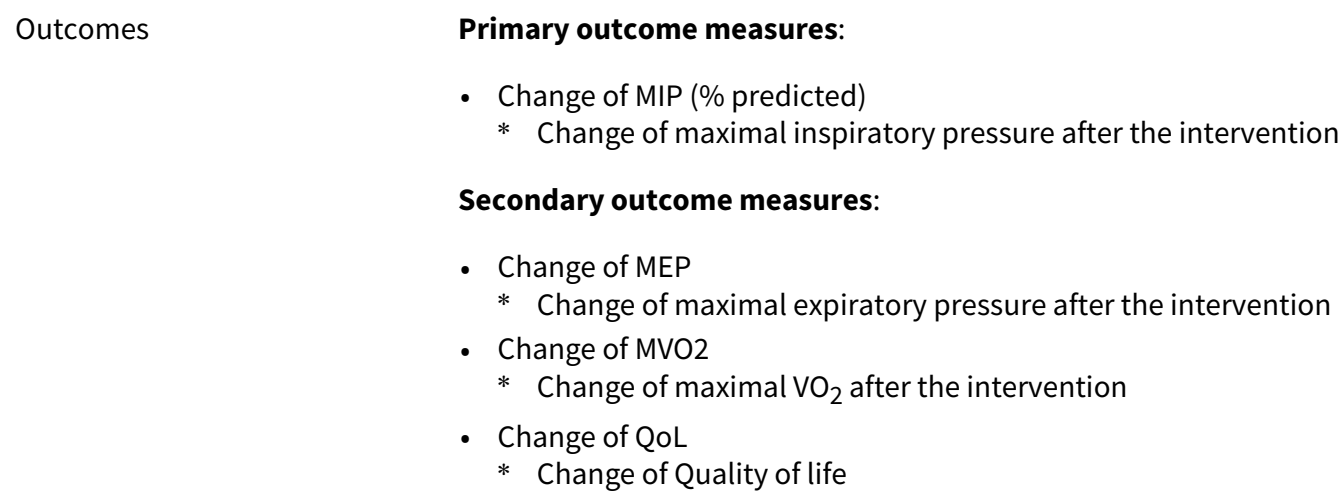

- Change of MIP (\% predicted)

* Change of maximal inspiratory pressure after the intervention

\section{Secondary outcome measures:}

- Change of MEP

* Change of maximal expiratory pressure after the intervention

- Change of MVO2

* Change of maximal $\mathrm{VO}_{2}$ after the intervention

- Change of QoL

* Change of Quality of life

\begin{tabular}{ll}
\hline Starting date & December 2017 \\
\hline Contact information & Principal Investigator: Daniel Tobler \\
\hline Notes & Unpublished. Author team contacted and they were unable to share data. \\
\hline
\end{tabular}

\section{ISRCTN74643496}

$\begin{array}{ll}\text { Study name } & \begin{array}{l}\text { Improving the effectiveness of psychological interventions for depression and anxiety in the car- } \\ \text { diac rehabilitation pathway: a single blind randomised controlled trial with four month and twelve } \\ \text { month follow up comparing GroupMCT plus usual CR (intervention) with usual CR (control). }\end{array}\end{array}$
month follow up comparing GroupMCT plus usual CR (intervention) with usual CR (control).

\begin{tabular}{ll}
\hline Methods & RCT. Metacognitive therapy vs. usual care control. \\
\hline Participants & Inclusion: \\
- Competent level of English language skills (able to read, understand and complete questionnaires & in English). \\
- Acute coronary syndrome used for any condition brought on by sudden, reduced blood flow to \\
the heart \\
- Following revascularisation is the restoration of perfusion to a body part or organ that has suffered \\
ischaemia \\
- Stable heart failure
\end{tabular}


ISRCTN74643496 (Continued)

- Stable angina is chest pain or discomfort that most often occurs with activity or stress

- Following implantation of cardioverter defibrillators/cardiac resynchronisation devices

- Heart valve repair/replacement

- Heart transplantation and ventricular assist devices

- Adult congenital heart disease identified in adulthood

- A score of $=8$ on either the depression or anxiety subscale of the HADS.

Interventions

Experimental: metacognitive therapy plus CR Group psychological treatment focused on reducing worry and rumination and modifying beliefs about thinking in addition to treatment as usual (standard cardiac rehabilitation). Metacognitive therapy (MCT) helps clients to identify episodes of worry and rumination in response to negative thoughts and bring these responses under control. This process is facilitated by exercises that enhance the flexibility of attention control, challenge unhelpful beliefs about thinking and enable new relationships with thoughts 2. Active Comparator: Usual group-based cardiac rehabilitation (treatment as usual) involving stress management, exercise, education.

\section{Outcomes}

\section{Primary}

- Change in Hospital Anxiety and Depression Scale (HADS) (time frame: baseline pre treatment, four-month post baseline, 12 months' follow-up)

\section{Secondary}

- Metacognitions Questionnaire

- Cognitive Attentional Syndrome

- Impact of Event Scale-Revised

- Health-related quality of life

- Economic Patient Questionnaire (EPQ)

\begin{tabular}{ll}
\hline Starting date & 1 June 2015 \\
\hline Contact information & $\begin{array}{l}\text { Jane Garnett, University of Manchester 5th Floor (Research) St. Mary's Hospital Oxford Road M13 } \\
\text { 9WL Manchester United Kingdom }\end{array}$ \\
\hline Notes & $\begin{array}{l}\text { Control group are exercise training. Mixed population of Non congenital heart as well as congenital } \\
\text { heart patients. Would not be eligible for inclusion into this review unless the intervention group un- } \\
\text { derwent no exercise/physical activity. }\end{array}$ \\
\hline
\end{tabular}

NCT01397110

Study name Influence of respiratory and exercise therapy on oxygen uptake, quality of life in patients with severe associated pulmonary arterial hypertension (apah) as part of a congenital heart defect with/ without Eisenmenger's syndrome

\begin{tabular}{ll}
\hline Methods & Randomized parallel assignment \\
\hline Participants & Inclusion Criteria: \\
- & signed consent form \\
- & men and women 18 years $<80$ years \\
& II-IV), invasively diagnosed by right heart and left heart catheterization: mean pulmonary arterial \\
pressure (mPAP) $\geq 25 \mathrm{mmHg}$, with targeted PAH medication for at least two months stable before \\
study inclusion (exception: compensated WHO class II without vasodilating drug therapy)
\end{tabular}


Randomized, prospective, controlled, blinded study of three-week inpatient rehabilitation and subsequent continuing of the training at home for 12 weeks. The control group received conventional rehabilitation without a specific training program. After 15 weeks training is also offered to patients in the control group.

No Intervention: Control group without exercise training

Patients of the control group continue their sedentary lifestyle without given advice for exercise training.

The time before start of rehabilitation (three months) serves as control group. Afterwards patients take part in the training program as well.

\section{Primary outcomes}

- Changes in the maximum 6-minute walk distance (6MGT) (time frame: up to 15 weeks)

- Changes in quality of life (time frame: up to 15 weeks)

\section{Secondary outcomes}

- Changes in maximum oxygen uptake

- Changes in exercise capacity: 6-minute walk distance, recumbent bike (watts), respiratory economy $\left(\mathrm{EQO}_{2}, \mathrm{EQCO}_{2}\right)$

- Improved condition(NYHA class, Borg scale)

- Changes in magnetic resonance tomography and echocardiographic parameters of right and left ventricle: size and pump function

- Change of laboratory parameters, which are markers of right heart failure as NTproBNP, interleukins

- Changes in haemodynamics (time frame: up to 15 weeks)

Starting date January 2012

\section{Study name}

Start-to-sport - feasibility and efficacy of individualized, telemonitored, home-based exercise for adolescents and adults with congenital heart disease

\begin{tabular}{ll}
\hline Methods & Randomized parallel assignment \\
\hline Participants & Inclusion Criteria: \\
& - adolescents and adults with congenital heart disease \\
& Exclusion Criteria: \\
& - congenital rhythm or conduction disorders \\
& - isolated congenital coronary artery anomalies \\
& - bregnancy \\
& - inability to perform standard physical activities due to mental/physical disability.
\end{tabular}


NCT02240147 (Continued)

Interventions
During a 30 minute face-to-face motivational interview with an exercise specialist, the patient will be advised and coached about his exercise prescription, on how to implement it in his own daily life and on how to prevent relapse. Furthermore, the patients will receive instructions on how to monitor their exercise intensity and on recognising adverse signals. During the following 12 weeks, patients will be asked to exercise 4.5 hours per week within the prescribed exercise intensity range according to the guidelines

peak oxygen uptake (time frame: baseline, post-intervention, after 1 year)
physical activity (time frame: baseline, post-intervention and after 1 year)

\begin{tabular}{ll}
\hline Starting date & 1 January 2015 \\
\hline Contact information & Principal investigator: Roselien Buys, PhD KU Leuven \\
& Principal investigator: Werner Budts, PhD KU Leuven \\
\hline Notes & Unpublished. Author team contacted and they were unable to share data. \\
\hline NCT02283255 & \\
\hline Study name & $\begin{array}{l}\text { Cardiovascular, Pulmonary and Skeletal Muscle Evaluation in Late Postoperative Period of the } \\
\text { Fontan Surgery }\end{array}$ \\
\hline Methods & $\begin{array}{l}\text { A long-term randomized clinical study that will include } 60 \text { patients between } 12 \text { and 30 years, sub- } \\
\text { mitted to total cavopulmonary connection for at least } 5 \text { years post operative at the Heart Institute, } \\
\text { University of São Paulo Medical School. The patients will be divided into four groups: } 1) \text { Exercise } \\
\text { training with aerobic exercise + lower and upper limb strength exercise (GTF-I); } 2) \text { Respiratory train- } \\
\text { ing with respiratory muscle exercise (GTF-II); 3) Exercise training with aerobic exercise + lower and } \\
\text { upper limb strength exercise + Respiratory training with respiratory muscle exercise (GTF-III); and } \\
\text { A non-exercise group as control group (GNTF-IV). The patients will be revaluated after the 4-month } \\
\text { period of intervention. }\end{array}$ \\
\hline
\end{tabular}

Participants

\section{Inclusion criteria:}

- Both gender, aged between 12 and 30 years

- Patients undergoing the Fontan operation with time postoperatively $\geq 5$ years

- Clinically stable patients, no arrhythmia in the last electrocardiogram or clinical assessment

- Consent by the cardiologist

- Patients who voluntarily signed the consent form.

\section{Exclusion criteria:}

- Patients with hypoplastic left heart syndrome

- Changes that reduce musculoskeletal walking skills

- Neurological sequelae, patients with associated genetic syndrome, disturbance cognitive or psychiatric

- Patients with a history of ventricular arrhythmias, cardio respiratory arrest, users of anti-arrhythmic drugs and/or underwent implantation of pacemaker

- Atrial arrhythmia requiring treatment in the last 6 months

- Patients with heart failure not controlled by medications and lung hypertension

- Patients with protein-losing enteropathy

- Severe hypoxemia (oxygen saturation $<80 \%$ at rest)

- Symptomatic patients with a diagnosis of diaphragmatic paresis or paralysis postoperative patients, with or without plication

- Patients with moderate to severe asthma 
NCT02283255 (Continued)

- Patients who live outside the area of Sao Paulo

Interventions

Aerobic training: Aerobic training and muscle strength exercise for upper and lower limbs, 3 times a week for 4 months.

Respiratory training: muscle training using POWERbreathe device, 7 times a week, 3 series of 30 repetitions per day, for 4 months.

Aerobic and respiratory training: aerobic training and muscle strength exercise for upper and lower limbs, 3 times a week for 4 months and respiratory muscle training using POWERbreathe device, 7 times a week, 3 series of 30 repetitions per day, for 4 months.

No physical activity: control group (usual care)

\section{Outcomes}

- Improvement exercise tolerance and physical capacity (time frame: baseline and 4 months)

- Improvement in the functional capacity post exercise training programme (time frame: baseline and 4 months)

- Improvement in pulmonary function post physical exercise programme (time frame: baseline and 4 months)

- Change in autonomic function post exercise training programme (time frame: baseline and 4 months)

- Improvement in peripheral blood flow post exercise training programme (time frame: baseline and 4 months)

- Change in the plasma epinephrine level post exercise training programme (time frame: baseline and 4 months)

- Change in muscle metabolism post exercise training programme (time frame: baseline and 4 months)

\begin{tabular}{|c|c|c|}
\hline Starting date & 2014 & \\
\hline \multirow[t]{2}{*}{ Contact information } & $\begin{array}{l}\text { Contact: Aida LR Turquetto, Researcher } \\
\text { to@me.com }\end{array}$ & +551126615399 ext +5511981140723 aidaturquet- \\
\hline & $\begin{array}{l}\text { Contact: Marcelo B Jatene, Researcher } \\
\text { cor.usp.br }\end{array}$ & +551126615399 ext+551126615399 marcelo.jatene@in- \\
\hline
\end{tabular}

Notes

\section{NCT02658266}

\begin{tabular}{ll}
\hline Study name & Effect of resistance training in adults with complex congenital heart disease \\
\hline Methods & RCT \\
& Behavioural: home-based resistance training \\
\hline
\end{tabular}

\section{Participants} Inclusion criteria:

- Complex congenital heart disease ( e.g. tetralogy of Fallot, transposition of the great arteries, pulmonary atresia, patients palliated with Fontan procedure or total cavo-pulmonary connection).

- Clinically stable without significant change the last 3 months.

- Adult (> 18 years of age).

- Informed consent.

Exclusion criteria:

- Cognitive impairment affecting the ability of independent decision making. 
NCT02658266 (Continued)

- Present strategy of regularly executing resistance training $>2$ times per week in purpose to increase muscle strength.

- Other comorbidity affecting physical activity.

- Other circumstance making participation unsuitable.
Home-based resistance training 12 weeks home based resistance training 3 times per week, 10 to 12 reps, 2 sets

\begin{tabular}{|c|c|}
\hline Outcomes & $\begin{array}{l}\text { - Change in muscle endurance (number of repetitions) (time frame: change from baseline muscle } \\
\text { - Cndurance at } 12 \text { weeks' follow-up) } \\
\text { - Change in total body skeletal muscle mass (kg) (time frame: change from baseline total body } \\
\text { - Change in appendicular skeletal muscle mass (kg) (time frame: change from baseline appendicu- } \\
\text { lar skeletal muscle mass at } 12 \text { weeks' follow-up) } \\
\text { - Change in body fat percentage (time frame: change from baseline body fat percentage at } 12 \\
\text { weeks' follow-up) } \\
\text { - Change in bone mineral density (g/ } \mathrm{cm}^{2} \text { ) (time frame: change from baseline bone mineral density } \\
\text { at } 12 \text { weeks' follow-up) } \\
\text { - Muscle metabolism (time frame: change from baseline muscle metabolism at } 12 \text { weeks' follow-up) } \\
\text { - Compliance to study protocol (time frame: at completion of study protocol } 12 \text { weeks) } \\
\text { - men until the follow-up at } 12 \text { weeks) }\end{array}$ \\
\hline
\end{tabular}

\begin{tabular}{ll}
\hline Starting date & 2017 \\
\hline Contact information & Contact: Bengt Johansson, MD, PhD +46907852782 bengt.johansson@medicin.umu.se \\
& Contact: Camilla Sandberg, RPT, PhD +46907858441 camilla.sandberg@medicin.umu.se \\
\hline
\end{tabular}

Notes

NCT03335475

\begin{tabular}{ll}
\hline Study name & Congenital Heart Disease Physical Activity Lifestyle Study (CHD-PALS) \\
\hline Methods & $\begin{array}{l}\text { Randomized. Study includes } 2 \text { possible conditions to which participants are randomized: (1) Fitbit } \\
\text { only and (2) Fitbit + coaching sessions. }\end{array}$ \\
\hline
\end{tabular}

Participants
$\begin{aligned} & \text { - Between the ages of } 15 \text { and } 18 \text { (if } 18, \text { must be in high school and/or still living at home) } \\ & \text { - Are diagnosed with moderate or complex structural congenital heart disease } \\ & \text { - Live within } 120 \text { miles of Nationwide Children's Hospital } \\ & \text { - Able to complete an exercise stress test on a treadmill }\end{aligned}$

Interventions

Intervention: In the Fitbit + Coaching Sessions arm, participant will receive their exercise prescription, as devised from their baseline exercise stress test results, a Fitbit, and will have 8 sessions with a coach (interventionist) over the course of 20 weeks. They will undergo a 9 week (interim) and a 22 week assessment (follow-up).

Control: In the Fitbit Only arm, participants will receive their exercise prescription, as devised from their baseline exercise stress test results, and a Fitbit. They will undergo a 9 week (interim) and a 22 week assessment (follow-up). 
- Number of minutes spent in moderate to vigorous physical activity as measured by an accelerometer

* Moderate to vigorous physical activity (time frame: from baseline to follow-up (approximately 22 weeks))

\section{Secondary outcome measures:}

- Number of minutes spent being sedentary as measured by an accelerometer.

- Maximal oxygen utilization during physical activity as measured by V02max during an exercise stress test.

- Sedentary behaviour (time frame: from baseline to follow-up (approximately 22 weeks))

- Exercise tolerance (time frame: from baseline to follow-up (approximately 22 weeks))

\begin{tabular}{ll}
\hline Starting date & 7 November 2017 \\
\hline Contact information & Principal investigator: Jamie L Jackson, PhD Nationwide Children's Hospital \\
\hline Notes & \\
\hline
\end{tabular}
controlled trial of enhanced physical activity support in clinical care

\section{Inclusion criteria:}

- All patients 5 to 17 years with CHD diagnoses classified as moderate or severe in complexity by the American College of Cardiology/American Heart Association joint guidelines.

\section{Exclusion criteria:}

- Cardiac intervention (catheterization or surgery) in preceding 6 months. Syndrome/diagnosis affecting physical activity (e.g., developmental disability) or the ability to complete the assessment questionnaires.

\begin{tabular}{ll}
\hline Interventions & $\begin{array}{l}\text { Clinician counselling about physical activity using standardised tools to promote daily physical ac- } \\
\text { tivity. }\end{array}$ \\
\hline Putcomes & Primary outcome: \\
- Pedometer step counts per day & $*$ Change in daily physical activity (time frame: baseline then first week of each month for 6 \\
months) \\
Secondary outcomes: \\
- Children's Self-Perceived Adequacy and Predilection for Physical Activity Scale \\
- Paediatric Quality of Life Inventory (PedsQL), \\
$*$ Change in physical activity adequacy and predilection (time frame: baseline, 6 months)(time \\
frame: baseline, 6 months) \\
$*$ Change in quality of life (time frame: baseline, 6 months) \\
$*$ Change in physical literacy (time frame: baseline, 6 months)
\end{tabular}


NCT03435354 (Continued)

Contact information Principal Investigator: Patricia Longmuir, PhD Scientist

Notes

\section{NCT03479957}

\begin{tabular}{ll}
\hline Study name & Remotely monitored and coached exercise based cardiac rehabilitation in northern Sweden \\
\hline Methods & RCT \\
\hline
\end{tabular}

\section{Participants}

\section{Inclusion criteria:}

- Scheduled appointment with physiotherapist for follow-up after cardiac event: myocardial infarction (MI)

- Per cutaneous coronary intervention (PCI) due to $\mathrm{MI}$ or angina pectoris

- Open heart surgery due to coronary artery disease or valvar disease

- Living in the catchment area of Heart centre, University Hospital of Umeå.

Interventions

Remotely monitored and coached exercise training in real time using the REMOTE-CR system. The patients randomized to remotely monitored exercise can either work out with self-selected activities e.g. Nordic-walking, cycling, skiing or participate in supervised exercise session via video link. The patients randomized to be controls will receive individualized information and instructions regarding current exercise recommendations but will not be monitored or coached during their exercise sessions (usual care).

Primary outcome:
The aerobic exercise capacity (W) will be evaluated using a standardised submaximal exercise test
on cycle ergometer
- Change in submaximal aerobic exercise capacity (time frame: baseline and 12 weeks)
Secondary outcome:
- Number of repetitions achieved during test of Unilateral isotonic shoulder flexion and Unilateral
- isotonic heel-lift
- Isometric grip strength
- International Physical Activity Questionnaire
prises 17 items assessing subjective rating of kinesiophobia. The total score varies between $17-68$
and a score $>37$ defines a high level of kinesofobia.

Starting date $\quad 3$ September 2019

Contact information Camilla Sandberg, PhD+46907858441 camilla.sandberg@umu.se

Notes Most likely will not meet participant inclusion criteria

\section{NCT03690518}

Study name

Impact of cardiovascular rehabilitation on the quality of life of adolescents and young adults with congenital heart disease: a randomized controlled multicentre trial 
NCT03690518 (Continued)

Methods

Inclusion Criteria:
$\begin{array}{ll}\text { - } & \text { Patient aged } 13 \text { to } 25 \text { years included } \\ \text { - } & \text { With a congenital heart diseases (CHD) as defined in the international CHD classification. } \\ & \text { Recent }(<3 \text { months) cardio-pulmonary exercise test }(\mathrm{CPET}) \text { with maximum oxygen uptake } \\ & \text { VO2max. } \\ \text { - } & \text { Consent of the adult patient or the parents or legal guardians of the minor patient. } \\ \text { - } & \text { Beneficiary of the social security scheme. }\end{array}$

Interventions

Cardiac rehabilitation: rehabilitation will have a regular follow-up with intervention (rehabilitation program)

\section{Outcomes}

\section{Primary outcomes:}

- Evolution of the PedsQL 4.0 self-reported scores from month 0 to month 12

- Quality of life score (PedsQL, 24 items), range score from 0 to 100, higher score indicating better quality of life. (time frame: follow-up of patients over 12 months)

\section{Secondary outcomes:}

- Disease knowledge questionnaire (Leuven questionnaire, 34 items, total range score from 0 to 100 , a higher score indicating better knowledge)

- Number of consultation in cardiology, number of hospitalization in cardiology, number of cardiovascular events

- Score of physical activity (Ricci and Gagnon questionnaire, 9 items, total range score from 6 to 45 , higher score indicating a higher level of physical activity)

- NYHA functional class= New York Association functional class from the World Health Organization

- Variation of cardiac output during exercise tests measured by impedance measurement (Physioflow)

* Peak oxygen uptake $\left(\mathrm{VO}_{2} \mathrm{max}, \mathrm{ml} / \mathrm{kg} / \mathrm{min}\right)$ (time frame: Month 0 and Month 12)

* Ventilatory anaerobic threshold (VAT, $\mathrm{ml} / \mathrm{kg} / \mathrm{min}$ ) (time frame: Month 0 and Month 12)

* Knowledge of the disease (time frame: Month 0 and Month 12)

* Cardiac events (time frame: Month 0 and Month 12)

* Physical activity scoring (time frame: Month 0 and Month 12)

* Functional NYHA class (time frame: Month 0 and Month 12)

* Cardiac output during exercise (time frame: Month 0 and Month 12)

\begin{tabular}{ll}
\hline Starting date & 27 July 2018 \\
\hline Contact information & Contact: Sophie GUILLAUMONT0467336632 s-guillaumont@chu-montpellier.fr \\
& Contact: Pascal AMEDRO0467336632 p-amedro@chu-montpellier.fr \\
\hline Notes & Amedro P, Gavotto A, Legendre A, Lavastre K, Bredy C, De La Villeon G, Matecki S, Vandenberghe D, \\
& Ladeveze M, Bajolle F, Bosser G, Bouvaist H, Brosset P, Cohen L, Cohen S, Corone S, Dauphin C, Du- \\
& lac Y, Hascoet S, Iriart X, Ladouceur M, Mace L, Neagu OA, Ovaert C, Picot MC, Poirette L, Sidney F, \\
& Soullier C, Thambo JB, Combes N, Bonnet D, Guillaumont S. Impact of a centre and home-based \\
& cardiac rehabilitation program on the quality of life of teenagers and young adults with congeni- \\
& tal heart disease: The QUALI-REHAB study rationale, design and methods. Int J Cardiol. 2019 May \\
& $15 ; 283: 112-118$. doi: 10.1016/j.ijcard.2018.12.050. Epub 2018 Dec 20.
\end{tabular}


NCT03999320

\begin{tabular}{ll}
\hline Study name & Sophrology and congenital heart disease (SOPHRO CARE) \\
\hline Methods & RCT \\
\hline
\end{tabular}

Participants

\section{Inclusion criteria:}

- Patient aged 13 to 25 years old

- With a congenital heart disease (CHD) as defined in the international anatomic and clinical classification (ACC) - CHD classification

- Informed consent from adult patients or parents/legal guardians for minor patients

Interventions Sophrology sessions

Outcomes $\quad$ Primary outcome:

$\mathrm{VO}_{2}$ max Variation

1. Maximum oxygen uptake (VO2 max) (time frame: variation between baseline (M0) and at 12 months (M12))

\section{Secondary outcomes:}

- Quality of life score variation (PedsQL, 24 items), range score from 0 to 100, higher score indicating better quality of life.

- Score of physical activity (Ricci and Gagnon questionnaire, 9 items, total range score from 6 to 45, higher score indicating a higher level of physical activity)

* Quality of life score (time frame: evolution of the PedsQL 4.0 self-reported scores from month 0 to month 12)

* Physical activity score (time frame: variation between Baseline (M0) and at 12 months (M12))

Starting date 19 July 2019

Contact information Pascal AMEDRO, MD0467336632 p-amedro@chu-montpellier.fr

Notes

\section{NCT04135859 (YACHD-PALS)}

Study name Young Adult Congenital Heart Disease Physical Activity Lifestyle Study (YACHD-PALS)

\begin{tabular}{ll}
\hline Methods & This study will adapt a physical activity lifestyle intervention to emerging adult congenital heart \\
disease $(\mathrm{CHD})$ survivors with the primary goal of increasing physical activity levels.
\end{tabular}
disease (CHD) survivors with the primary goal of increasing physical activity levels.

The study will be split into 2 phases. In Phase 1, participants will be asked to complete questionnaires, wear an accelerometer around the waist for 7 days, and undergo an exercise stress test. The accelerometer and exercise stress test will be used to determine whether participants are eligible to be randomized for the intervention study. In Phase 2, participants will be randomized to one of two conditions: 1) receiving a physical activity tracker (a Fitbit) or 2) receiving a Fitbit AND engaging in videoconferencing sessions with a physical activity coach. During Phase 2, participants will also be asked to complete 3 assessments (weeks 9 and 22, and a 6-month follow-up). The week 9 assessment will consist of completing questionnaires and wearing an accelerometer for 7 days. Week 22 will be similar to week 9 with the addition of a final exercise stress test. The 6 -month follow-up will mirror the week 9 assessment.

Participants

\section{Inclusion Criteria:}

- Between the ages of 18 and 25 (if 18 , must no longer be in high school and no longer living at home) 
NCT04135859 (YACHD-PALS) (Continued)

- Diagnosed with moderate or complex structural congenital heart disease

- Live within 120 miles of Nationwide Children's Hospital

- Able to complete an exercise stress test on a treadmill

\section{Exclusion Criteria:}

- Do no speak or write proficiently in English

- Have cognitive impairments that would interfere with the completion of study procedures

- Are diagnosed with a genetic syndrome (e.g. Downs, Marfans)

- Have been engaged in a formal exercise program within the past 6 months

- Underwent open-heart surgery or have had a transcatheter valve replacement in the last 3 months

- Are otherwise prohibited by their cardiologist to engage in at least moderate levels of physical activity

- Are unable to complete a treadmill-based exercise stress test

- Are currently pregnant

- Have contraindications for exercise based on an exercise stress test (e.g., exercise-induced arrhythmias or evidence of cardiac ischaemia)

- > $150 \mathrm{~min} /$ weekday of moderate-to-vigorous physical activity per the accelerometer

- Do not have access or a device for videoconferencing with the coach

Interventions

In the Fitbit Only arm, participants will receive their exercise prescription, as devised from their baseline exercise stress test results, and a Fitbit. They will undergo a 9 week (interim) and a 22 week assessment (follow-up).

Intervention: Behavioral: Physical Activity Monitoring

In the Fitbit + Coaching Sessions arm, participants will receive their exercise prescription, as devised from their baseline exercise stress test results, a Fitbit, and will have 8 sessions with a coach (interventionist) over the course of 20 weeks. They will undergo a 9 week (interim) and a 22 week assessment (follow-up).

Interventions:

- Behavioral: physical activity lifestyle intervention

- Behavioral: physical activity monitoring

- Active Comparator: Fitbit only

- Experimental: Fibit + coaching sessions

Outcomes Number of minutes spent in moderate to vigorous physical activity as measured by an accelerometer.

\begin{tabular}{ll}
\hline Starting date & 2019 \\
\hline Contact information & Jamie Jackson, Nationwide Children's Hospital \\
\hline
\end{tabular}

\section{NCT04208893}

\begin{tabular}{ll}
\hline Study name & Exercise training strategies for children with repaired tetralogy of Fallot \\
\hline Methods & RCT \\
\hline Participants & Paediatrics with repaired tetralogy of Fallot \\
\hline
\end{tabular}


NCT04208893 (Continued)

Interventions
The aerobic training intervention will include 60 minutes/session, 3 times/week for 12 weeks at an intensity of $65 \%$ to $85 \%$ of participants' heart rate reserve (HRR), as determined by the CPET. Patients will be asked to wear a fitness-tracking device to monitor their heart rate response and in order to comply with the prescribed training intensity. All training sessions will start with a 10-minute warm up, 40-minute aerobic interventions, and ends with a 10-minutes cool down. One study doctor will be on call during in-hospital training. Onsite supervised aerobic interventions will include play-based activities, whereas home-based aerobic activities will include stationary bikes and exercise activities that would target desired heart rate ranges. Home exercise equipment will be provided.
Primary

- Consent rate (time frame: 1 year)

- Enrolment rate (time frame: 1 year)

- Adherence rate (time frame: 1 year)

- Completion rate (time frame: 1 year)

- Attrition rate (time frame: 1 year)

- Acceptability questionnaire

Secondary

- The effect of aerobic training only versus combined aerobic and strength training on exercise capacity using cardiopulmonary exercise test in children with repaired tetralogy of Fallot (ToF) (peak exercise $\mathrm{ml} / \mathrm{kg} / \mathrm{min}$ ) (time frame: from baseline to 3 months post intervention)

- The effect of aerobic training only versus combined aerobic and strength training on pulmonary measures using pulmonary function test in children with repaired tetralogy of Fallot (ToF) (Change in time in force vital capacity (FVC) (litres)) (time frame: from baseline to 3 months post intervention).

- Many others planned outcomes see registry

Starting date 2019

Notes

\section{NCT04264650}

Study name

Long-term effectiveness of an mHealth intervention for improving the disease knowledge and physical activity of youth With congenital heart disease: a randomized controlled trial

Methods

- No Intervention: control group

- Experimental: one active intervention group

- Experimental: the other active intervention group

Participants

\section{Inclusion criteria:}

- being diagnosed with CHD by a paediatric cardiologist and qualifying as having simple or moderate CHD complexity according to the 2008 American College of Cardiology/American Heart Association guidelines;

- having a regular pulse;

- being 15 to 24 years of age;

- being conversant in Mandarin and Taiwanese;

- possessing a smartphone with Internet connection;

- agreeing to wear an exercise-monitoring wristband to record physiological data; 
NCT04264650 (Continued)

- agreeing to engage in exercises designed to test cardiopulmonary endurance;

- agreeing to participate in the study and sign an informed consent form for a relevant interview. For participants under 20 years of age, guardian approval by signing a written consent form was required.

\section{Exclusion criteria:}

- having cognitive impairment to the extent of being noncommunicative;

- having CHD complicated with other congenital abnormalities;

- having undergone a cardiac catheter-related intervention or surgery within the past 6 months;

- being pregnant

Interventions

The COOL program is a 12-month randomized controlled trial that compared two active intervention groups to a standard-care control group $(n=47)$. Participants with simple and moderate CHD aged 15-24 years were recruited from paediatric or adult CHD outpatient departments. Participants in one active intervention group $(n=49)$ were provided with COOL Passport, a mobile healthcare application. Those in the other group $(n=47)$ were provided with access to the Health Promotion Cloud system and use of game-based interactive platforms along with COOL Passport. Outcomes were the Leuven Knowledge Questionnaire for CHD and the International Physical Activity Questionnaire-Taiwan Show-Card Version.

\begin{tabular}{ll}
\hline Outcomes & Cardiac disease knowledge and physical activity \\
\hline Starting date & 2020 \\
\hline Contact information & Chi-Wen Chen, PhD National Yang Ming University \\
\hline
\end{tabular}

Notes

Study name Evaluation test about safety and efficacy of the respiratory muscle training therapy by abdominal respiratory weight exercises in chronic cardiovascular disease patients

\begin{tabular}{ll}
\hline Methods & Parallel randomized \\
\hline Participants & Inclusion criteria: \\
& Patients with chronic cardiovascular disease in outpatient or in hospital of Kurume University \\
- Patients with informed consent \\
- Patients with chronic cardiovascular disease shown in the following \\
- Ischaemic heart disease \\
- Valvular heart disease \\
- Hypertensive heart disease \\
- Cardiomyopathy \\
- Arrhythmia \\
- Pdult congenital heart disease \\
- Exclusion criteria: Patients with obstructive respiratory disease \\
- Patients with the device planted \\
- Patients with difficult musculoskeletal disease \\
- Patients with symptoms at rest \\
- Patients with pulmonary hypertension of the WHO classification 3 more
\end{tabular}


UMIN000021661 (Continued)

- Patients with hypoxaemia in spite of the use of breathing ancillary equipment

- Patients with uncontrolled high blood pressure

- Patients with poor control of arrhythmia, such as adverse effects on haemodynamics

- Patients that may be in or pregnancy

- Others, patients who are judged that this study is unsuitable by physician

Interventions

The respiratory muscle training therapy is performed in addition to performing conventional cardiac rehabilitation. The respiratory muscle training therapy is abdominal muscle training method. Intervention period is 6 months

\begin{tabular}{ll}
\hline Outcomes & - Cardiac function \\
- Respiratory function \\
- Exercise capacity \\
- Relief of symptoms \\
- Autonomic function \\
- Body composition \\
- Carbohydrate metabolism \\
- Lipid metabolism
\end{tabular}

\section{Starting date} 4 April 2016

Contact information

Miki Biwa

biwa_miki@med.kurume-u.ac.jp

Notes

RISK OF BIAS

\section{Legend: $\vee$ Low risk of bias $\quad$ High risk of bias $\sim$ Some concerns}

Risk of bias for analysis 1.1 Maximal cardiorespiratory fitness

\begin{tabular}{|c|c|c|c|c|c|c|}
\hline & & & Bias & & & \\
\hline Study & $\begin{array}{c}\text { Randomisation } \\
\text { process }\end{array}$ & $\begin{array}{l}\text { Deviations } \\
\text { from intended } \\
\text { interventions }\end{array}$ & $\begin{array}{c}\text { Missing } \\
\text { outcome data }\end{array}$ & $\begin{array}{l}\text { Measurement } \\
\text { of the outcome }\end{array}$ & $\begin{array}{l}\text { Selection of } \\
\text { the reported } \\
\text { results }\end{array}$ & Overall \\
\hline \multicolumn{7}{|c|}{ Subgroup 1.1.1 Exercise training } \\
\hline Therrien 2003 & & & & & & \\
\hline Moalla 2006 & & & & & & $\sim$ \\
\hline Madhavi 2011 & & & & & $\sim$ & $\mathbf{x}$ \\
\hline Winter 2012 & & & & & 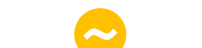 & $\sim$ \\
\hline
\end{tabular}

Physical activity interventions for people with congenital heart disease (Review) 


\begin{tabular}{|c|c|c|c|c|c|c|}
\hline & & & Bias & & & \\
\hline Study & $\begin{array}{c}\text { Randomisation } \\
\text { process }\end{array}$ & $\begin{array}{l}\text { Deviations } \\
\text { from intended } \\
\text { interventions }\end{array}$ & $\begin{array}{l}\text { Missing } \\
\text { outcome data }\end{array}$ & $\begin{array}{l}\text { Measurement } \\
\text { of the outcome }\end{array}$ & $\begin{array}{l}\text { Selection of } \\
\text { the reported } \\
\text { results }\end{array}$ & Overall \\
\hline $\begin{array}{l}\text { Westhoff-Bleck } \\
2013\end{array}$ & & & & & & $\sim$ \\
\hline Duppen 2015 & & & & & & $\sim$ \\
\hline Avila 2016 & & & & & & $\sim$ \\
\hline Novakovic 2018 & & & & & & $\sim$ \\
\hline Novakovic 2018 & & & & & & $\sim$ \\
\hline Opotowsky 2018 & & & & & & $\sim$ \\
\hline Sandberg 2018 & & & & & & $\sim$ \\
\hline van Dissel 2019 & & & & & & $\sim$ \\
\hline \multicolumn{7}{|c|}{ Subgroup 1.1.2 Physical activity promotion } \\
\hline Morrison 2013 & & & & & & $\sim$ \\
\hline Klausen 2016 & & & & & & $\sim$ \\
\hline \multicolumn{7}{|c|}{ Subgroup 1.1.3 Inspiratory muscle training } \\
\hline Fritz 2020 & & & & & & $\sim$ \\
\hline
\end{tabular}

Risk of bias for analysis 1.2 Health-related quality of life

\begin{tabular}{lccccc}
\hline Study & $\begin{array}{c}\text { Randomisation } \\
\text { process }\end{array}$ & $\begin{array}{c}\text { Deviations } \\
\text { from intended } \\
\text { interventions }\end{array}$ & $\begin{array}{c}\text { Missing } \\
\text { outcome data }\end{array}$ & $\begin{array}{c}\text { Measurement } \\
\text { of the outcome }\end{array}$ & $\begin{array}{c}\text { Selection of } \\
\text { the reported } \\
\text { results }\end{array}$ \\
\hline Madhavi 2011 & $\mathbf{X}$ & & $\mathbf{X}$ & $\mathbf{X}$ & \\
\hline Opotowsky 2018 & & & & & \\
\hline
\end{tabular}




\begin{tabular}{|c|c|c|c|c|c|c|}
\hline \multicolumn{7}{|c|}{ Bias } \\
\hline Study & $\begin{array}{c}\text { Randomisation } \\
\text { process }\end{array}$ & $\begin{array}{l}\text { Deviations } \\
\text { from intended } \\
\text { interventions }\end{array}$ & $\begin{array}{c}\text { Missing } \\
\text { outcome data }\end{array}$ & $\begin{array}{l}\text { Measurement } \\
\text { of the outcome }\end{array}$ & $\begin{array}{l}\text { Selection of } \\
\text { the reported } \\
\text { results }\end{array}$ & Overall \\
\hline Sandberg 2018 & & & & 8 & $\sim$ & $\mathbf{x}$ \\
\hline
\end{tabular}

Risk of bias for analysis 1.3 Physical activity (device-worn)

\begin{tabular}{|c|c|c|c|c|c|c|}
\hline & & & Bias & & & \\
\hline Study & $\begin{array}{c}\text { Randomisation } \\
\text { process }\end{array}$ & $\begin{array}{l}\text { Deviations } \\
\text { from intended } \\
\text { interventions }\end{array}$ & $\begin{array}{c}\text { Missing } \\
\text { outcome data }\end{array}$ & $\begin{array}{l}\text { Measurement } \\
\text { of the outcome }\end{array}$ & $\begin{array}{l}\text { Selection of } \\
\text { the reported } \\
\text { results }\end{array}$ & Overall \\
\hline Duppen 2015 & & & & & $\sim$ & $\sim$ \\
\hline Klausen 2016 & & & & & & $\sim$ \\
\hline Morrison 2013 & & & & & & $\sim$ \\
\hline Opotowsky 2018 & & & & & & $\sim$ \\
\hline
\end{tabular}

Risk of bias for analysis 1.4 Submaximal cardiorespiratory fitness (gas exchange threshold)

\begin{tabular}{|c|c|c|c|c|c|c|}
\hline \multicolumn{7}{|c|}{ Bias } \\
\hline Study & $\begin{array}{c}\text { Randomisation } \\
\text { process }\end{array}$ & $\begin{array}{l}\text { Deviations } \\
\text { from intended } \\
\text { interventions }\end{array}$ & $\begin{array}{c}\text { Missing } \\
\text { outcome data }\end{array}$ & $\begin{array}{l}\text { Measurement } \\
\text { of the outcome }\end{array}$ & $\begin{array}{l}\text { Selection of } \\
\text { the reported } \\
\text { results }\end{array}$ & Overall \\
\hline Moalla 2006 & & & & & $\sim$ & $\sim$ \\
\hline $\begin{array}{l}\text { Westhoff-Bleck } \\
2013\end{array}$ & & & & & & $\sim$ \\
\hline Duppen 2015 & & & & & & $\sim$ \\
\hline Avila 2016 & & & & & & $\sim$ \\
\hline Novakovic 2018 & & & & & & $\sim$ \\
\hline Novakovic 2018 & & & & & & $\sim$ \\
\hline
\end{tabular}


Risk of bias for analysis 1.5 Muscular strength

\begin{tabular}{|lccccc}
\hline Study & $\begin{array}{c}\text { Randomisation } \\
\text { process }\end{array}$ & $\begin{array}{c}\text { Deviations } \\
\text { from intended } \\
\text { interventions }\end{array}$ & $\begin{array}{c}\text { Missing } \\
\text { outcome data }\end{array}$ & $\begin{array}{c}\text { Measurement } \\
\text { of the outcome }\end{array}$ & $\begin{array}{c}\text { Selection of } \\
\text { the reported } \\
\text { results }\end{array}$ \\
\hline Moalla 2006 & & & & \\
\hline
\end{tabular}

Risk of bias for analysis 1.6 Maximal cardiorespiratory fitness (type of ConHD subgroup analysis)

\begin{tabular}{|c|c|c|c|c|c|c|}
\hline \multicolumn{7}{|c|}{ Bias } \\
\hline Study & $\begin{array}{l}\text { Randomisation } \\
\text { process }\end{array}$ & $\begin{array}{l}\text { Deviations } \\
\text { from intended } \\
\text { interventions }\end{array}$ & $\begin{array}{c}\text { Missing } \\
\text { outcome data }\end{array}$ & $\begin{array}{l}\text { Measurement } \\
\text { of the outcome }\end{array}$ & $\begin{array}{l}\text { Selection of } \\
\text { the reported } \\
\text { results }\end{array}$ & Overall \\
\hline \multicolumn{7}{|c|}{ Subgroup 1.6.1 Population with a single ventricle } \\
\hline Winter 2012 & & & & & & $\sim$ \\
\hline $\begin{array}{l}\text { Westhoff-Bleck } \\
2013\end{array}$ & & & & & & $\sim$ \\
\hline Duppen 2015 & & & & & & $\sim$ \\
\hline Fritz 2020 & & & & & & $\sim$ \\
\hline \multicolumn{7}{|c|}{ Subgroup 1.6.2 Population with repaired Tetralogy of Fallot } \\
\hline Therrien 2003 & & & & & & $\mathbf{x}$ \\
\hline Duppen 2015 & & & & & & $\sim$ \\
\hline Avila 2016 & & & & & & $\sim$ \\
\hline Novakovic 2018 & & & & & & $\sim$ \\
\hline Novakovic 2018 & & & & & $\sim$ & $\sim$ \\
\hline Subgroup 1.6.3 & er or mixed ConH & populations & & & & \\
\hline Moalla 2006 & & & & & $\sim$ & $\sim$ \\
\hline
\end{tabular}




\begin{tabular}{|c|c|c|c|c|c|c|}
\hline \multicolumn{7}{|c|}{ Bias } \\
\hline Study & $\begin{array}{c}\text { Randomisation } \\
\text { process }\end{array}$ & $\begin{array}{l}\text { Deviations } \\
\text { from intended } \\
\text { interventions }\end{array}$ & $\begin{array}{c}\text { Missing } \\
\text { outcome data }\end{array}$ & $\begin{array}{l}\text { Measurement } \\
\text { of the outcome }\end{array}$ & $\begin{array}{l}\text { Selection of } \\
\text { the reported } \\
\text { results }\end{array}$ & Overall \\
\hline Madhavi 2011 & & $\sim$ & & & $\sim$ & $x$ \\
\hline Morrison 2013 & & & & & & $\sim$ \\
\hline Klausen 2016 & & & & & & $\sim$ \\
\hline Opotowsky 2018 & & & & & & $\sim$ \\
\hline Sandberg 2018 & & & & & & $\sim$ \\
\hline van Dissel 2019 & & & & & & $\sim$ \\
\hline
\end{tabular}

\section{DATA AND ANALYSES}

Comparison 1. Physical activity promotion, exercise training and inspiratory muscle training interventions versus no activity (usual care) in people with congenital heart disease

\begin{tabular}{|c|c|c|c|c|}
\hline Outcome or subgroup title & No. of studies & $\begin{array}{l}\text { No. of partici- } \\
\text { pants }\end{array}$ & Statistical method & Effect size \\
\hline $\begin{array}{l}\text { 1.1 Maximal cardiorespiratory fit- } \\
\text { ness }\end{array}$ & 14 & 732 & $\begin{array}{l}\text { Mean Difference (IV, Random, } \\
95 \% \mathrm{CI} \text { ) }\end{array}$ & $1.89[-0.22,3.99]$ \\
\hline 1.1.1 Exercise training & 11 & 435 & $\begin{array}{l}\text { Mean Difference (IV, Random, } \\
95 \% \mathrm{CI})\end{array}$ & $2.74[0.36,5.12]$ \\
\hline 1.1.2 Physical activity promotion & 2 & 259 & $\begin{array}{l}\text { Mean Difference (IV, Random, } \\
95 \% \mathrm{CI} \text { ) }\end{array}$ & $-1.71[-4.64,1.22]$ \\
\hline 1.1.3 Inspiratory muscle training & 1 & 38 & $\begin{array}{l}\text { Mean Difference (IV, Random, } \\
95 \% \mathrm{CI} \text { ) }\end{array}$ & $0.70[-4.83,6.23]$ \\
\hline 1.2 Health-related quality of life & 3 & 163 & $\begin{array}{l}\text { Std. Mean Difference (IV, Ran- } \\
\text { dom, } 95 \% \mathrm{Cl} \text { ) }\end{array}$ & $0.76[-0.13,1.65]$ \\
\hline 1.3 Physical activity (device-worn) & 4 & 328 & $\begin{array}{l}\text { Std. Mean Difference (IV, Ran- } \\
\text { dom, } 95 \% \mathrm{Cl} \text { ) }\end{array}$ & $0.38[-0.15,0.92]$ \\
\hline $\begin{array}{l}\text { 1.4 Submaximal cardiorespiratory } \\
\text { fitness (gas exchange threshold) }\end{array}$ & 5 & 179 & $\begin{array}{l}\text { Mean Difference (IV, Random, } \\
95 \% \mathrm{CI} \text { ) }\end{array}$ & $2.05[0.05,4.05]$ \\
\hline 1.5 Muscular strength & 1 & & $\begin{array}{l}\text { Mean Difference (IV, Random, } \\
95 \% \mathrm{CI})\end{array}$ & $\begin{array}{l}\text { Totals not select- } \\
\text { ed }\end{array}$ \\
\hline
\end{tabular}




\begin{tabular}{lllll}
\hline Outcome or subgroup title & No. of studies & $\begin{array}{l}\text { No. of partici- } \\
\text { pants }\end{array}$ & Statistical method & Effect size \\
\hline $\begin{array}{l}\text { 1.6 Maximal cardiorespiratory fit- } \\
\text { ness (type of ConHD subgroup } \\
\text { analysis) }\end{array}$ & 14 & 732 & $\begin{array}{l}\text { Mean Difference (IV, Random, } \\
95 \% \mathrm{Cl})\end{array}$ & $1.90[-0.14,3.95]$ \\
\hline $\begin{array}{l}\text { 1.6.1 Population with a single ven- } \\
\text { tricle }\end{array}$ & 4 & 154 & $\begin{array}{l}\text { Mean Difference (IV, Random, } \\
95 \% \text { Cl) }\end{array}$ & $2.05[-0.25,4.35]$ \\
\hline $\begin{array}{l}\text { 1.6.2 Population with repaired } \\
\text { Tetralogy of Fallot }\end{array}$ & 4 & 104 & $\begin{array}{l}\text { Mean Difference (IV, Random, } \\
95 \% \text { Cl) }\end{array}$ & $1.97[-1.11,5.05]$ \\
\hline $\begin{array}{l}\text { 1.6.3 Other or mixed ConHD popula- } \\
\text { tions }\end{array}$ & 7 & 474 & $\begin{array}{l}\text { Mean Difference (IV, Random, } \\
95 \% \text { Cl) }\end{array}$ & $1.98[-1.67,5.62]$ \\
\hline
\end{tabular}

Analysis 1.1. Comparison 1: Physical activity promotion, exercise training and inspiratory muscle training interventions versus no activity (usual care) in people with congenital heart disease, Outcome 1: Maximal cardiorespiratory fitness

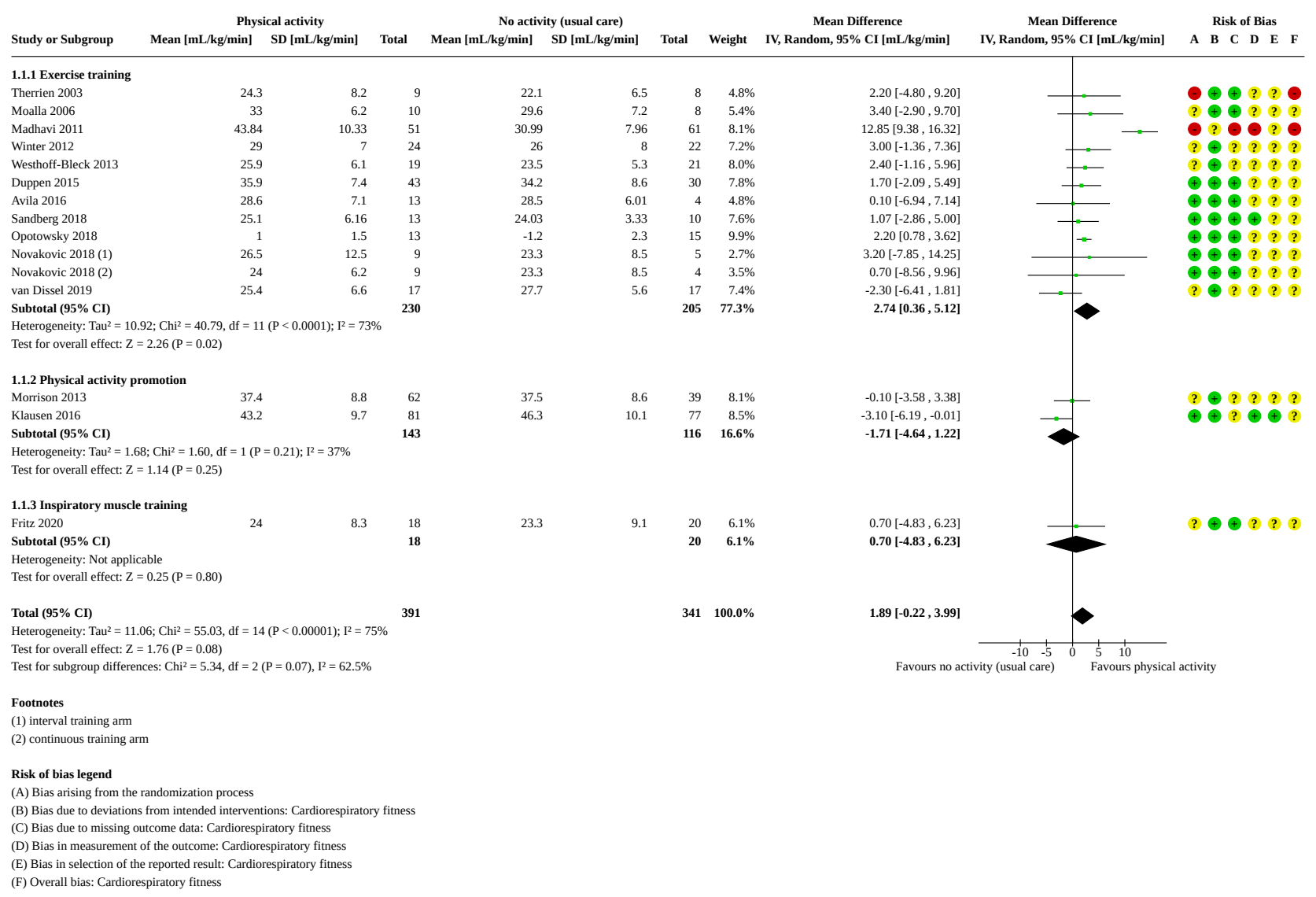


Analysis 1.2. Comparison 1: Physical activity promotion, exercise training and inspiratory muscle training interventions versus no activity (usual care) in people with congenital heart disease, Outcome 2: Health-related quality of life

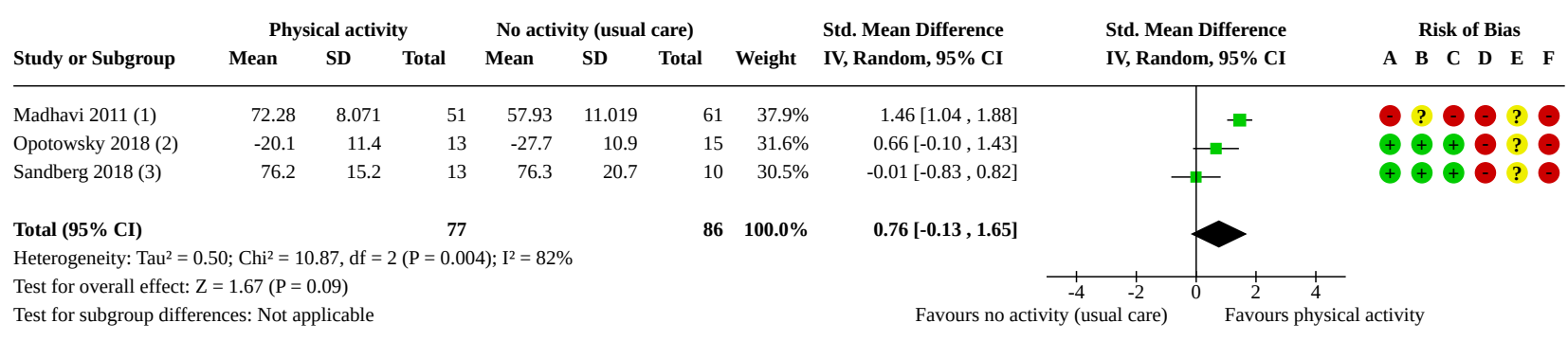

Footnotes

(1) SF-36 (total score)

(2) MLHFQ

(3) EQ5D VAS

Risk of bias legend

(A) Bias arising from the randomization process

(B) Bias due to deviations from intended interventions: Health-related quality of life

(C) Bias due to missing outcome data: Health-related quality of life

(D) Bias in measurement of the outcome: Health-related quality of life

(E) Bias in selection of the reported result: Health-related quality of life

(F) Overall bias: Health-related quality of life

Analysis 1.3. Comparison 1: Physical activity promotion, exercise training and inspiratory muscle training interventions versus no activity (usual care) in people with congenital heart disease, Outcome 3: Physical activity (device-worn)

\begin{tabular}{|c|c|c|c|c|c|c|c|c|c|c|c|c|c|c|}
\hline \multirow[b]{2}{*}{ Study or Subgroup } & \multicolumn{3}{|c|}{ Physical activity } & \multicolumn{3}{|c|}{ No activity (usual care) } & \multirow[b]{2}{*}{ Weight } & \multirow{2}{*}{$\begin{array}{l}\text { Std. Mean Difference } \\
\text { IV, Random, } 95 \% \text { CI }\end{array}$} & \multirow{2}{*}{$\begin{array}{l}\text { Std. Mean Difference } \\
\text { IV, Random, 95\% CI }\end{array}$} & \multicolumn{5}{|c|}{ Risk of Bias } \\
\hline & Mean & SD & Total & Mean & SD & Total & & & & A $\mathbf{B}$ & C & D & $\mathbf{E}$ & $\mathbf{F}$ \\
\hline Duppen 2015 (1) & 12.7 & 8.1 & 28 & 11.8 & 6.2 & 18 & $23.7 \%$ & $0.12[-0.47,0.71]$ & - & $\oplus \oplus$ & $\oplus$ & ? & $?$ & ? \\
\hline Klausen 2016 & 40.3 & 21.8 & 81 & 41.3 & 22.9 & 77 & $30.2 \%$ & $-0.04[-0.36,0.27]$ & & $+\oplus$ & ? & + & + & ? \\
\hline Morrison 2013 & 57.2 & 32.2 & 62 & 29.2 & 27.3 & 39 & $27.8 \%$ & $0.91[0.49,1.33]$ & -- & ? $\odot$ & $?$ & ? & $?$ & ? \\
\hline Opotowsky 2018 & 103 & 56 & 11 & 75 & 25 & 12 & $18.3 \%$ & $0.63[-0.21,1.47]$ & & $\oplus \oplus$ & 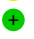 & ? & $?$ & ? \\
\hline Total (95\% CI) & & & 182 & & & 146 & $100.0 \%$ & $0.38[-0.15,0.92]$ & & & & & & \\
\hline \multicolumn{15}{|c|}{ Heterogeneity: $\mathrm{Tau}^{2}=0.22 ; \mathrm{Chi}^{2}=13.81, \mathrm{df}=3(\mathrm{P}=0.003) ; \mathrm{I}^{2}=78 \%$} \\
\hline Test for overall effect & $=1.42(\mathrm{P}=$ & $16)$ & & & & & & & -1 & & & & & \\
\hline
\end{tabular}

Footnotes

(1) Measure of activity: time spent in moderate-to-very-vigorous activity as a percentage. All other studies report minutes of MVPA per day.

Risk of bias legend

(A) Bias arising from the randomization process

(B) Bias due to deviations from intended interventions: Physical activity (device-worn)

(C) Bias due to missing outcome data: Physical activity (device-worn)

(D) Bias in measurement of the outcome: Physical activity (device-worn)

(E) Bias in selection of the reported result: Physical activity (device-worn)

(F) Overall bias: Physical activity (device-worn) 
Analysis 1.4. Comparison 1: Physical activity promotion, exercise training and inspiratory muscle training interventions versus no activity (usual care) in people with congenital heart disease, Outcome 4: Submaximal cardiorespiratory fitness (gas exchange threshold)

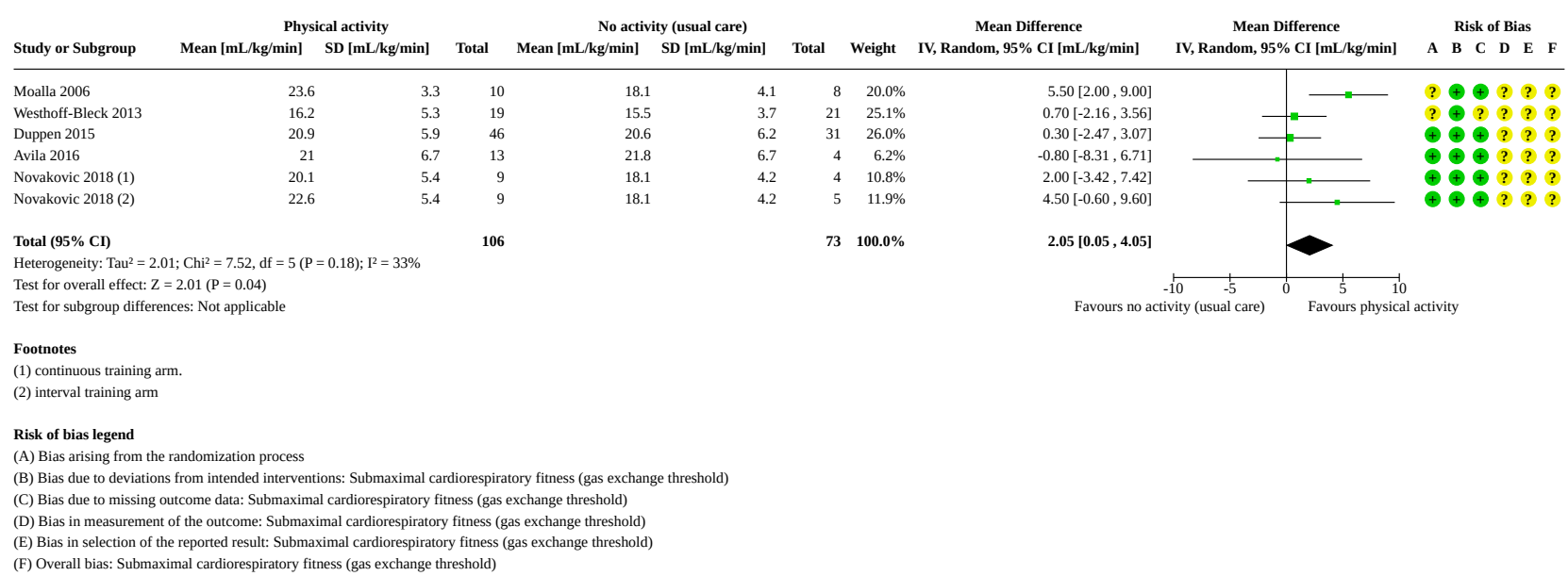

Analysis 1.5. Comparison 1: Physical activity promotion, exercise training and inspiratory muscle training interventions versus no activity (usual care) in people with congenital heart disease, Outcome 5: Muscular strength

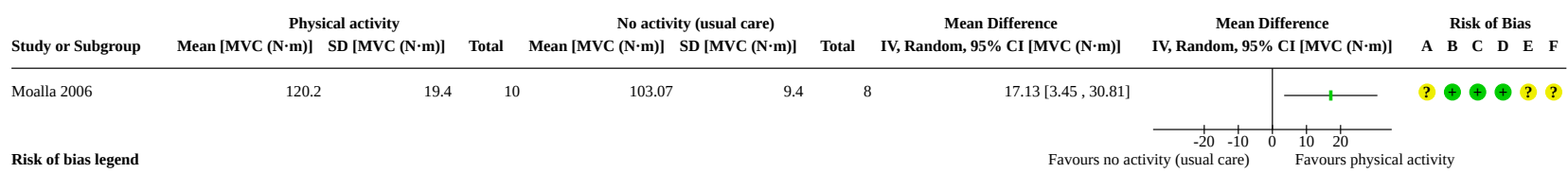

(A) Bias arising from the randomization process

(B) Bias due to deviations from intended interventions: Muscular strength

(C) Bias due to missing outcome data: Muscular strength

(D) Bias in measurement of the outcome: Muscular strength

(E) Bias in selection of the reported result: Muscular strength

(F) Overall bias: Muscular strength 
Analysis 1.6. Comparison 1: Physical activity promotion, exercise training and inspiratory muscle training interventions versus no activity (usual care) in people with congenital heart disease, Outcome 6: Maximal cardiorespiratory fitness (type of ConHD subgroup analysis)

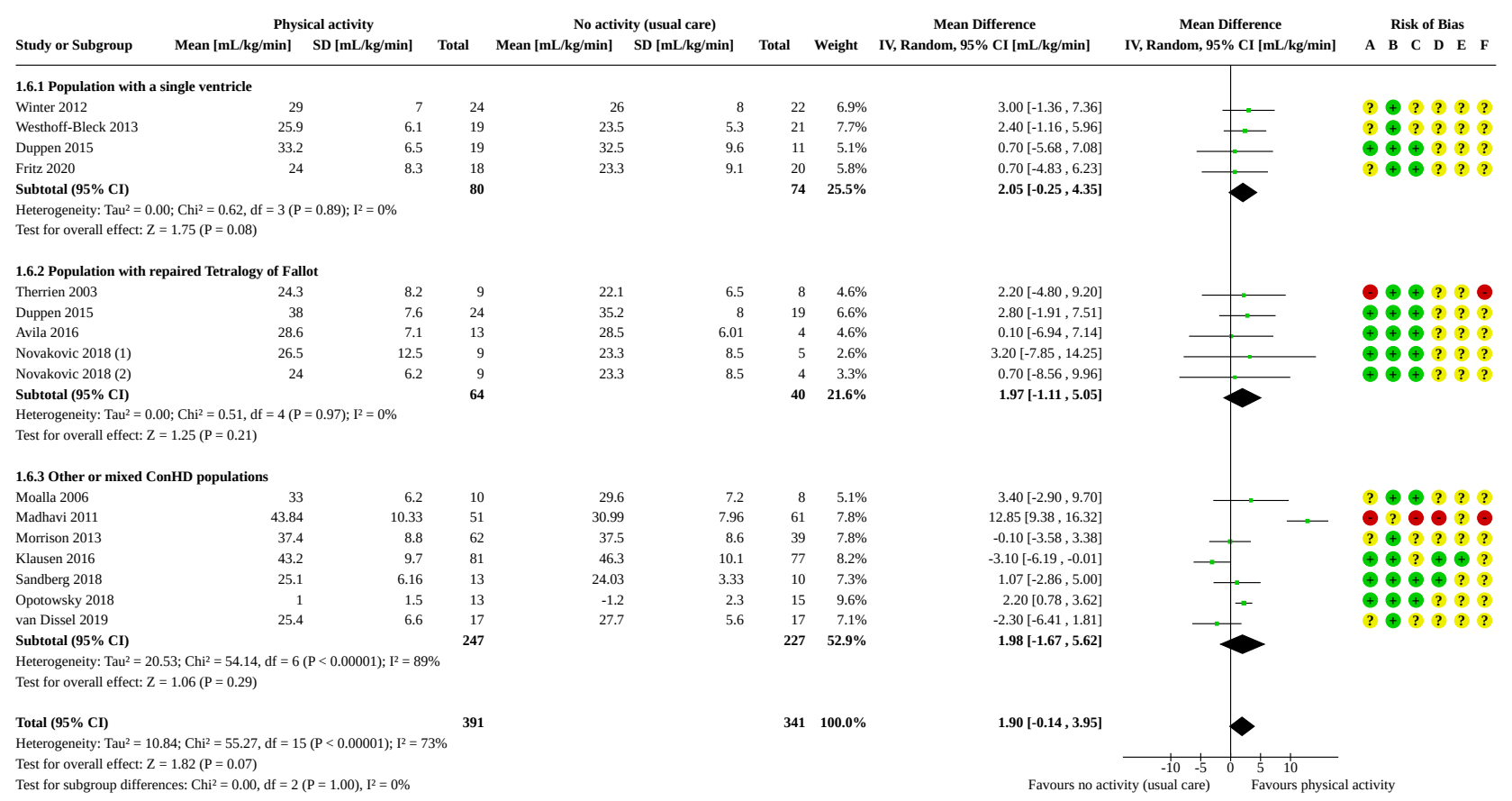

(1) interval training arm

(2) continuous training arm

Risk of bias legend

(A) Bias arising from the randomization proces

(B) Bias due to deviations from intended interventions: Maximal cardiorespiratory fitness (type of ConHD subgroup analysis)

(C) Bias due to missing outcome data: Maximal cardiorespiratory fitness (type of ConHD subgroup analysis)

(D) Bias in measurement of the outcome: Maximal cardiorespiratory fitness (type of ConHD subgroup analysis)

(E) Bias in selection of the reported result: Maximal cardiorespiratory fitness (type of ConHD subgroup analysis)

(F) Overall bias: Maximal cardiorespiratory fitness (type of ConHD subgroup analysis) 


\begin{tabular}{|c|c|c|c|c|c|c|c|}
\hline \multirow{13}{*}{ 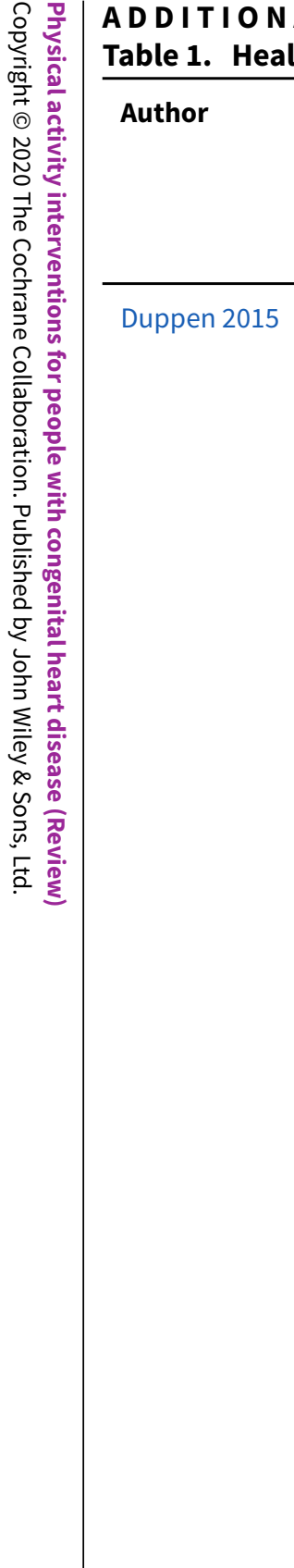 } & Sample size & $\begin{array}{l}\text { Type of inter- } \\
\text { vention }\end{array}$ & Questionnaire & Domain & $\begin{array}{l}\text { Intervention vs. control at follow } \\
\text { up } \\
\text { Mean (Standard deviation) \& be- } \\
\text { tween group P value }\end{array}$ & Direction of effect & $\begin{array}{l}\text { Overall risk } \\
\text { of bias }\end{array}$ \\
\hline & 73 & $\begin{array}{l}\text { Exercise train- } \\
\text { ing }\end{array}$ & $\begin{array}{l}\text { SF-36 ( } 8 \text { do- } \\
\text { mains) }+\end{array}$ & $\begin{array}{l}\text { Physical function- } \\
\text { ing }\end{array}$ & $94.6(10.9) 95.0(8.5) \mathrm{P}=0.71$ & Exercise $=$ control & High \\
\hline & & & $\begin{array}{l}\text { SF-36 ( } 8 \text { do- } \\
\text { mains) + }\end{array}$ & Bodily pain & $96.6(8.1) 93.2(17.3) \mathrm{P}=0.96$ & Exercise $=$ control & High \\
\hline & & & $\begin{array}{l}\text { SF-36 ( } 8 \text { do- } \\
\text { mains) + }\end{array}$ & General health & $68.3(27.9) 67.5(19.1) \mathrm{P}=0.94$ & Exercise $=$ control & High \\
\hline & & & $\begin{array}{l}\text { SF-36 ( } 8 \text { do- } \\
\text { mains) + }\end{array}$ & Vitality & $71.7(18.0) 70(17.0) \mathrm{P}=0.56$ & Exercise $=$ control & High \\
\hline & & & $\begin{array}{l}\text { SF-36 ( } 8 \text { do- } \\
\text { mains) + }\end{array}$ & $\begin{array}{l}\text { Role limitations } \\
\text { due to physical lim- } \\
\text { itations }\end{array}$ & $100(0.0) 91.7(21.2) \mathrm{P}=0.16$ & Exercise $=$ control & High \\
\hline & & & $\begin{array}{l}\text { SF-36 ( } 8 \text { do- } \\
\text { mains) + }\end{array}$ & Social functioning & $95.8(10.0) 100.0(0.0) \mathrm{P}=0.09$ & Exercise $=$ control & High \\
\hline & & & $\begin{array}{l}\text { SF-36 ( } 8 \text { do- } \\
\text { mains) + }\end{array}$ & $\begin{array}{l}\text { Role limitations } \\
\text { due to emotional } \\
\text { problems }\end{array}$ & $100(0.0) 100(0.0) P=0.72$ & Exercise $=$ control & High \\
\hline & & & $\begin{array}{l}\text { SF-36 (8 do- } \\
\text { mains) + }\end{array}$ & Mental health & $85.0(16.8) 81.3(10.2) P=0.65$ & Exercise $=$ control & High \\
\hline & & & TACQOL + & Symptoms & $95.6(7.90) 97.8(3.7) \mathrm{P}=0.16$ & Exercise $=$ control & High \\
\hline & & & TACQOL + & $\begin{array}{l}\text { Impact of cardiac } \\
\text { surveillance }\end{array}$ & $85(6.30) 85.7(4.80) P=0.07$ & Exercise $=$ control & High \\
\hline & & & TACQOL + & Worries & $95.7(8.70) 88.6(270) P=0.67$ & Exercise $=$ control & High \\
\hline & & & TACQOL-CF + & $\begin{array}{l}\text { Pain and physical } \\
\text { symptoms }\end{array}$ & $26.3(6.2) 24(7.15) \mathrm{P}=0.21$ & Exercise $=$ control & High \\
\hline
\end{tabular}




\begin{tabular}{|c|c|c|c|c|c|c|c|}
\hline \multirow{8}{*}{ 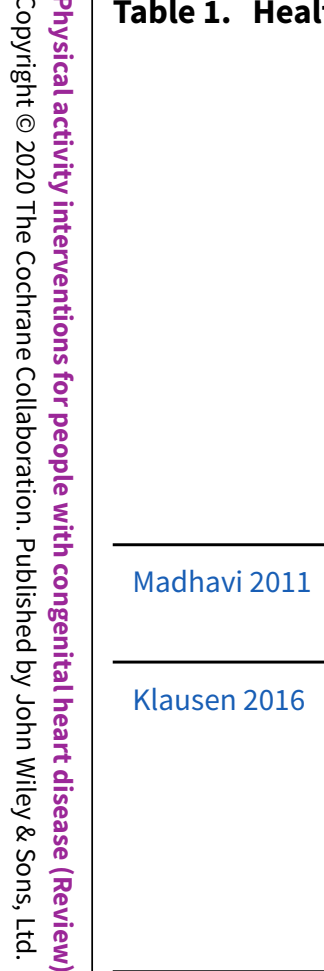 } & & & \multirow{2}{*}{$\begin{array}{l}\text { TACQOL-CF + } \\
\text { TACQOL-CF + }\end{array}$} & \multirow{2}{*}{$\begin{array}{l}\text { Motor functioning } \\
\text { Cognitive function- } \\
\text { ing }\end{array}$} & \multirow{2}{*}{$\begin{array}{l}30.1(1.9) 29.5(4.37) P=0.51 \\
28.6(6.2) 29.7(6.9) P=0.05\end{array}$} & \multirow{2}{*}{$\begin{array}{l}\text { Exercise }=\text { control } \\
\text { Exercise }=\text { control }\end{array}$} & \multirow{2}{*}{$\begin{array}{l}\text { High } \\
\text { High }\end{array}$} \\
\hline & & & & & & & \\
\hline & & & TACQOL-CF + & Social functioning & $31.5(1.2) 32(0) P=0.45$ & Exercise $=$ control & High \\
\hline & & & TACQOL-CF + & $\begin{array}{l}\text { Positive emotional } \\
\text { functional }\end{array}$ & $14.2(3.5) 14.43(2.9) P=0.39$ & Exercise $=$ control & High \\
\hline & & & TACQOL-CF + & $\begin{array}{l}\text { Negative emotional } \\
\text { functioning }\end{array}$ & $12.7(2.12) 14.2(2.2) \mathrm{P}=0.34$ & Exercise $=$ control & High \\
\hline & 112 & $\begin{array}{l}\text { Exercise train- } \\
\text { ing }\end{array}$ & SF-36+ & SF36 total score & $23.3(13.2) 11.3(14.3) \mathrm{P}<0.001$ & Exercise $>$ control & High \\
\hline & 158 & $\begin{array}{l}\text { Physical activ- } \\
\text { ity promotion }\end{array}$ & $\begin{array}{l}\text { Danish Paedi- } \\
\text { atric QoL Inven- } \\
\text { tory + }\end{array}$ & Generic & NR & Exercise $=$ control & High \\
\hline & & & $\begin{array}{l}\text { Danish Paedi- } \\
\text { atric QoL Inven- } \\
\text { tory + }\end{array}$ & Disease specific & NR & Exercise $=$ control & High \\
\hline $\begin{array}{l}\text { Opotowsky } \\
2018\end{array}$ & 28 & $\begin{array}{l}\text { Exercise train- } \\
\text { ing }\end{array}$ & MLHFQ - & MLHFQ & $20.1(11.4) 27.7(10.9) P=0.13$ & Exercise $=$ control & High \\
\hline $\begin{array}{l}\text { Sandberg } \\
2018\end{array}$ & 23 & $\begin{array}{l}\text { Exercise train- } \\
\text { ing }\end{array}$ & EQ5D VAS + & EQ5D VAS & $76.2(15.2) 76.3(20.7) \mathrm{P}=0.31$ & Exercise $=$ control & High \\
\hline \multirow[t]{2}{*}{$\begin{array}{l}\text { Novakovic } \\
2018\end{array}$} & 14 & $\begin{array}{l}\text { Exercise train- } \\
\text { ing (Interval) }\end{array}$ & SF36+ & $\begin{array}{l}\text { Physical compo- } \\
\text { nent }\end{array}$ & $86.7(40.2) 101.0(16.6) P>0.05$ & Exercise $=$ control & High \\
\hline & & & SF36+ & Mental component & $80.0(21.0) 87.3(21.9) \mathrm{P}>0.05$ & Exercise $=$ control & High \\
\hline \multirow[t]{2}{*}{$\begin{array}{l}\text { Novakovic } \\
2018\end{array}$} & 13 & $\begin{array}{l}\text { Exercise train- } \\
\text { ing (Continu- }\end{array}$ & SF36 + & $\begin{array}{l}\text { Physical compo- } \\
\text { nent }\end{array}$ & $103(5.2) 101.0(16.6) P>0.05$ & Exercise $=$ control & High \\
\hline & & & SF36+ & Mental component & $89.3(18.4) 87.3(21.9) \mathrm{P}>0.05$ & Exercise $=$ control & High \\
\hline $\begin{array}{l}\text { West- } \\
\text { hoff-Bleck } \\
2013\end{array}$ & 40 & $\begin{array}{l}\text { Exercise train- } \\
\text { ing }\end{array}$ & $\mathrm{KCCQ}+$ & KCCQ & NR & Exercise $=$ control & High \\
\hline
\end{tabular}


Table 1. Health-related quality of life (Continued)

Winter 2012

46

Exercise train-

\begin{tabular}{lllll} 
SF-36 + & Mental component & $\mathrm{P}=0.17$ & Exercise $=$ control & High \\
\hline $\begin{array}{l}\text { SF-36 }+ \\
\text { Physical compo- } \\
\text { nent }\end{array}$ & $\mathrm{P}=0.20$ & Exercise $=$ control & High \\
\hline $\begin{array}{l}\text { ConHD-TAAQOL } \\
+\end{array}$ & Symptoms & $85(10.79) 83(10.47) \mathrm{P}=0.31$ & Exercise $=$ control & High \\
\hline $\begin{array}{l}\text { ConHD-TAAQOL } \\
+\end{array}$ & Worries & $77(15.4) 84.5(9.21) \mathrm{P}=0.30$ & Exercise $=$ control & High \\
\hline $\begin{array}{l}\text { ConHD-TAAQOL } \\
+\end{array}$ & Impact & $84(7.19) 85.25(6.20) \mathrm{P}=0.91$ & Exercise $=$ control & High
\end{tabular}

Each study's outcome of health related quality of life was individually assessed using risk of bias 2; all studies were judged as a high risk of bias under the domain 'Measurement of the outcome'. '+' = a higher score represents better health; '-' = a lower score represents better health; HRQoL, Health related quality of life; SF-36, 36-Item Short Form Health Survey; MLHFQ, Minnesota living with heart failure questionnaire; TACQOL, TNO/AZL child quality of life questionnaire; ConHD TAAQOL, The congenital heart disease - TNO/AZL adult quality of life questionnaire; EQ5D VAS, EuroQol Vertical Visual Analogue Scale; KCCQ, Kansas City Cardiomyopathy Questionnaire. 
Table 2. Individual ConHD lesions pooled into the meta-analyses

\begin{tabular}{llll}
\hline Study & Age & Type of ConHD and (sample size, \%) & Classification \\
\hline Avila 2016 & $35 \pm 11$ & Repaired ToF (17, 100\%) & Severe \\
\hline Duppen 2015 & $15 \pm 3$ & Fontan circulation $(43,48 \%)$ & Severe \\
& & {$[$ Intra-atrial lateral tunnel 47\%; extracardiac conduit 44\%; other } \\
& $9 \%]$ & \\
\cline { 2 - 4 } & & Repaired ToF $(47,52 \%)$
\end{tabular}

\begin{tabular}{lll}
\hline Fritz $2020 \pm 9$ & Fontan circulations (42, 100\%) & Severe \\
& $\begin{array}{l}\text { [Atrioventricular Anastomosis 19\%; Atriopulmonary Anastomo- } \\
\text { sis 21\%; Total Cavopulmonary Connection 60\%] }\end{array}$ \\
\hline
\end{tabular}

\begin{tabular}{|c|c|c|c|}
\hline \multirow[t]{8}{*}{ Klausen 2016} & \multirow[t]{8}{*}{$15 \pm 1$} & Coarctation of the aorta $(52,33 \%)$ & \multirow[t]{8}{*}{ Severe } \\
\hline & & TGA $(35,22 \%)$ & \\
\hline & & Steno-Fallot tetralogy $(21,13 \%)$ & \\
\hline & & Double outlet right ventricle $(7,4 \%)$ & \\
\hline & & Truncus arteriosus $(4,3 \%)$ & \\
\hline & & Atrioventricular septal defect $(9,6 \%)$ & \\
\hline & & TCPC $(6,4 \%)$ & \\
\hline & & Other $(24,15 \%)$ & \\
\hline Madhavi 2011 & $29 \pm 11$ & Acyanotic Congenital Heart Disease $(112,100 \%)$ & Mild \\
\hline \multirow[t]{4}{*}{ Moalla 2006} & \multirow[t]{4}{*}{$13 \pm 1$} & Fontan $(4,22 \%)$ & \multirow[t]{4}{*}{ Mild to Severe } \\
\hline & & TGA (Senning/Mustard procedure) $(5,28 \%)$ & \\
\hline & & Repaired ToF $(5,28 \%)$ & \\
\hline & & Repaired ASD (4, 22\%) & \\
\hline \multirow[t]{4}{*}{ Morrison 2013} & \multirow[t]{4}{*}{$15 \pm 2$} & Minor CHD (no surgical intervention) $(39,27 \%)$ & \multirow[t]{4}{*}{ Mild to Severe } \\
\hline & & Acyanotic corrected ConHD $(61,43 \%)$ & \\
\hline & & Cyanotic corrected $(30,21 \%)$ & \\
\hline & & Cyanotic palliated $(13,9 \%)$ & \\
\hline Novakovic 2018 & $38 \pm 8$ & Repaired ToF $(30,100 \%)$ & Severe \\
\hline \multirow[t]{2}{*}{ Opotowsky 2018} & \multirow[t]{2}{*}{$41 \pm 12$} & ToF with pulmonary stenosis or atresia or, DORV $(13,46 \%)$ & \multirow[t]{2}{*}{ Severe } \\
\hline & & TGA with a systemic RV, (9, 32\%) & \\
\hline
\end{tabular}


Table 2. Individual ConHD lesions pooled into the meta-analyses (Continued)

\begin{tabular}{|c|c|c|c|}
\hline & & Fontan $(2,7 \%)$ & \\
\hline & & $\begin{array}{l}\text { Pulmonary atresia with intact ventricular septum with biven- } \\
\text { tricular repair }(2,7 \%)\end{array}$ & \\
\hline & & Truncus arteriosus $(1,4 \%)$ & \\
\hline & & Ebstein anomaly $(1,4 \%)$ & \\
\hline Sandberg 2018 & $30 \pm 11$ & ToF $(5,22 \%)$ & Severe \\
\hline & & ccTGA \& d-TGA $(8,35 \%)$ & \\
\hline & & $\mathrm{TCPC}(5,22 \%)$ & \\
\hline & & $\mathrm{PA}(2,9 \%)$ & \\
\hline & & Complete AV-septal defect $(1,4 \%)$ & \\
\hline & & Ebstein anomaly $(1,4 \%)$ & \\
\hline & & Miscellaneous $(1,4 \%)$ & \\
\hline Therrien 2003 & $35 \pm 9$ & Repaired ToF $(18,100 \%)$ & Severe \\
\hline $\begin{array}{l}\text { Westhoff-Bleck } \\
2013\end{array}$ & $29 \pm 3$ & Systemic right ventricle - TGA [Mustard] $(48,100 \%)$ & Severe \\
\hline Winter 2012 & $32+11$ & Systemic right ventricle - TGA and ccTGA $(46,100 \%)$ & Severe \\
\hline van Dissel 2019 & $40 \pm 9$ & ToF $(12,30 \%)$ & Severe \\
\hline & & TGA $(13,33 \%)$ & \\
\hline & & Fontan circulation $(9,22 \%)$ & \\
\hline & & Pulmonary atresia $(3,7.5 \%)$ & \\
\hline & & Other $(3,7.5 \%)$ & \\
\hline
\end{tabular}

ToF, tetralogy of Fallot; TGA, transposition of the great arteries; ccTGA, congenitally corrected transposition of the great arteries; d-TGA, dextro-transposition of the great arteries; ASD, atrial septal defect; TCPC, Total cavopulmonary connection; DORV, double-outlet right ventricle; RV, right ventricle. 


\begin{tabular}{|c|c|c|c|c|c|c|c|c|}
\hline Study & $\begin{array}{l}\text { Age group \& } \\
\text { severity }\end{array}$ & $\begin{array}{l}\text { Location \& su- } \\
\text { pervision }\end{array}$ & $\begin{array}{l}\text { Frequencya } \\
\text { (sessions } \\
\text { per week) }\end{array}$ & Intensity & $\begin{array}{l}\text { Timeb }^{b}(\mathrm{~min}- \\
\text { utes) }\end{array}$ & Type & $\begin{array}{l}\text { Durationc } \\
\text { (Weeks) }\end{array}$ & $\begin{array}{l}\text { Dose } \\
\left(a^{\star} b^{\star} c\right)\end{array}$ \\
\hline Avila 2016 & $\begin{array}{l}\text { Adult \& severe } \\
\text { (ToF) }\end{array}$ & $\begin{array}{l}\text { Hospital \& su- } \\
\text { pervised }\end{array}$ & 1 to 2 & $\begin{array}{l}70 \% \text { to } 80 \% \text { of the maximum } \mathrm{HR} \\
\text { (increased throughout interven- } \\
\text { tion) }\end{array}$ & 60 & $\begin{array}{l}\text { Combination } \\
\text { of resistance } \\
\text { and aerobic dy- } \\
\text { namic (running, } \\
\text { rowing etc.) ex- } \\
\text { ercise }\end{array}$ & 12 & 1080 \\
\hline $\begin{array}{l}\text { Duppen } \\
2015\end{array}$ & $\begin{array}{l}\text { Paediatric \& se- } \\
\text { vere (ToF and } \\
\text { Fontan) }\end{array}$ & $\begin{array}{l}\text { Hospital \& su- } \\
\text { pervised }\end{array}$ & 2 to 3 & $\begin{array}{l}\text { Resting heart rate plus } 60 \% \text { to } \\
70 \% \text { of the HR reserve }\end{array}$ & 60 & $\begin{array}{l}\text { Aerobic dynam- } \\
\text { ic }\end{array}$ & 12 & 1800 \\
\hline $\begin{array}{l}\text { Madhavi } \\
2011\end{array}$ & Adult \& mild & NR & NR & Individualised (NR) & NR & NR & 12 & $\mathrm{~N} / \mathrm{A}$ \\
\hline Moalla 2006 & $\begin{array}{l}\text { Paediatric \& } \\
\text { mild/severe }\end{array}$ & $\begin{array}{l}\text { Home \& se- } \\
\text { mi-supervised }\end{array}$ & 3 & HR at the gas exchange threshold & 60 & Cycling & 12 & 2160 \\
\hline $\begin{array}{l}\text { Novakovic } \\
2018\end{array}$ & $\begin{array}{l}\text { Adult \& severe } \\
\text { (ToF) }\end{array}$ & NR & 2 to 3 & $\begin{array}{l}80 \% \text { of HRpeak in high intensity } \\
\text { exercise }\end{array}$ & 42 & $\begin{array}{l}\text { Cycling or } \\
\text { speed walking }\end{array}$ & 12 & 1260 \\
\hline & & & & $\begin{array}{l}70 \% \text { of HRpeak in continuous in- } \\
\text { tensity exercise }\end{array}$ & & & & \\
\hline $\begin{array}{l}\text { Opotowsky } \\
2018\end{array}$ & Adult \& severe & $\begin{array}{l}\text { Hospital \& su- } \\
\text { pervised }\end{array}$ & 2 & HR at Gas Exchange Threshold & 60 & $\begin{array}{l}\text { Combination of } \\
\text { resistance and } \\
\text { aerobic dynam- } \\
\text { ic }\end{array}$ & 12 & 1440 \\
\hline $\begin{array}{l}\text { Sandberg } \\
2018\end{array}$ & Adult \& severe & $\begin{array}{l}\text { Home \& se- } \\
\text { mi-supervised }\end{array}$ & 3 & $\begin{array}{l}\text { HR was calculated according to } \\
\text { the Karvonen method and to } \\
\text { achieve BORG } 15 \text { to } 16\end{array}$ & 31 & Cycling & 12 & 1116 \\
\hline $\begin{array}{l}\text { Therrien } \\
2003\end{array}$ & $\begin{array}{l}\text { Adult \& severe } \\
\text { (ToF) }\end{array}$ & $\begin{array}{l}\text { Hospital and } \\
\text { home (1:2 ratio) } \\
\text { \& supervised }\end{array}$ & 3 & $\begin{array}{l}60 \% \text { to } 85 \% \text { of pre training peak } \\
\mathrm{VO}_{2}\end{array}$ & 50 & $\begin{array}{l}\text { Cycling and } \\
\text { walking }\end{array}$ & 12 & 1800 \\
\hline $\begin{array}{l}\text { West- } \\
\text { hoff-Bleck } 2013\end{array}$ & $\begin{array}{l}\text { Adult \& severe } \\
\text { 3(Mustard proce- } \\
\text { dure) }\end{array}$ & $\begin{array}{l}\text { Home \& se- } \\
\text { mi-supervised }\end{array}$ & $3-5$ & $\begin{array}{l}\text { HR corresponding to } 50 \% \text { of peak } \\
\mathrm{VO}_{2}\end{array}$ & 10 to 30 & Cycling & 24 & $2550^{d}$ \\
\hline
\end{tabular}




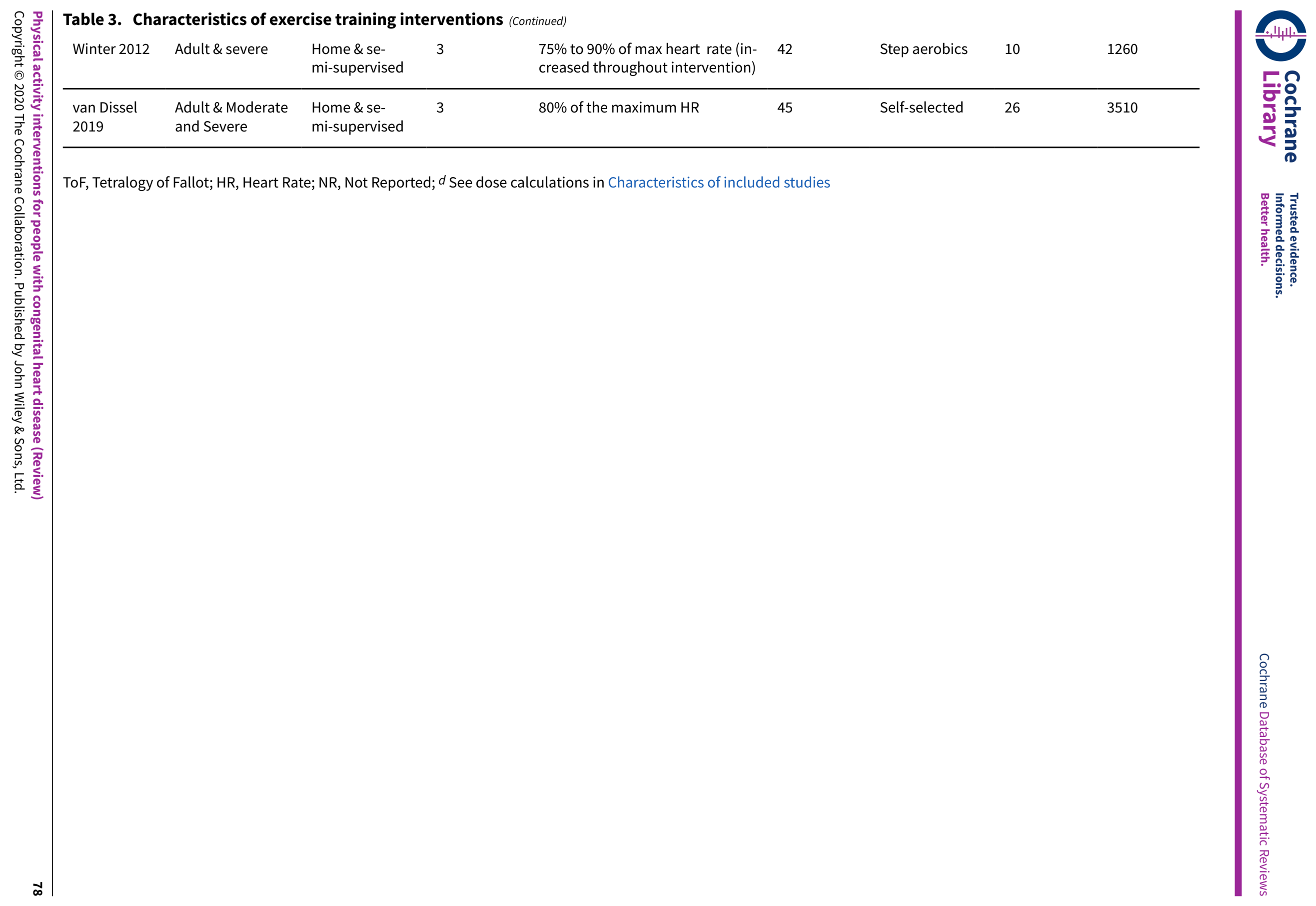


Table 4. Univariate meta-regression analysis

\begin{tabular}{lll}
\hline Potential effect modifiers & $\begin{array}{l}\text { Regression coefficient and } \\
\text { (Standard error) }\end{array}$ & P value \\
\hline Age (adult vs. paediatric) & $2.5(2.2)$ & 0.262 \\
\hline Baseline CRF (peak $\left.\mathrm{VO}_{2} \mathrm{~mL}_{\mathrm{k}}{ }^{-1} \cdot \mathrm{min}^{-1}\right)$ & $-0.2(0.1)$ & 0.186 \\
\hline Dose (intervention length*no. sessions per week*session length) & $-0.2(0.3)$ & 0.614 \\
\hline Follow-up period/intervention length (weeks) & $-0.18(0.1)$ & $\mathbf{0 . 0 3 1}$ \\
\hline Percentage of male & $-0.5(0.3)$ & 0.083 \\
\hline Risk of bias & $9.1(2.2)$ & $\mathbf{0 . 0 1}$ \\
\hline Sample size & $-0.001(0.02)$ & 0.963 \\
\hline Setting (home or hospital based) & $-2.3(1.6)$ & 0.171 \\
\hline Study location (Continent) & $-3.5(1.8)$ & 0.070 \\
\hline Type of intervention (exercise training, PA promotion, IMT) & $-2.3(1.7)$ & 0.208 \\
\hline
\end{tabular}

Bold = statistically significant; CRF, Cardiorespiratory fitness;

\section{AP PEN DICES}

\section{Appendix 1. Search strategy}

\section{CENTRAL}

\#1 MeSH descriptor: [Exercise] explode all trees

\#2 MeSH descriptor: [Physical Fitness] this term only

\#3 MeSH descriptor: [Sports] explode all trees

\#4 MeSH descriptor: [Rehabilitation] this term only

\#5 MeSH descriptor: [Dance Therapy] this term only

\#6 MeSH descriptor: [Exercise Therapy] explode all trees

\#7 MeSH descriptor: [Recreation Therapy] this term only

\#8 MeSH descriptor: [Physical Exertion] this term only

\#9 MeSH descriptor: [Physical Education and Training] explode all trees

\#10 MeSH descriptor: [Dancing] this term only

\#11 exercis ${ }^{\star}$

\#12 aerobic $^{*}$

\#13 sport*

$\# 14$ walk* 


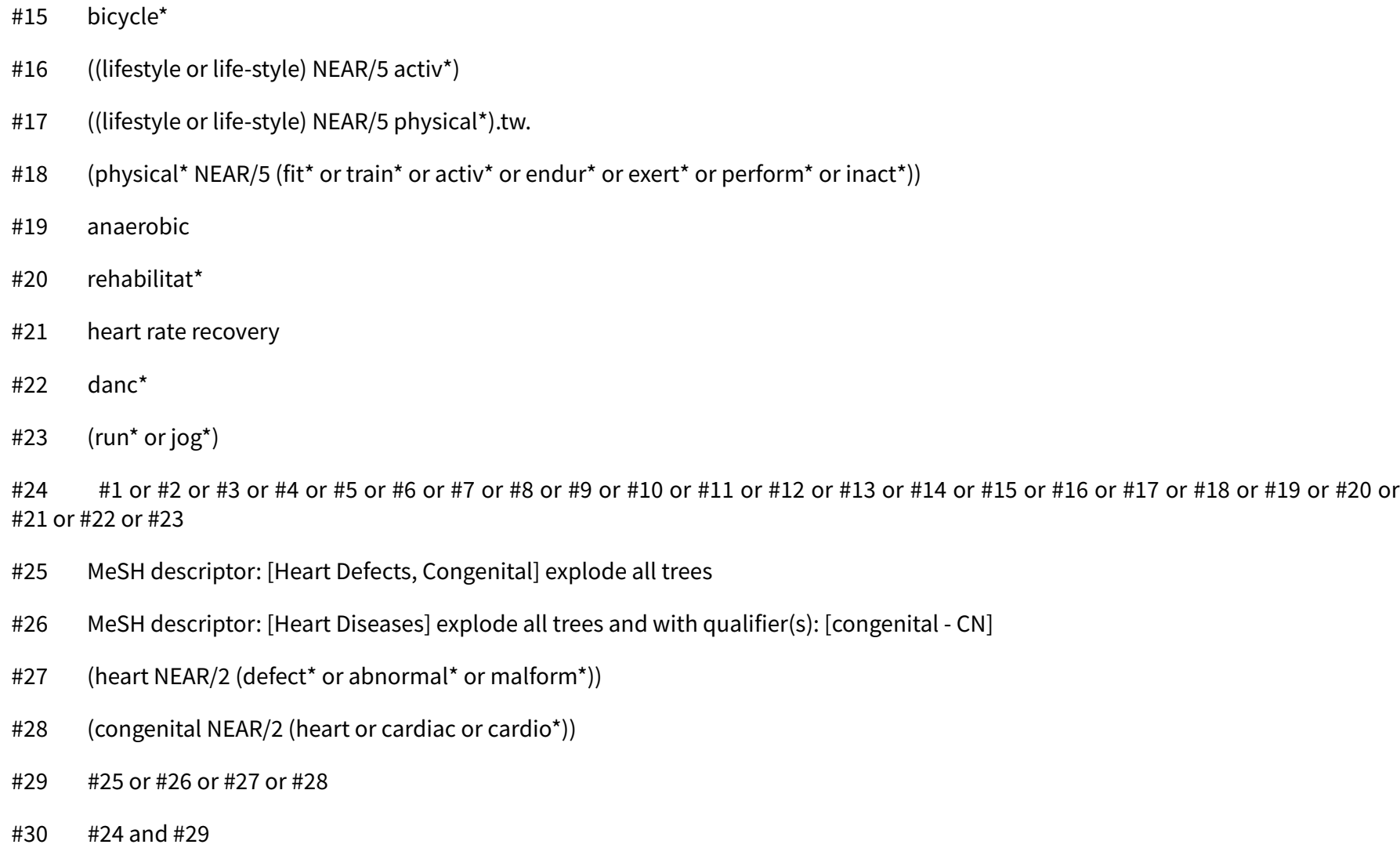

\section{MEDLINE Ovid}

1 exp Exercise/

2 Physical Fitness/

3 exp Sports/

4 Rehabilitation/

5 Dance Therapy/

6 exp Exercise Therapy/

7 Recreation Therapy/

8 Physical Exertion/

9 exp "Physical Education and Training"/

10 Dancing/

11 exercis*.tw.

12 aerobic\$.tw.

13 sport\$.tw.

14 walk\$.tw.

15 bicycle\$.tw.

16 ((lifestyle or life-style) adj5 activ\$).tw.

17 ((lifestyle or life-style) adj5 physical\$).tw. 
18 (physical\$ adj5 (fit\$ or train\$ or activ\$ or endur\$ or exert\$ or perform or inact ${ }^{\star}$ )).tw.

19 anaerobic.tw.

20 rehabilitat\$.tw.

21 heart rate recovery.tw.

22 danc ${ }^{\star}$.tw.

$23\left(\right.$ run $^{\star}$ or jog $\left.{ }^{\star}\right)$. tw.

24 or/ $1-23$

25 exp Heart Defects, Congenital/

26 exp Heart Diseases/cn [Congenital]

27 (heart adj2 (defect* or abnormal ${ }^{\star}$ or malform $\left.{ }^{\star}\right)$ ).tw.

28 (congenital adj2 (heart or cardiac or cardio*)).tw.

29 or $/ 25-28$

3024 and 29

31 randomized controlled trial.pt.

32 controlled clinical trial.pt.

33 randomized.ab.

34 placebo.ab.

35 drug therapy.fs.

36 randomly.ab.

37 trial.ab.

38 groups.ab.

3931 or 32 or 33 or 34 or 35 or 36 or 37 or 38

40 exp animals/ not humans.sh.

4139 not 40

4230 and 41

\section{Embase Ovid}

1 exp exercise/

2 fitness/

3 exp sport/

4 rehabilitation/

5 dance therapy/

6 exp kinesiotherapy/

7 recreational therapy/

8 exp physical education/

9 dancing/

Physical activity interventions for people with congenital heart disease (Review) 
10 exercis*.tw.

11 aerobic\$.tw.

12 sport\$.tw.

13 walk\$.tw.

14 bicycle\$.tw.

15 ((lifestyle or life-style) adj5 activ\$).tw.

16 ((lifestyle or life-style) adj5 physical\$).tw.

17 (physical\$ adj5 (fit\$ or train\$ or activ\$ or endur\$ or exert\$ or perform* or inact $^{\star}$ )).tw.

18 anaerobic.tw.

19 rehabilitat\$.tw.

20 heart rate recovery.tw.

21 danc*.tw.

22 (run* or jog*).tw.

231 or 2 or 3 or 4 or 5 or 6 or 7 or 8 or 9 or 10 or 11 or 12 or 13 or 14 or 15 or 16 or 17 or 18 or 19 or 20 or 21 or 22

24 exp congenital heart malformation/

25 heart disease/cn [Congenital Disorder]

26 (heart adj2 (defect* or abnormal ${ }^{\star}$ or malform $\left.{ }^{\star}\right)$ ).tw.

27 (congenital adj2 (heart or cardiac or cardio*)).tw.

2824 or 25 or 26 or 27

2923 and 28

30 random\$.tw.

31 factorial\$.tw.

32 crossover\$.tw.

33 cross over\$.tw.

34 cross-over\$.tw.

35 placebo\$.tw.

36 (doubl\$ adj blind\$).tw.

37 (singl\$ adj blind\$).tw.

38 assign\$.tw.

39 allocat\$.tw.

40 volunteer\$.tw.

41 crossover procedure/

42 double blind procedure/

43 randomized controlled trial/

44 single blind procedure/

Physical activity interventions for people with congenital heart disease (Review) 
4530 or 31 or 32 or 33 or 34 or 35 or 36 or 37 or 38 or 39 or 40 or 41 or 42 or 43 or 44

46 (animal/ or nonhuman/) not human/

$47 \quad 45$ not 46

$48 \quad 29$ and 47

CINAHL

S52 S31 OR S32 OR S33 OR S34 OR S35 OR S36 OR S37 OR S38 OR S39 OR S40 OR S41 OR S42 OR S43 OR S44 OR S45

S51 S49 not S50

S50 MH (human)

S49 S46 OR S47 OR S48

S48 TI (animal model $\left.{ }^{\star}\right)$

S47 MH (animal studies) S46 MH animals+

S45 AB (cluster W3 RCT)

S44 MH (crossover design) OR MH (comparative studies)

S43 AB (control W5 group)

S42 PT (randomized controlled trial)

S41 MH (placebos)

S40 MH (sample size) AND AB (assigned OR allocated OR control)

S39 TI (trial)

S38 $\quad A B($ random*)

S37 TI (randomised OR randomized)

S36 MH cluster sample

S35 MH pretest-posttest design

S34 MH random assignment

S33 MH single-blind studies

S32 MH double-blind studies

S31 MH randomized controlled trials

S30 S24 AND S29

S29 S25 OR S26 OR S27 OR S28

S28 TX (congenital n2 (heart or cardiac or cardio*))

S27 TX (heart n2 (defect* or abnormal* or malform*))

S26 (MH "Heart Diseases+/FG")

S25 (MH "Heart Defects, Congenital+")

S24 S1 OR S2 OR S3 OR S4 OR S5 OR S6 OR S7 OR S8 OR S9 OR S10 OR S11 OR S12 OR S13 OR S14 OR S15 OR S16 OR S17 OR S18 OR S19 OR S20 OR S21 OR S22 OR S23

S23

TX (run* or jog $\left.{ }^{\star}\right)$

Physical activity interventions for people with congenital heart disease (Review) 
S22 TX danc*

S21 TX heart rate recovery

S20 TX rehabilitat*

S19 TX anaerobic

S18 TX (physical ${ }^{\star}$ n5 (fit ${ }^{\star}$ or train ${ }^{\star}$ or activ $^{\star}$ or endur $^{\star}$ or exert $^{\star}$ or perform ${ }^{\star}$ or inact $\left.^{\star}\right)$ )

S17 TX ((lifestyle or life-style) n5 physical $\left.{ }^{\star}\right)$

S16 TX ((lifestyle or life-style) n5 activ*)

S15 TX bicycle*

S14 TX walk*

S13 TX sport*

S12 TX aerobic*

S11 TX exercis*

S10 (MH "Dancing")

S9 (MH "Physical Education and Training+")

S8 (MH "Exertion")

S7 (MH "Recreational Therapy")

S6 (MH "Therapeutic Exercise+")

S5 (MH "Dance Therapy")

S4 (MH "Rehabilitation")

S3 (MH "Sports+")

S2 (MH "Physical Fitness")

S1 (MH "Exercise+")

\section{AMED}

1 exp Exercise/

2 Physical fitness/

3 exp Sports/

4 Rehabilitation/

5 Dance therapy/

6 exp Exercise therapy/

7 Recreation/

8 Exertion/

9 exp Physical education/

10 Dancing/

11 exercis*.tw.

12 aerobic\$.tw.

Physical activity interventions for people with congenital heart disease (Review) 
13 sport\$.tw.

14 walk\$.tw.

15 bicycle\$.tw.

16 ((lifestyle or life-style) adj5 activ\$).tw.

17 ((lifestyle or life-style) adj5 physical\$).tw.

18 (physical\$ adj5 (fit\$ or train\$ or activ\$ or endur\$ or exert\$ or perform* or inact $\left.{ }^{\star}\right)$ ).tw.

19 anaerobic.tw.

20 rehabilitat\$.tw.

21 heart rate recovery.tw.

22 danc*.tw.

23 (run* or jog $)^{\star}$.tw.

241 or 2 or 3 or 4 or 5 or 6 or 7 or 8 or 9 or 10 or 11 or 12 or 13 or 14 or 15 or 16 or 17 or 18 or 19 or 20 or 21 or 22 or

25 exp Heart defects congenital/

26 (heart adj2 (defect* or abnormal ${ }^{\star}$ or malform $\left.{ }^{\star}\right)$ ).tw

27 (congenital adj2 (heart or cardiac or cardio*)).tw.

$28 \quad 25$ or 26 or 27

2924 and 28

30 randomized controlled trial.pt.

31 controlled clinical trial.pt.

32 randomized.ab.

33 placebo.ab.

34 randomly.ab.

35 trial.ab.

36 groups.ab.

3730 or 31 or 32 or 33 or 34 or 35 or 36

38 exp animals/ not humans.sh.

$39 \quad 37$ not 38

$40 \quad 29$ and 39

\section{Web of Science and BIOSIS}

\# 20 \#19 AND \#18

\# 19 TS=(random* or blind ${ }^{\star}$ or allocat ${ }^{\star}$ or assign* or trial* or placebo* or crossover $^{\star}$ or cross-over $\left.^{\star}\right)$

\# 18 \#17 AND \#14

\# 17 \#16 OR \#15

\# 16 TS=(congenital NEAR/2 (heart or cardiac or cardio*))

\# 15 TS=(heart NEAR/2 (defect ${ }^{\star}$ or abnormal ${ }^{\star}$ or malform $\left.{ }^{\star}\right)$ )

Physical activity interventions for people with congenital heart disease (Review) 
\# 14 \#13 OR \#12 OR \#11 OR \#10 OR \#9 OR \#8 OR \#7 OR \#6 OR \#5 OR \#4 OR \#3 OR \#2 OR \#1

\# 13 TS=(run* or jog $\left.{ }^{\star}\right)$

\# $12 \mathrm{TS}=$ danc*

\# 11 TS=heart rate recovery

\# 10 TS=rehabilitat*

\# 9 TS=anaerobic

\# 8 TS=(physical ${ }^{\star}$ NEAR/5 (fit ${ }^{\star}$ or train ${ }^{\star}$ or activ ${ }^{\star}$ or endur ${ }^{\star}$ or exert ${ }^{\star}$ or perform ${ }^{\star}$ or inact $\left.\left.{ }^{\star}\right)\right)$

\# 7 TS=((lifestyle or life-style) NEAR/5 physical $\left.^{\star}\right)$

\# 6 TS=((lifestyle or life-style) NEAR/5 activ*)

\# 5 TS=bicycle*

\# 4 TS=walk*

\# 3 TS=sport ${ }^{*}$

\# 2 TS=aerobic ${ }^{\star}$

\# 1 TS=exercis ${ }^{*}$

\section{LILACS}

(heart or cardiac\$ or cardio\$) AND (defect or congenital or malform\$ or abnormal\$) [Words] and Exercise\$ or aerobic\$ or sport\$ or walk\$ or bicycle or anaerobic $\$$ or rehabilitat $\$$ or heart rate recovery $\$$ or danc\$ or run\$ or jog\$ or active $\$$ or train\$ or fit\$ [Words]

\section{DARE}

heart or cardiac* or cardio* AND defect or congenital or malform* or abnormal ${ }^{\star}$ AND exercise* or aerobic* or sport* or walk ${ }^{\star}$ or bicycle* or anaerobic ${ }^{\star}$ or rehabilitat ${ }^{\star}$ or heart rate recovery ${ }^{\star}$ or danc ${ }^{\star}$ or run ${ }^{\star}$ or jog* or active* or train* or fit*

\section{ClinicalTrials.gov}

Condition or disease: Congenital Heart Disease

Other terms: exercise

Study type: Interventional studies (Clinical Trials)

\section{Appendix 2. Severity classification in congenital heart disease}

Severity of congenital heart disease is most often classified by lesion-specific data. While this approach is appropriate in most cases, it must be stressed that severity is highly individual and should be judged by a physician using validated criteria (Budts 2013; Budts 2020).

\section{Mild ConHD}

Mild ConHD is the least severe classification in our planned review. Patients with mild ConHD may be asymptomatic and have no significant murmur. Some example lesions of mild ConHD are as follows.

- Bicuspid aortic valve (BAV)

- Small atrial septal defects (ASD)

- Small ventricular septal defects (VSD)

- Small patent ductus arteriosus (PDA)

\section{Moderate ConHD}

Patients with moderate ConHD are likely to be symptomatic and the lesions will likely be identified in a clinical study. For example:

- mild or moderate aortic stenosis (AS) or aortic incompetence;

- moderate pulmonary stenosis (PS) or incompetence;

- non-critical coarctation of the aorta;

Physical activity interventions for people with congenital heart disease (Review) 
- large atrial septal defect;

- complex forms of ventricular septal defect.

\section{Severe ConHD}

This category includes complex conditions that usually require immediate medical intervention. Some example lesions are:

- dextro-transposition of the great arteries;

- tetralogy of fallot, including pulmonary atresia and absent pulmonary valve;

- hypoplastic right heart;

- tricuspid atresia;

- pulmonary atresia with an intact ventricular septum;

- Ebstein anomaly;

- hypoplastic left heart;

* aortic atresia

* mitral atresia

- hypoplastic left heart;

* aortic atresia

* mitral atresia

- double outlet right ventricle;

- truncus arteriosus;

- total anomalous pulmonary venous connection;

- large atrioventicular septal defect; large VSD; large PDA;

- severe AS and/or severe PS;

- critical coarctation of the aorta.

This framework has been adopted from the work of Hoffman 2002 and Warnes 2008.

WHAT'S NEW

\begin{tabular}{lll}
\hline Date & Event & Description \\
\hline 21 May 2021 & Amended & Link to Table in in Results section corrected. \\
\hline
\end{tabular}

\section{H I S T O R Y}

Protocol first published: Issue 8, 2019

Review first published: Issue 10, 2020

\begin{tabular}{lll}
\hline Date & Event & Description \\
\hline 8 February 2021 & Amended & Technical issue with risk of bias tables resolved \\
\hline 26 January 2021 & Amended & Minor edits to abstract and summary of findings table. \\
\hline
\end{tabular}

\section{CONTRIBUTIONS OF AUTHORS}

CAW and CW independently completed title and abstract screening, full text review, risk of bias assessments, data extraction and GRADE.

CAW had overall control of the design of the study and co-wrote the manuscript.

CW assisted data analysis, produced the SoF table and co-wrote the manuscript.

GEP gave specialist clinical insight into the literature and population with congenital heart disease.

Physical activity interventions for people with congenital heart disease (Review) 
GS gave specialist clinical insight into the literature and population with congenital heart disease

RST designed and carried out the statistical analysis and arbitrated any discrepancies.

LL was the lead author overseeing the project and arbitrated any discrepancies.

All authors contributed to the peer review and agreed on the final version of this manuscript.

\section{DECLARATIONS OF INTEREST}

CAW has received funding from Heart Research UK and Canon Medical Systems Ltd to complete research into the heart health of young people. The author had full control of the design of the study, methods used, outcome parameters, analysis of the data and production of any manuscripts. Neither of these organisations have a financial interest in this review.

CW has a funded PhD scholarship from the University of Exeter and Canon Medical. Canon Medical Systems Ltd does not have a financial interest in this review.

GEP is lead researcher in a contractual research partnership between the University of Bristol and Canon Medical Systems UK Ltd. Canon Medical Systems Ltd does not have a financial interest in this review.

GS is Medical Director of Sports Cardiology UK. Research grant from Heart research UK to evaluate an exercise prescription programme in congenital heart patients. Fee for lecturing at scientific meetings and financial support for educational arrhythmia meeting in February 2019 from Medtronic Actelion. None of the organisations named have a financial interest in this review.

LL has no known conflicts of interest.

RST has no known conflicts of interest.

\section{SOURCES OF SUPPORT}

\section{Internal sources}

- Canon Medical UK Ltd., UK

C Wadey was funded by an industrial PhD studentship from the University of Exeter and Canon Medical Systems UK Ltd.

GE Pieles is lead researcher in a contractual research partnership between the University of Bristol and Canon Medical Systems UK Ltd. investigating cardiac function during exercise in children.

Authors had full control of the design of the study, methods used, outcome parameters, analysis of the data and production of any manuscripts.

\section{External sources}

- NIHR, UK

This project was supported by the National Institute for Health Research, via Cochrane Infrastructure funding to the Heart Group. The views and opinions expressed herein are those of the authors and do not necessarily reflect those of the Systematic Reviews Programme, NIHR, NHS or the Department of Health and Social Care.

\section{DIFFERENCES BETWEEN PROTOCOLANDREVIEW}

- WHO ICTRP was unavailable due to increased traffic to the site because of COVID 19, therefore it was not searched. Clinical trials.gov was searched.

- Two studies estimated cardiorespiratory fitness (CRF) using validated CPET protocols, these were pooled with direct measures (gas analysis) of CRF

- Baseline CRF and risk of bias were added to the univariate meta regression.

- A vote counting table was used to synthesise all the information regarding health related quality of life.

- Sensitivity analysis was changed from 'all studies versus only including those studies we judge to have overall low risk of bias (low risk in all domains)' to all studies versus exclusion of high risk studies. This was changed as only one study had a low risk of bias in all domains.

\section{N O T ES}

None 


\section{N D EX TERMS}

\section{Medical Subject Headings (MeSH)}

Bias; "Breathing Exercises; Cardiorespiratory Fitness [ ${ }^{\star}$ physiology]; Exercise [ ${ }^{\star}$ physiology]; Heart Defects, Congenital [ ${ }^{\star}$ rehabilitation]; Muscle Strength; Oxygen Consumption [physiology]; Quality of Life; Randomized Controlled Trials as Topic

\section{MeSH check words}

Adolescent; Adult; Child; Female; Humans; Male 